

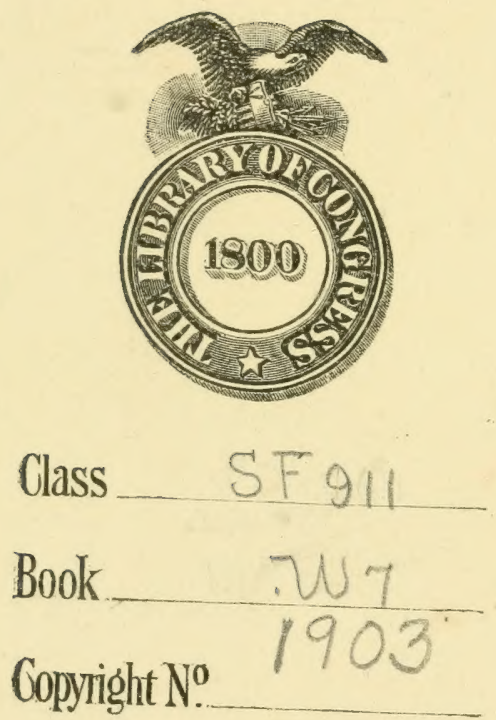

COPYRIGHT DEPOSIT. 



\title{
SURGICAL AND OBSTETRICAL
}

\section{OPERATIONS}

FOR

\section{Veterinary Students and Practitioners}

\author{
BY \\ W. L.. WILLIAMS
}

Professor of Obstetrics and Surgery in the New York State Veterinary

College, Cornell University.

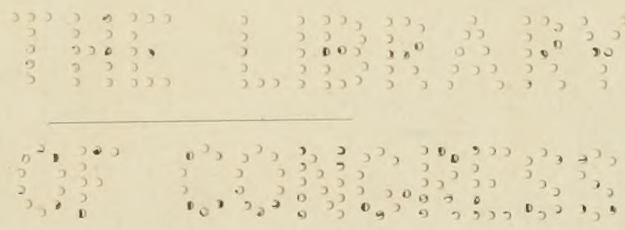

Embodying portions of the OPERATIONSKURSUS of Dr. W. Pfeiffer, Professor of Veterinary Science in the University of Giessen. 


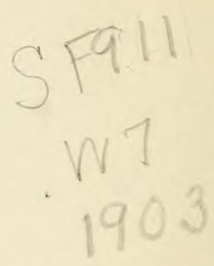

THE LIBRARY OF
CONGRESS.
Two Copies Received
SEP 301903
Copyright Entry
SEp.19,1903
CLASS 2 XXa No
$6860 \% 3$
COPY 8.

COPYRIGHT, I9O3, BY

W. L. WILLIAMS.

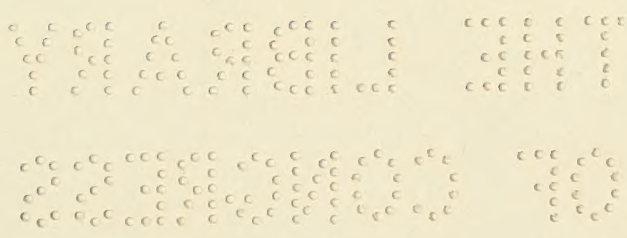

PRESS OF

ANDRUS \& CHURCH

ITHACA, N. Y. 


\section{PREFACE.}

The author caused to be published in igoo a bookiet entitled: "A Course in Surgical Operations by W. Pfeiffer and W. L. Williams, " consisting of an anthorized translation of Dr. Pfeiffer's Operations-Cursus with such changes, omissions and additions as were deemed desirable. Three years of constant use, with such criticisms as have come to the author from others, have served to point out desirable changes of so sweeping a character as to demand a practically new treatise and to render the continuance of a formal joint authorship inexpedient. The author has drawn freely upon Dr. Pfeiffer's Operations-Cursus in the preparation of the text which in many chapters is practically copied therefrom, including the illustrations, and gratefully acknowledges his profound obligations thereto. On the other hand nothing has been copied or extracted except it could be freely adopted as the author's own view, releasing Dr. Pfeiffer from all responsibility for the character of any of the contents.

The volume is primarily designed for the use of the author's classes in laboratory surgery and embryotomy in which. the student performs the surgical operations described, on animals procured for the express purpose, under chloroform anaesthesia whenever possible, after which the subject is destroyed while still anaesthetized; at the same time it has been aimed to render the volume of the greatest possible value to the practitioner consistent with this plan. The operations included under this scheme are necessarily limited to those which can be reasonably well performed on comparatively sound animals of little value and regularly procurable for laboratory purposes. The list covers a wide range and is designed to give to the student as thorough training as is practicable in a laboratory course and includes well nigh all the more important varieties of confinement, anaesthesia, disinfection, sutures, bandaging, dressing and other adjuncts to operative work. The chapter on trephin- 
ing of the facial sinuses has been dealt with at length in order to fully and clearly describe the author's method of operating; a new operation for poll evil has been inserted and there has been included a description of some of the most important embryotomy operations as they are carried out in the laboratory by means of freshly killed, new.born calves which are placed in the position desired, in the artificial uterus of a specially prepared skeleton.

Generally but one method of operating is described, the one chosen being that which in the author's experience has proven the most valuable in actual practice, and no operation has been introduced purely for practice but each one has been tested and known to have practical value.

Where two methods of operating are given, they are inserted because each has definite points of superiority over the other and one method may be specially applicable in a given case, another in a different patient where the same operation is to be performed as for example, a milk cow is best spayed through the vagina while a heifer must be operated on by an incision throngh the abdominal walls.

Considerable stress has been laid upon the surgical anatomy of the parts involved in each operation ; some uses of the various operations are mentioned; some of the chief dangers of each are pointed out and in some cases references to literature upon the operation or the diseases for which the operation is designed, are cited.

The figures in the text except Nos. 5, IO and I I, and the Plates Nos. I, II, VIII, X, XII, XIV, XVII, XVIII, XXI, XXII, XXII, XXV, XXVIII and XXIX are from Dr. Pfeiffer's Operations-Cursus ; Plate No. III was drawn by Dr. C. F. Flocken, Bureau of Animal Industry, Washington, D. C., and the remaining Plates were drawn under the direction of the author by Mr. C. W. Furlong, Instructor in Industrial Drawing and Art in Sibley College, Cornell University.

Cornell University, October, rgoz.

W. I. WILLIAMS. 


\section{CONTENTS.}

I.

I. OPERATIONS ON THE HEAD :

Page.

I. Extraction of Teeth

2. Repulsion of 'Teeth

Trephining the Facial Sinuses _.......................... IS

3. Trephining of the Frontal Sinuses

4. Trephining the Maxillary Sinuses ........................ 33

5. Trephining the Nasal Fossae _..._._. 36

6. Poll Evil Operation _._._. 37

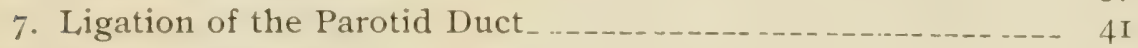

8. Entropium Operation _._. 46

9. Staphylotomy _... 47

IO. 'Trifacial Neurotomy ........ 48

II. OPERATIONS ON THE NECK :

II. Opening the Guttural Pouches _._. 53

12. Tracheotomy _._. 59

13. Arytenectomy _........... 6 I

14. Intra-tracheal Irrigation _. 66

I5. Intravenous Injection _...... 67

16. $a$. Phlebotomy with Fleams _._. 69

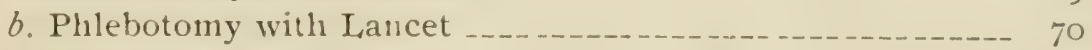

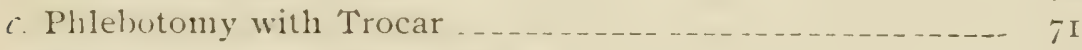

17. Ligation of the Carotid Artery _.......... 7 I

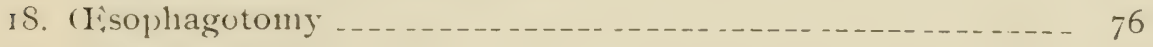

III. OPERATIONS ON THE TRUNK AND ON THE GENITAL, ORGANS :

19. Puncture of the Cinest _...

20. Puncture of the Intestine

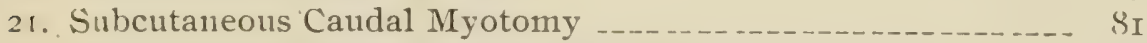

22. Caudal Myectomy for Gripping of the Reins _............. 83

23. Amputation of the Tail _..... 88

24. [rethrotomy......

25. Amputation of the Penis_..._. 93

26. Vaginal Ovariotomy in the Mare _._. 97

27. Vaginal Ovariotomy in the Cow

2S. Ovariotomy in the Cow by the Flank 
29. Ovariotomy in the Bitch by the Flank IIO

30. Ovariotomy in the Bitch by the Linea Alba

3I. Ovariotomy in the Cat

IV. OPERATIONS ON THE EXTREMITIES :

32. Tenotomy of the Flexor Tendons of the Foot

33. Tenotomy of the Peroneal Tendon (Stringhalt Operation) I 2 I

34. Tenotomy of the Cunean Tendon (Spavin Operation) I 25 Neurotomy

35. Digital Neurotomy I32

36. Plantar Neurotomy 137

37. Median Neurotomy............................... I4 I

38. Ulnar Neurotomy _........ 147

39. Sciatic Neurotomy …_... 153

40. Anterior Tibial Neurotomy _....................... 163

4I. Resection of the Lateral Cartilages .................... I65

42. Resection of the Flexor Pedis Tendon _............... 172

43. Amputation of the Claws of Ruminants_______._._. 174

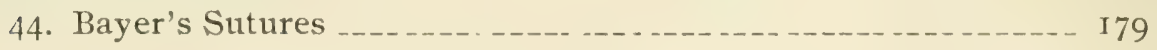

II.

EMBRYOTOMY OPERATIONS :

45. Cephalotomy _... I $8_{3}$

46. Decapitation _. 185

47. Subcutaneous Amputation of Anterior Limb …............. I $8_{5}$

48. Amputation at the Humero-radial Articulation _............ I 87

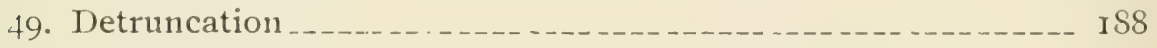

50. Destruction of the Pelvic Girdle, Anterior Presentation_____ 192

5I. Amputation of the Limbs at the Tarsus _................. 196

52. Intra-pelvic Amputation of the Posterior Limbs, Breech Presentation _...... 200

53. Evisceration of the Fetus _.... . 


\section{IN'TRODUC'TION.}

Many details must ine omitted in the succeeding text which are of importance in each operation, but which, if inserted, would render the volume unwieldy in size for the purpose designed.

These details are in a measure alike in each case, and it is assumed that the student has already familiarized himself with them. The more important of these may be summarized as follows :

I. The subject should bu securely confined in each case as directed, becanse the method designated has been fomd effective in the operation under description, and serves to fix the relations of the parts in such a way as to conform to the surgical anatomy of the region as ontlined in the text. It is to be constantly borne in mind that a change in the attitude of the animal is capable of causing profound alterations in the relations of parts which may greatly embarass the operator, or even prevent his carrying out the operation according to the technic given. In securing an animal for operation we must confune the whole body in a way that will sufficiently control movements and will insure safety to the patient and operator; the part to be operated upon must be so fixed as to properly limit its motion and in a position to afford the greatest facility for the carrying ont of the operation according to the best technic known.

2. Anaesthesia should be carefully carried out everywhere possible, because in addition to the humane sentiments involved, the resulting perfect control of the animal is an essential in aseptic or antiseptic surgery. The student slould make a careful study of anaesthesia in these exercises and acquire invaluable experience and confidence for use in actual practice.

3. Disinfection must be scrupulously applied in every detail since upon its effectiveness must hang the verdict of 
success or failure as measured by modern surgical knowledge. 'The operator's hands and, if need be, his arms should be thoroughly scrubbed with a stiff brush in hot water with soap for a period of fifteen minutes, the finger nails well trimmed and cleansed, and all dirt and old epidermal scales removed. The parts may then be disinfected by immersing in a hot concentrated sulution of permanganate of potassium for ten minutes and then decolorized in a strong solution of oxalic acid in sterile water. Or the hands may be disinfected after the washing with soap and water by immersing and scrubbing them for ten minutes in a I to 1000 solution of corrosive sublimate, but in order to make this thoroughly effective the solution needs be alcoholic, or the hands should first be immersed in alcohol, ether, or other substance capable of dissolving fats and permitting the disinfectant to penetrate the sebaceous glands. Great care should be exercised by the student to not touch any object after the hands have been disinfected for the operation unless it has been disinfected or sterilized, or in case it becomes necessary to touch objects not sterile, the disinfecting process should be repeated before proceeding further with the operation. This constitutes one of the most difficult of all details for the beginner to acquire, and each failure should be remedied by repeating the disinfection over and over until the habit of maintaining effectual sterilization is acquired and fixed.

The operation field should always be carefully shaved before beginning the operation, and the shaved area should aIways be very ample, so as to insure against contamination from adjacent hairs, as well as to give a clear view of the field. The area should then be disinfected in a reliable manner, that advised for the operator's hands serving as a type. Whenever circumstances will permit the operation field should be kept in an antiseptic bath or pack for twentyfour hours prior to the operation in order that the deeper parts of the skin, especially the hair follicles and sebaceous 
glands, sinall become thoroughly disinfected, a process well nigh impossible in a short period.

The suturing, dressing and bandaging of the wound should be carried out carefully in every case and no operation left withont completing it in the best manner possible.

The sturlent should make each operation as real as possible and not onit any detail eren if he thinks he already knows it sufficiently well as the repetition of a supposedly familiar detail serves an important purpose in the fixing of a habit which is inestimably more raluable to the surgeon than any theoretical knowledge of technic.

The safe surgeon is he who has so accustomed himself to the technique of asepsis and antisepsis that he carries them ont rigidly in an antomatic manner and can leare his attention riveted on the surgical problems before him.

The student who consults his interests will go yet farther and prior to mudertaking any operation on the living subject will study the regional anatomy of the part on the cadaver and learn therefrom all that he can of the structure of the part which he must finally complete upon the living animal. No dissection of the cadaver can ever teach true surgical, structure as the dead tissues can not be like the living, but such dissection can and does give great aid and should be pursued as far as it can lead and enough will still remain to be learned on the living subject.

He should further take occasion to study in connection with each operation the object or objects for which it is performed in practice, its effect on the diseased or other parts, the untoward results to be anticipated, etc.

Suggestions occur from time to time in the text designed to aid the student in these lines and help weave connecting bands between the operation, its objects and results.

Surgical operations are in themselves valueless or worse and acquire value only when properly correlated to disease and skillfully performed. 


\title{
Surgical and 0bstetrical Operations.
}

\author{
I. SURGICAL OPERATIONS.
}

OPERATIONS ON THE HEAD.

I. EXTRACTION OF TEETH.

PLATES I AND II.

Prefatory remarks. The grinding teeth of the horse consisting of three molars and three premolars in each row are of such dimensions and attachments that their remoral in case of disease or defect often presents difficulties of 110 small degree.

These teeth attain their greatest size at the time of eruption and most of the tooth remains firmly imbedded in its alveolus while a very shallow crown projects into the buccal carity. The teeth are gradually pushed out of their alveoli as their crowns are worn away with age and the proportion of the intra- to the extra-alveolar part gradually decreases until in very old animals the alveoli become obliterated and the last restige of what was once the apex of the fang rests insecurely in the buccal mucous membrane.

The facility with which teeth may be extracted increases as the age of the animal increases, being easily drawn with forceps in the old, while in case of freshly erupted teeth in the young horse we have not been able to extract them with forceps of any kind, except in those cases where they have become somewhat loosened as a result of disease or accident. When aberrations in derelopment occur, leading to the formation of dental tumors or odontomes the possibility of extraction by means of forceps is frequently wholly excluded and in cases where dental disorder has led to empyema of the facial sinuses, even if the tooth may be drawn by means of forceps, further operation is generally necessary, in order 
to assure a prompt recovery, by the removal of the effects of the disease of the tooth.

The removal of molars may therefore involve extraction with forceps, trephining the dental alveolus and repulsion of the tooth and trephining of the sinuses because of empyema or other pathologic conditions referable to the dental affection ; consequently all of these should be studied as related topics.

Instruments. Extracting forceps, fulcra of various sizes, mouth speculum with abundant lateral working room, exporteur forceps, tooth pick, splinter forceps, reflecting lamp.

Technic. In simple cases with a quiet animal the patient may be sufficiently confined by being backed into a corner or very much better by securing in stocks. In complicated cases or very resistant animals it is best to place upon the operating table or in default of this, cast and secure in lateral decubitis on the opposite side to the affected tooth.

Apply the speculum and identify the diseased tooth by manual exploration; determine if the tooth is of mnnatural size or form, if it is loose, if the gums are separated from the neck at any point, if it is ont of line with the other teeth in the row, if it is painful to the touch, if it be split, etc. An external tooth fistula or a tumefaction orer the affected nember may aid in distinguishing it. Aid may also be had by illuminating the mouth with a reflecting electric or other lamp.

Remove any accumulations of partially masticated food by means of the toothpick or with the fingers.

For extracting molars use forceps acting as a lever of the first class, with a fulcrum having a plane and a conrex surface; for the premolars use forceps acting as a lever of the second class. In case of the superior premolars some prefer forceps bent on the flat as shown in Plate II, because if straight the forceps handles strike against the superior incisors and hinder the deep fixation of the forceps jaws upon the tooth crown. 
In applying the forceps to the tooth have an assistant draw the tongue well ont at the commissure of the lips on the side opposite to the affected nember and introducing one hand into the month, place the index finger on the posterior border of the diseased tooth and with the other hand push the opened forceps backwards upon the tooth row until they reach the finger, then firmly grasp the affected tooth with the instrument, pressing the jaws down as deeply as possible against the alveolus. In many cases the diseased tooth can be clearly seen especially with the aid of the reflecting lamp and the forceps readily applied with risual aid and is frequently preferable to the guide of touch. Withdraw the free hand from the month, grasp the handles with both hands and loosen the tooth in its alveolus by establishing and maintaining as long as necessary a gentle to and fro lateral morement. The tooth is thus loosened in its alveolus by causing it to revolve very slightly back and forth on its long axis. When the tooth has become well loosened, as indicated by its moring with the forceps and by the audible crackling sound caused by the passage of air bubbles to and fro through the blood and lymph in the alreolus; maintain the forceps in position with one hand and with the other introduce the fulcrum as far back as possible in the case of molars and place it with the plane surface resting upon the crowns of the teeth as shown in Plate I. The fulcrum needs be held firmly in place in order to prevent it from gliding forward under pressure.

The tooth fang is extracted by forcing the handles of the forceps toward the jaw in which it is located, so that as it is gradually drawn out the forceps tend to glide over the convex surface of the fulcrum in a way to permit the tooth to emerge from the alveolus in the direction of the long axis of the latter. By referring to Plate III it will be seen that the axes of the different teeth vary, that of the molars being obliquely forwards toward the incisors while the crowns of the premolars are directed obliquely back- 
PLATE I.

EXTRACTION OF TEETH.

Sagittal section through the oral cavity, showing plan for extracting the first inferior molar, viewed from within the mouth. 


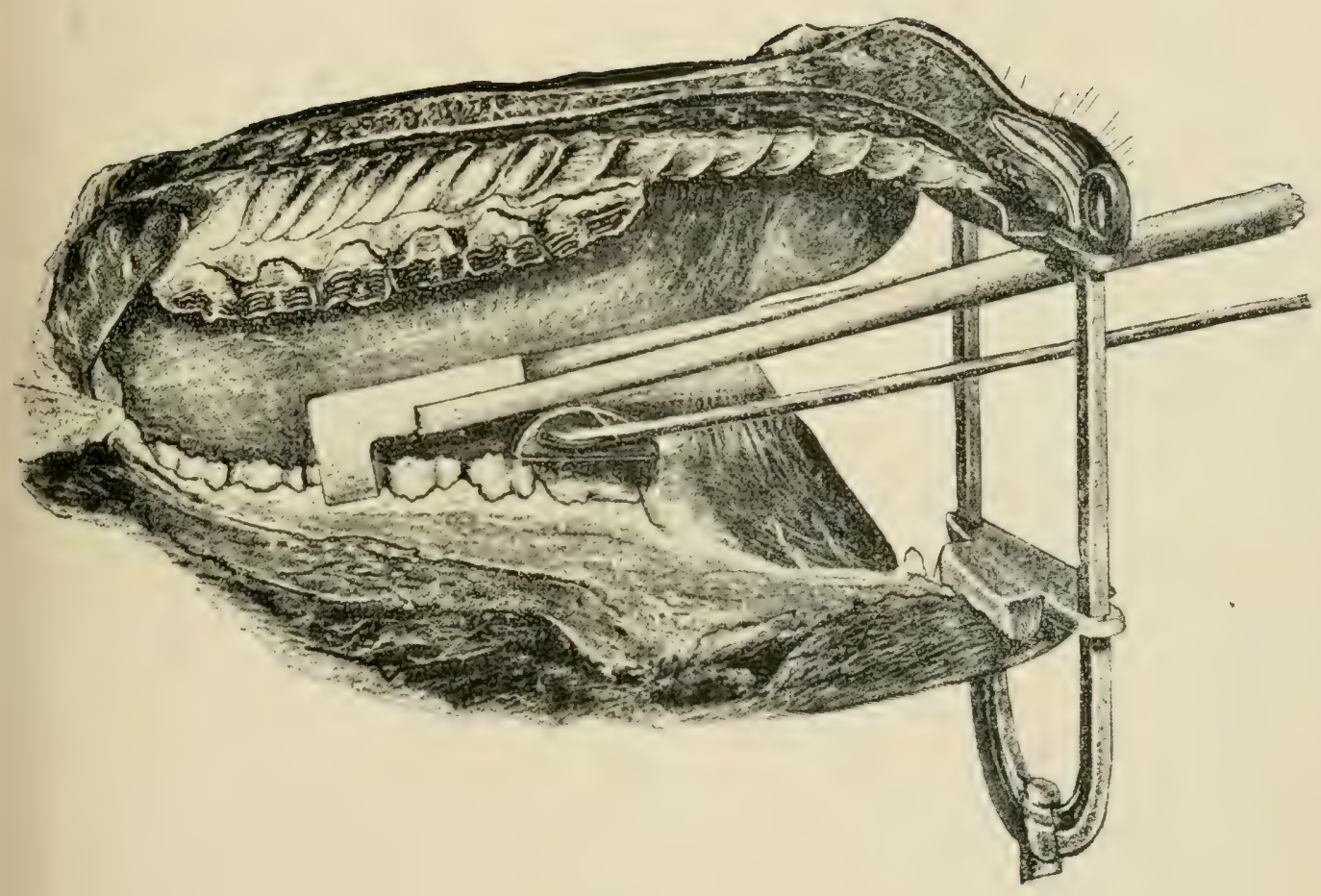



wards from the incisors. The slant of the teeth is most marked at the ends of the row and at the middle they acquire a practically perpendicular position. In drawing the last molar the forceps will generally strike against the opposite row of teeth before the tooth has completely emerged from its socket and in order to complete its removal it may be necessary to take a deeper hold with the forceps or remove with the exporteur forceps or with the fingers. In young horses where the teeth are very long we have found it impossible to complete the extraction until the tooth had been divided transversely by means of the tooth cutting forceps.

With the premolars the fulcrum is placed beneath the extension beyond the jaws of the forceps which throngh its fulcrum then rests upon the grinding surface posterior to the diseased tooth and permits it to be withdrawn obliquely from before backward in its normal line of direction.

The dangers in the extraction of teeth are chiefly:

I. The fracture of the tooth crown leaving the fang still fixed in the alveolus, a danger not infrequently unavoidable when the crown has become greatly weakened by disease so that it wants the power of resistance necessary to its extraction ; under most other conditions it may be largely guarded against by the careful securing of the patient in a manner to effectively prevent sudden throwing of the head while the forceps are applied, and by using good judgment in the amount of force used while loosening the tooth in its alveolus.

2. Fracture of the alveolar walls is an accident which may generally be prevented by proper care in the application of force and the aroidance of any attempt to extract a tooth when the existence of an enlargement of the farg is apparent or suspected.

3. The tooth may slip from the forceps into the pharynx and be swallowed, an accident aroidable by inserting the hand into the month along with the forceps as the tooth begins to emerge and if need be grasp it with the fingers. 
PLATE II.

EXTRACTION OF TEETH.

Sagittal section through the walls of the oral cavity illustrating plan for extracting the second superior premolar. 


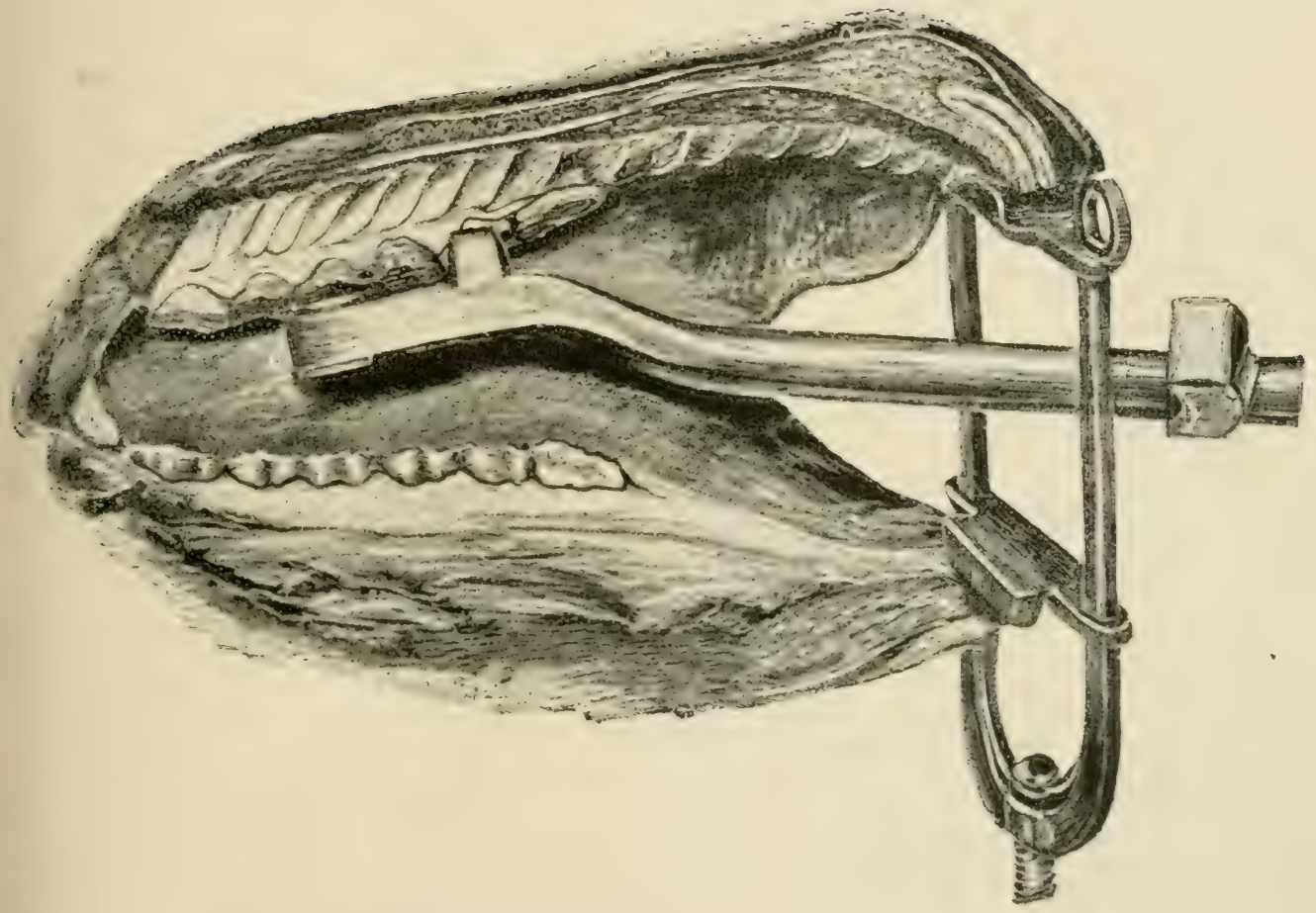





\section{REPULSION OF TEETH.}

PIATE III.

Uses. The removal of molars, pre-molars, tooth fangs from which the crowns have been broken away, alveolar odontomes, etc. which can not be remored safely by means of the forceps.

Instruments. Razor, conrex scalpels, trephine, bone gouge, Luer's sharp bone forceps, light and heary bone chisels, mallet, tooth punch, curette, compression artery forceps, scissors, needles, thread, absorbent cotton, antiseptic gauze, extracting forceps, splinter forceps, dressing forceps, tenacula, metal probe, mouth speculum.

Technic. Secure the animal in the lateral recumbent position with the affected side up. 'The operating table affords by far the best means for securing for the conrenience and safety of operator and patient. If the sinuses are so involred as to make possible the inhalation of pus, blood or other injurious matter, perform tracheotomy in ample time to arert danger. Anæsthetize. Shave and disinfect the operative area and trephine according to the method described in the following chapter down through the alveolar plate immediately over the fang of the affected tooth. Aroid dulling the trephine by striking it against the tooth fang itself. If a tooth fistula exists the identity of the affected tooth is best determined by passing a metallic probe through the fistula against the diseased fang while one hand is passed into the mouth and the location of the probe ascertained. Care should be exercised in trephining to not injure the adjoining teeth. After removing the disc of bone isolated by the trephine, control all hemorrhage and then enlarge the opening and remove the bony tissues till the tooth fang is bared its entire width. Insert a scalpel between the bone and soft tissues at the margin of the trephine opening nearest the 
month and with one hand in the oral cavity with the fingers resting upon the alveolar border on the lateral side of the tooth to serve as a guide, push the scalpel along between the bone and soft tissues until it emerges from the gums alongside the affected tooth and extend this incision backwards and forwards until the soft tissues are completely detached from the alveolar wall over the entire area of the diseased member. With a light, narrow bone chisel cut away and remove the entire external alveolar plate throughout the extent of the tooth, from the oral margin of the trephine opening into the mouth cavity. Hold the chisel so that the onter edge is inclined from the affected tooth toward the adjoining one, thus making a berelled channel through the alveolar plate which tends to loosen and detach the section of the alveolar wall to be removed without injury to that adjoining. Drive the chisel for a short distance only on one side and then apply it to the other side in order to detach but small pieces of bone at one time avoiding the detachment of large sections of the plate at once and having it extend to neighboring alveoli. With gonge and chisel remove all remnants of bone over the lateral side of the tooth laying it completely bare as shown in Plate III. 'The soft tissues of the part should not be disturbed beyond the removal of the circular piece over the disk of bone removed by the trephine and detatching them from the portion of bone to be chiseled away. When the tooth has been bared so that every part of its lateral surface can be seen or felt, the punch may be placed against the end of the fang, a few firm, quick blows given with the mallet, so directed that the force is in a line with the long axis of the tooth, driving it into the mouth where it is seized by the forceps or the hand and removed. If it is not readily and safely dislodged in this way, place the heary bone chisel against it and with the aid of the mallet comminute the tooth by breaking it transversely and splitting it longitudinally, in which process the fragments are gener- 


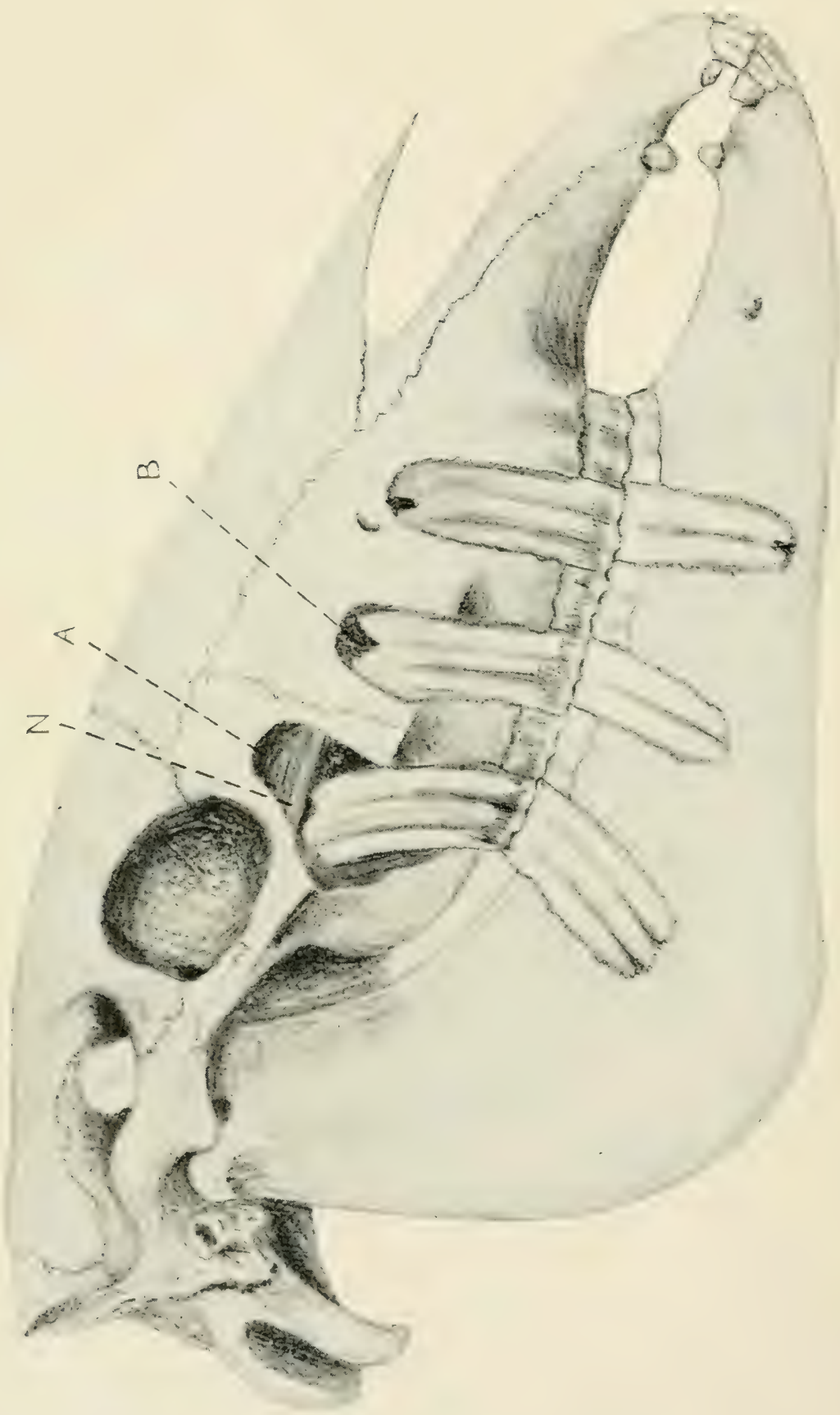




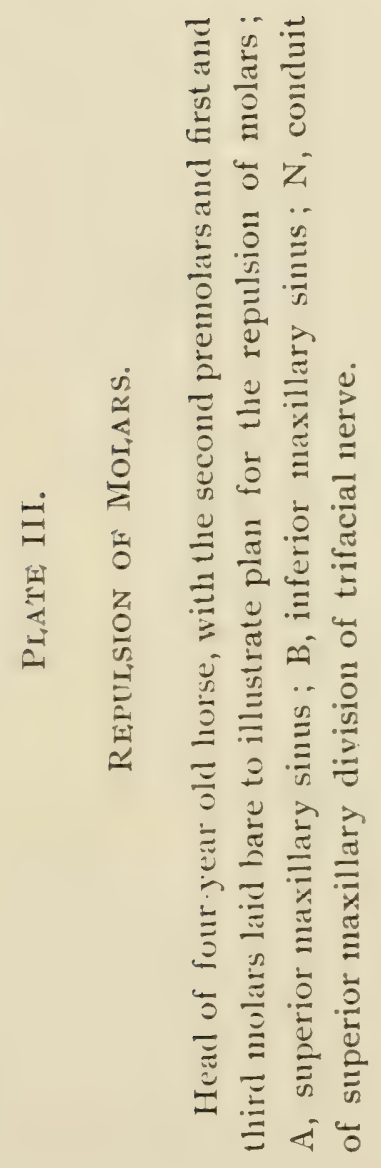


ally loosened and can then be readily removed with the aid of the gouge or forceps. Remove carefully all fragments of tooth or of loosened bone, cleanse and disinfect the wound, pack with iodoform gauze and dress daily.

In cases where a fistulous opening remains after repulsion of molars in the usual manner without the removal of the alveolar wall, or if a tooth has been drawn by means of the forceps and the alveolus fails to heal, the bony plate should be removed in the same manner as indicated for the removal of the teeth.

Dangers. Wounding of neighboring teeth, fracture of the inferior maxilla, fracture of the bony palate.

Wounding of the adjoining tooth is to be avoided chiefly by carefully locating the fang of the affected one and placing the center of the trephine as exactly as possible over the center of the tooth, by using a trephine not exceeding 2 to $2.5 \mathrm{~cm}$. in diameter and cautiously trephining through the compact layer of the external plate only, removing the cancellated tissue with the gonge and extending the opening in the desired direction after the outlines of the tooth fang have been clearly determined. If an adjoining fang is wounded the tooth should be removed as it will not heal but will result in a permanent tooth fistula.

The fracture of the alveolar walls of the inferior maxilla is to be constantly guarded against by being cautious to sec after each stroke on the punch that it has not slipped inward along the median side of the tooth, pressing the internal plate away from the tooth row and tending to produce a longitudinal fracture nearly or quite as long as the dental arcade. Careful digital exploration in the mouth may discover this fracture while still " simple" but a stroke or two more will convert it into the very much more serious " compound " fracture opening into the oral carity. Keeping one hand constantly in the mouth at the point of impact is always desirable as a precautionary measure. Transverse fracture of the tooth while 
yet in situ by means of the bone chisel, as above described, is a great safeguard against this injury by lessening the force required in repulsion and by the removal of the tapering fang, which then leaves a more secure base for the punch to act upon. It should never be forgotten that the impact from the punch must always be as nearly parallel to the long axis of the tooth as is possible.

The fracture of the superior maxilla and bony palate is not so probable as the preceding and is preventable by moderate care in the baring of the tooth before punching, by comminution of the tooth in bad cases, by the careful adjustment of the punch and applying the force in the proper direction.

Literature. Odontomes, Sir Bland Sutton, Jonr. Comp. Med. and Vet. Arch. Vol. XII, p. I ; A Clinical Study of Odontomes, W. L. Williams, Am. Vet. Review, Vol. XV, p. I ; Notes on Odontomes, do ; Am. Vet. Rev. Vol. XXIII, p. 82 and Oest. Mon. Thierheilkunde, Bd. XXIV, s. I 22. 


\section{TREPHINING OF THE FACIAL SINUSES.}

$$
\text { PLATES IV, V, VI, VII. }
$$

Prefatory Note. The facial sinuses of the horse constitute an exceedingly intricate and extensive group of cavities, communicating more or less freely with each other and with the exterior through the medium of the upper air passages, of which they are to be regarded as a part.

Their arrangement and relations permit them to frequently become the seat of, or central figure in many forms of disease which require for their differential diagnosis, amelioration or cure, the operation known as trephining. Their extent and relations to each other and to surrounding parts varies greatly with age and may be profoundly changed as a result of disease, amounting not infrequently in the frontal, superior and inferior maxillary sinuses ceasing to exist as separate cavities and becoming merged into one vast diverticulum. Similar changes may occur in the nasal and turbinated carities. The general position, extent and relations of these are indicated by Plates IV, V, VI and VII.

The uses of trephining are in a measure common to all the cavities involved and are chiefly for the relief of empyema of the cavities involved, necrosis of the bony or cartilaginous walls, tumors of various kinds, especially dental tumors in the young and malignant growths in the old, foreign bodies in the sinuses, differential diagnosis of diseases of this region, etc.

Veterinarians trephine the sinuses by two fundamentally different plans; with, and without excision of the cutaneous disk corresponding to the piece of bone remored. The first is generally used in Great Britain and North America while the last is the prevailing method in continental Europe and other parts of the world. The reasons for these variations in method have not been given so far as we know. To us 
there seem to be adequate reasons for preferring the excision of the cutaneous disk. We regard as the chief considerations in an operation the following: the aroidance of infection; the prevention of pain during the operation or the after-treatment; the reduction of the scar to a minimum; rapidity and certainty of recovery ; convenience in operating and dressing. Infection is largely dependent, aside from aseptic operation and protective dressing, upon the area of the wound, the facility for maintaining cleanliness and the degree of disturbance to the tissues while being dressed. The wound area in the bone is alike in all cases but that in the skin varies greatly. Jf we take as a type the usual German technic and compare it wh that given below we would find the wound areas approximately as follows: in the German method, an incision $2.7 \mathrm{in}$. ( $7 \mathrm{~cm}$.) long which assuming that the skin is $\frac{3}{16}$ in. thick would yield an area of $2.7^{\prime \prime} \times 2=$ $5.4^{\prime \prime} \times \frac{3}{16}{ }^{\prime \prime}=\mathrm{I}$ sq. in. The subcutem is then separated from the periostem and the skin drawn apart far enough to admit of the insertion of, say, a $\frac{\tau^{\prime \prime}}{s}$ trephine giving 2 triangles each having a base of $2.7^{\prime \prime}$ in. and a perpendicular of $\frac{7}{16}$ ". or an area of $2.7^{\prime \prime} \times \frac{7{ }^{\prime \prime}}{16}=1.2 \mathrm{sq}$. in.; thus giving a total wotnd area of $2.2 \mathrm{sq}$. in. Assmming the same thickness of skin and the same size of the trephine in the operation as given below we hare only the wound caused by the circular incision which would measure $\frac{7}{8} " \times 3.1416=2.7^{\prime \prime}$ in circumference $\times \frac{3}{16}{ }^{\prime \prime}=.44 \mathrm{sq}$. in. or proportionately the wound area in the soft tissues in the German operation to that given below wonld be as 5: $\mathrm{I}$.

It is rery evident that the technic below given affords immeasureably better facility for maintaining cleanliness in the wound and with a minimum anount of insult to the tissues in the process of dressing.

The amount of pain caused in the operation would depend chifly on the extent of the skin incision which is equal in the two plans so that the only difference rould be in the dis- 
section of the skin from the bone $n$ the German operation. The pain caused in dressing must be greater in the German method because the detached, overhanging skin must be mored and disturbed each time causing pain and inviting infection. The question of pain must always be seriously considered as it not only' affects the time required for dressing and its efficacy', but has an important relation to the docility of the animal after recovery, some horses having their dispositions permanently mined by the irritation due to the oft repeated painful dressing of wounds.

The cicatricial contraction of the tissues of the horse is so great that the removal of a circular disk of skin $7 / 8^{\prime \prime}$ to I $1 / 2$ " in diameter on the face does not leave a visible scar so that the question of blemish falls back upon that of infection which we have asserted above is far more probable by the German method.

The rapidity and certainty of recovery are dependent on considerations above discussed. The removal of the cutaneous disk is certainly easier and quicker than the other method. The convenience for dressing is evidently superior by the English and Amercan methud.

The opening of the maxillary sinuses into the nostrils is based upon the surgical principle that suppurating cavities should be provided with ample drainage from the most dependent part. The direction to leave the external wound open may at first thought seem antagonistic to general surgical principles but it should be remembered that the wound consists only of the incision through the skin, connective tissue and bone and that any plug which we can put in this opening can only serve to dam the secretions of the cavity back and can not prevent it from coming in contact with the wounded surface. It must further be regarded that the respiratory mucosa of the upper air passages are not irritated or injured in any manner so far as we can observe clinically by the direct admission of air into them through a trephine, or other artificial opening. 


\section{TREPHINING OF THE FRONTAL SINUSES}

Uses. Fracture of the bony walls, necrosis, tumors.

The ample communication below with the superior maxilary sinuses prevents the accumulation of pus or fluids in the frontal cavities even if formed therein unless the opening between the superior maxilary sinus and the nasal fossa at $\mathrm{N}$, Plates I and I'I becomes blocked, preventing the escape of fluids through the latter and cansing them to fill the superior maxilary sinus and then back up into the frontal. In case of enpyema of the frontal sinus, trephining does not give full relief but calls for a repetition of the operation on the maxilary sinuses also.

Instruments. Razur, scissors, convex scalpels, artery forceps, tenacula, probe, trephine, curette, gouge, Luer's sharp bone forceps, hammer, chisel, bone screw, lens-shaped bone knife, probe-pointed bistonry, dressing forceps, disinfecting and dressing materials.

Technic. Operate on the standing animal with the aid of the twitch or secured in stocks, with local anaesthesia or secure on the operating table or cast in lateral recumbency on the sound side. Clip and shave the hair from the region of the frontal bone on a level with the superior border of the orbital cavity as indicated in Plate IV and disinfect the area carefully. Within the shaved and disinfected area locate the point for trephining, $F$, Plate $I^{\top}$, so that the inferior border of the opening will be on a level with the superior border of the orbital carity at the dotted line below $F$ and the inner margin about $1 \mathrm{~cm}$. from the median line of the face. With a heavy conrex scalpel make a circular incision as large as the area of the trephine, directly through the skin, subcutem and periostemm down to the bone and remove in one piece the entire mass of encircled soft tissues by seizing the skin with a tenaculum and forcibly separating the periosteum 


\section{Plate IV.}

TRephining The Facial, Sinuses.

$\mathrm{F}$, opening into frontal sinus; $\mathrm{N}$, opening into nasal sinus; SM, opening into superior maxillary sinus; IM, opening into external portion of inferior maxillary sinus; IM', opening into the median portion of the inferior max1lary sinus. 


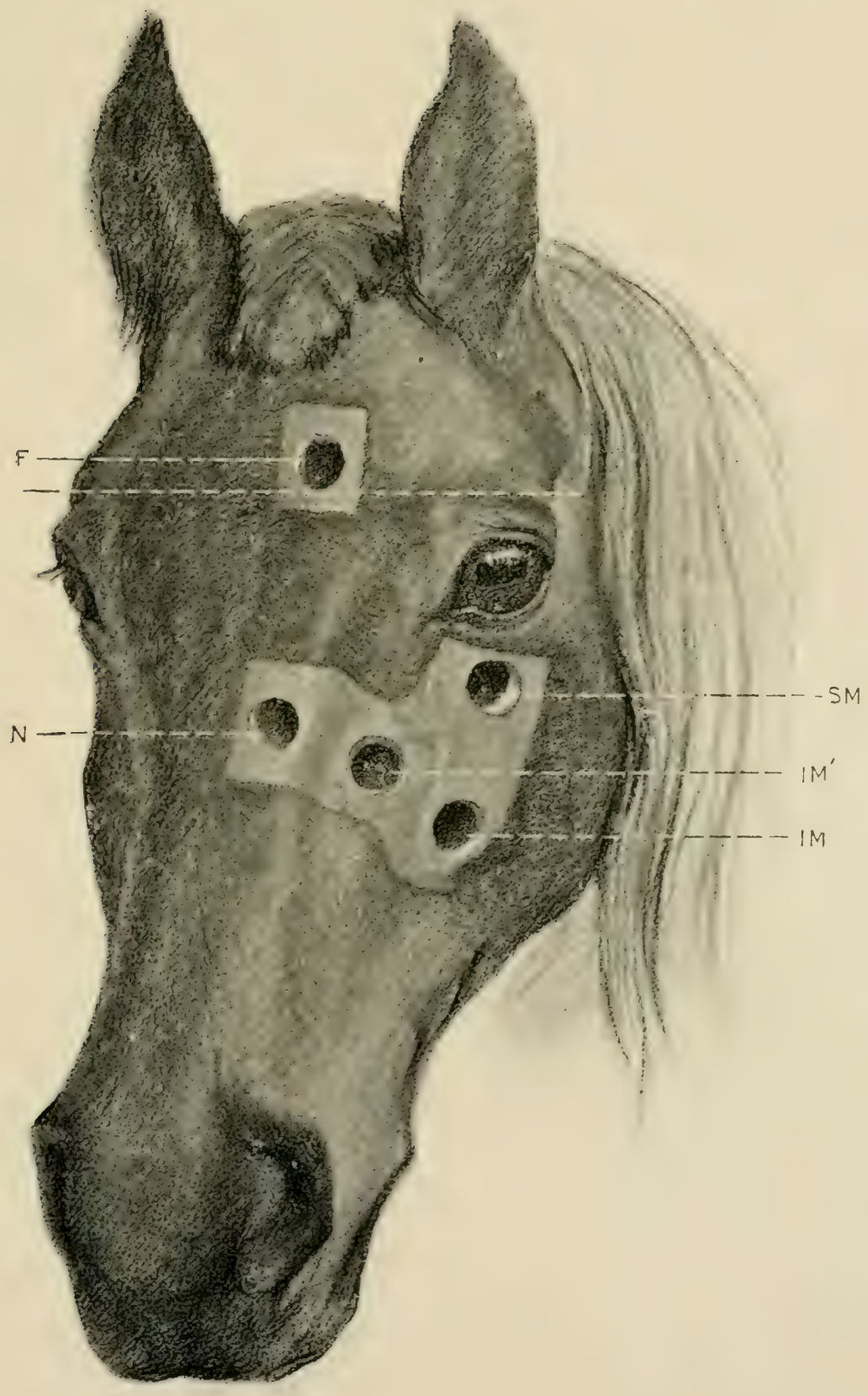



from the bone with a scalpel or bone scraper. Control the hemmorhage. With the center-bit extended place the trephine accurately upon the denuded area, perpendicular to the surface of the bone, and by revolving it to and fro force the center-bit into the bone and continue until the trephine has cut a distinct furrow, when the center-bit should be withdrawn and the operation continued, being careful to maintain the trephine perpendicular to the bone. 'The operation is facilitated by grasping the shaft of the trephine between the thumb and fingers of one hand, constituting a support in which it can glide back and forth. The pressure under which the sawing is carried out must not be too great. When the bony plate which has been sawed around begins to loosen, remove the trephine and insert the bone screw into the centerbit opening and break ont the piece of bone or pry it out with the bone gouge or chisel. Smooth any nneren edges of bone with the lens-shaped knife. The abnormal contents of the frontal sinus can now escape through the opening or be removed with the curette, forceps or scissors, and the cavity irrigated with an antiseptic fluid. Leave the trephine wound entirely open and dress daily with antiseptics. The frontal sinuses are in free communication with the superior maxillary and with the superior turbinated bone of the same side so that indirectly the irrigating fluid can escape through the nasal opening by way of the maxillary sinus or of a perforation through the superior turbinated bone.

In order to prevent the aspiration of the contents which are generally purulent, or may consist of blood or irrigating fluids, and to facilitate their escape, irrigation must be carried out with the poll elevated and the head flexed.

By studying Plates IV and $V$ it will be seen that any collection of pus or other disease products at $F$ would result in poor drainage so far as may be obtained by 
Plate V.

TREPHINING THE FACIAL SINUSFS.

Cross sectiun of the left side of the head of an aged horse at the second molar, seen from the front. $\mathrm{F}$, frontal sinus; $\mathrm{N}$, nasal sinus, opposite the communication between the nasal and inferior maxillary sinuses; IM, lateral portion of inferior maxillary sinus ; IM', melian portion of inferior maxillary sinus; SM, superior maxillary sinus; $N F$, superior maxillary division of trifacial nerve in its bony conduit; SZ, subzygomatic artery; $\mathrm{P}$, palatine artery; M2, second molar. 


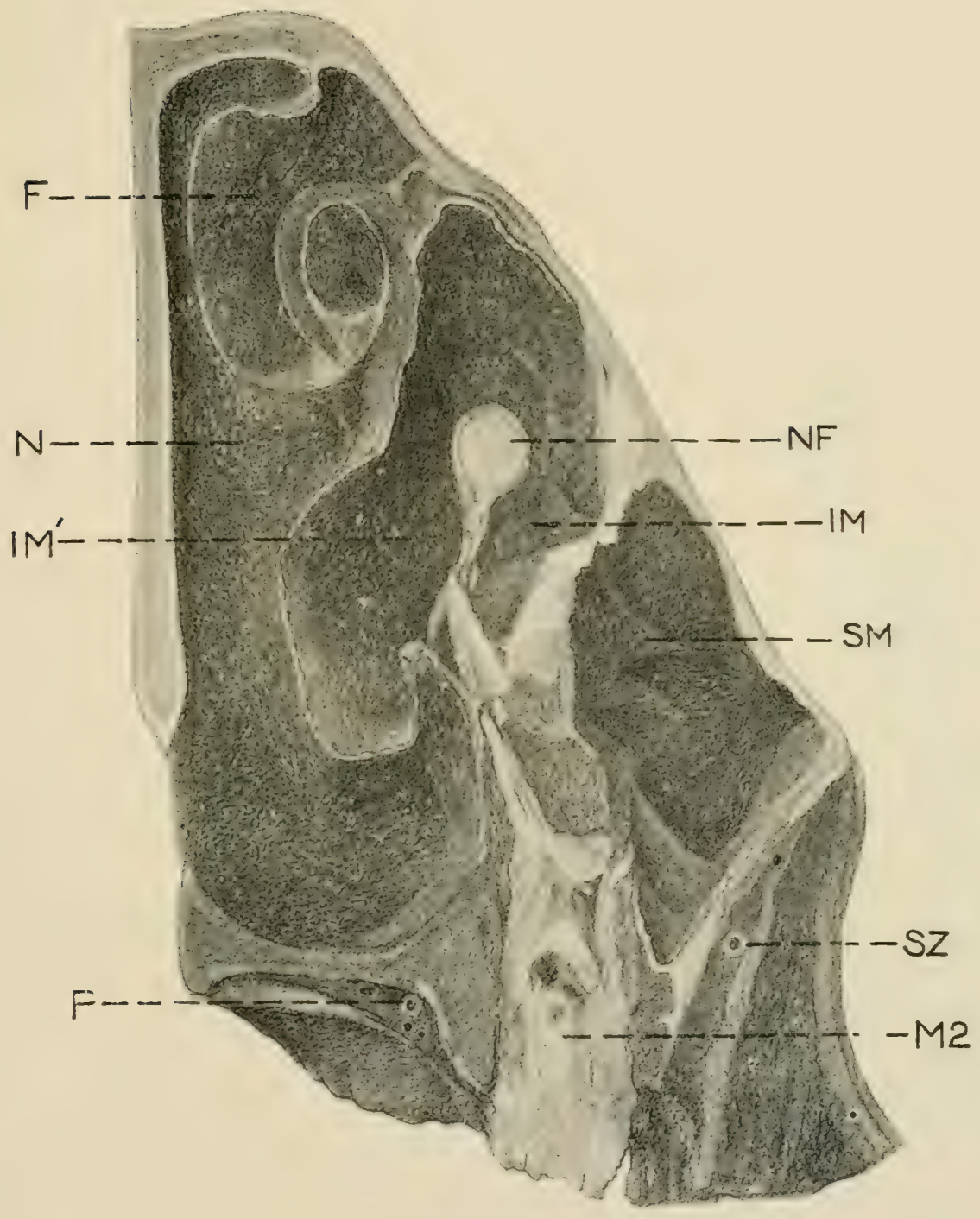



trephining through the external wall only, and consequently in order to complete the drainage aside from that through the superior maxillary sinus an artificial communication between the frontal sinus and nasal fossa may be made at ST, Plate VII, by first making a second trephine opening opposite that point near the median line and then breaking throngh the thin walls of the turbinated bone by means of a probe or other suitable instrument and enlarging the opening sufficiently with the probe pointed bistonry or with the finger. In order to prevent aspiration of fluids, the animal must be allowed to get up immediately or if under anaesthesia a trachea tube should be inserted sufficiently early to avoid danger. 'Thread a long probe with a heary silk suture about $75 \mathrm{~cm}$. long and inserting it through the trephine opening into the nasal passage draw it out through the nostril and removing the probe attach a strip of ganze $75 \mathrm{~cm}$. long to one end of the suture, draw it out through the nostril and tie the ends of the ganze together on the side of the face to prevent dislodgement. Retain the gauze in position for about furty-eight hours to insure the permanency of the opening through the turbinated bone. In case of severe hemorrhage the carity can be tamponed for twenty-four hours with a long strip of ganze which may be secured if necessary by suturing to the lips of the wound. In practice the operation can be best carried out generally with the animal in the standing position the operative area being first anaesthetized by the use of cocaine or by inducing artificial oedema. In the standing position we largely aroid the danger of aspiration of fluids and the hemorrhage is greatly lessened. 
Plate VI.

TrEPhining THE Facial, Sinuses.

Cross section, slightly oblique, through left half of head at fisst molar in a two year colt. $F$, frontal sinus ; N, nasal sinus at point of communication with the inferior maxillary sinus, IMI ; IM', median portion of inferior maxillary sinus; SM, superior maxillary sinus; MI, first molar; M2, second molar; $\mathrm{P}$, palatine artery; $\mathrm{S} Z$, sub-zygomatic artery. 


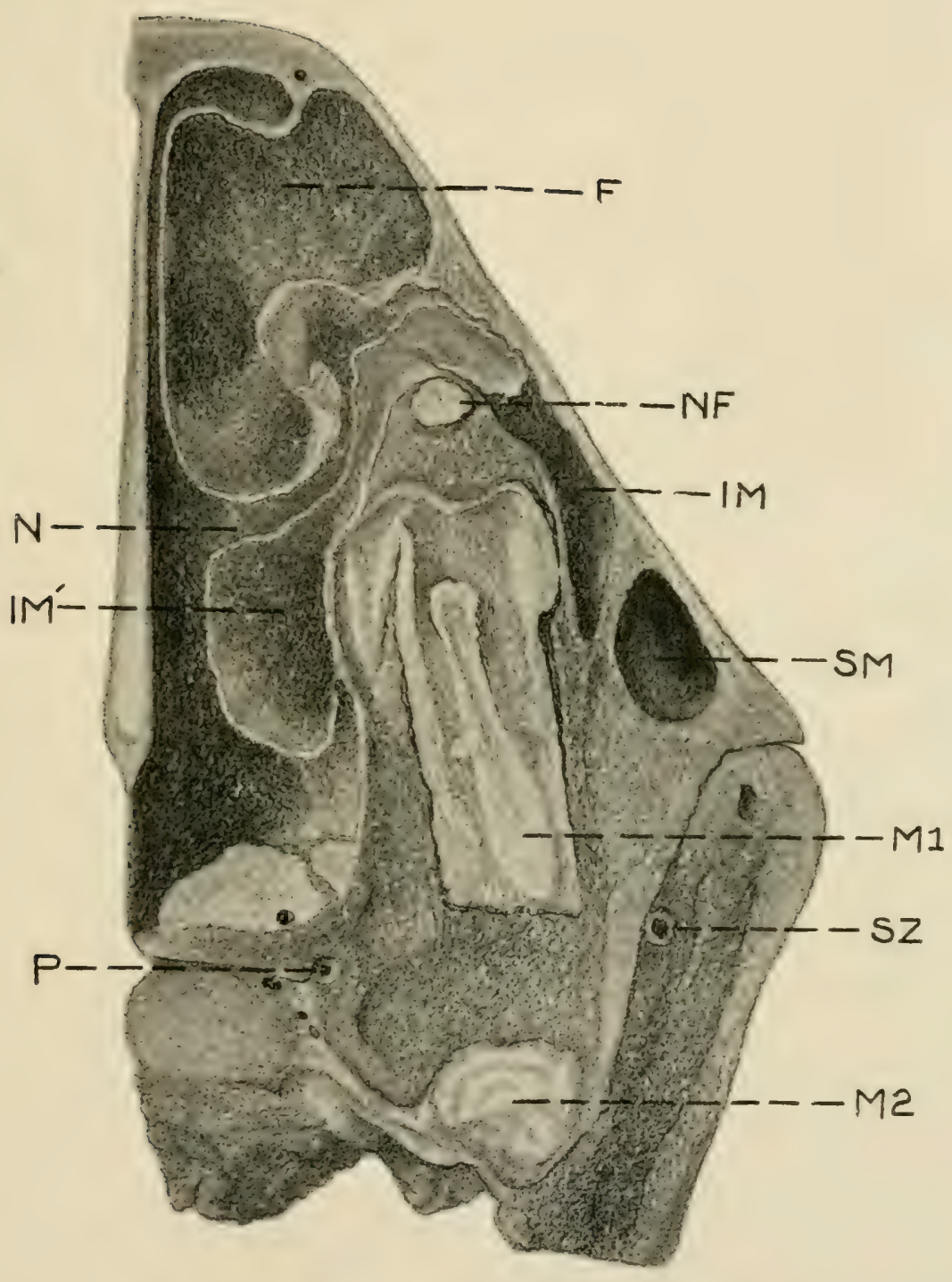


. 


\section{TREPHINING THE MAXILLARY SINUSES.}

Uses. Empyema, diseased teeth, odontomes, tumors.

Instruments. Same as for the frontal sinuses.

Anatomically there are two maxillary sinuses, superior SM, and inferior IM, Plates IV, V, and VI, having a thin imperforate bony partition between them. This partition shifts somewhat in position with age and in case of disease undergoes profound changes in location and is frequently. totally obliterated in cases of empyema, dental cysts and other affections, so that clinically in many cases its location, existence or non-existence is of scant interest. If present, good drainage of the superior sinus nstually demands its surgical destruction so that most authors adrise trephining directly over this partition in order to open the two sinuses simultaneously. In extensire disease the prior destruction of the partition renders such an operation superfluous; in limited disease the opening of both carities is ill adrised. The partition should be ignored in operating for extensive disease and the trephine opening be aimed at the probable focus of disease and, if missed, it should be located through the primary, or what now becomes an exploratory opening and a second operation made to directiy reach the seat of the affection and if need be, yet a third to secure proper drainage. Shave and disinfect as much of the area as may be required bounded above by the inferior border of the orbital cavity, laterally by the zygomatic ridge, iiferiorly by the lower end of the zygomatic ridge and medianwards by the middle line of the face. Determine the proper point for operation by percussion or otherwise. If it is desired to enter only the superior maxillary sinus, SM, Plates $V$ and and VI, locate the opening immediately beneath the orbital cavity and in front of the zygomatic ridge, SM, Plate IV, or at any point directly beneath this to within about 3 or $4 \mathrm{~cm}$. of 
the inferior end of the zygomatic ridge at about the level of the dotted line IM'. In order to penetrate the inferior maxillary sinus the trephine opening needs be located just in front of the lower end of the zygomatic ridge at IM, Plate IV, or on a line obliquely upwards therefrom as far as the furrow marking the suture between the maxillary and nasal bones at IM'. The trephining is carried out as described for the frontal sinuses. After the trephine opening has been made remove any purulent collection or tumors or carry out any other necessary operation in the affected sinuses and after cleansing, if the trephine opening does not insure perfect drainage of the lateral sac, either lower the opening already made by cutting away its inferior border with the bone forceps or make a second trephine opening at the necessary point. The median portion of the sinuses on the median side of the bony conduit of the trifacial nerve $\mathrm{NF}$, Plates V and VI, can not be drained properly throngh these openings SM and IM, Plate IV, and provision for their drainage must generally be made by making a trephine opening into the inferior maxillary sinus at $\mathrm{IM}^{\prime}$, Plate $\mathrm{IV}$, and then make an opening 3 to $5 \mathrm{~cm}$. in diameter through the inferior turbinated bone at IT, Plate VII, either with the finger, probe-pointed bistoury, or other suitable instrument, and inserting through this opening a long and thick strip of gauze which is brought out through the nostril and the ends tied together on the side of the face to prevent displacement. Retain this in position renewing daily until the permanency of the opening is assured.

If the partition between the two sinuses is intact it will be necessary to destroy it immediately above IM', Plate IV, in order to drain the median portion of the superior maxillary sinus if that is required. If a molar has been removed and in so doing the bony wall leading down from the nerve conduit NF, Plates V and VI, to the fang of the molar has been destroyed in the operation, sufficient drainage may be af- 
forded into the mouth and the opening through the turbinated bone be rendered unnecessary. Leave all wounds entirely open and irrigate daily with antiseptic solutions.

Dangers. Care must be exercised to not injure the superior maxillary division of the trifacial nerve, NF, Plates $\mathrm{V}$ and VI, either in trephining or after the sinuses have been opened. The bony conduit of this nerve is in rare cases entirely resorbed by pressure from dental cysts or other causes, leaving the nerve stretched across the cavity as a white nacrous cord, intensely sensitive. Any injury to this nerve canses intense pain and renders the animal very resistant to the necessary manipulations in the after care of the wound and may leave it permanently nervous about the liandling of its face.

Hemorhage is generally not severe and may occur from the skin, where it should be controlled by compression or ligation; from the inter-osseous ressels, where it may be controlled by pressure with absorbent cotton, by pushing a small portion of the cotton into the channel of the ressel with a needle or tenaculum or by plugging the vessel with a conical piece of wood; from the wo:nded turbinated bones where it may be controlled by packing with cheese cloth. These tampons should be remored after twenty-four hours. 


\section{TREPHINING THE NASAL FOSSAE.}

Uses. Operations on the septum nasii, upon the turbinated bones, the removal of tumors or foreign bodies.

Instruments. Same as for the frontal sinuses.

Technic. The trephining is carried out by the method described above, in the region of the nasal bone, close by the median line of the face and according to indications at any point from a level of the dotted line SM, Plate IV, to the upper extremity of the false nostril. The operation shonld be immediately against the median line since otherwise the frontal or superior turbinated sinuses may be opened, the highly vascular superior turbinated bone wounded or an important inter-osseous artery in the nasal bone just above its union with the superior turbinated bone, as shown in Plate VI, may be severed. Special care is also necessary that the trephining should not be carried too deeply and that the disc of bone be carefully removed in order to avoid wounding the highly vascular turbinated bone which lies in close proximity to the nasal bone. The operative area is narrow and the trephine used should not exceed $2 \mathrm{~cm}$. in diameter. Whenever possible the operation should be carried ont on the standing animal which decreases the hemorrhage and the danger from aspiration of fluids. Even in the standing animal, if extensive operations are to be carried ont on the very vascular septum nasii or on the turbine it is generally advisable to perfom tracheotomy before trephining, and retain the trachea tube in position until all danger has passed. When the animal is confined in the recumbent position the patient's safety demands that tracheotomy be performed before the operation is begun in almost all cases. Anæsthesia may be maintained in such cases by means of an ordinary fumnel with its spout bent at right angles and inserted into the trachea tube while 
the chloroform is dropped on a towel spread over the mouth of the funnel. After completing any required operation on the septum, turbinated bones or other parts, hemorrhage may be controlled by plugging one or both nasal fossa with single strips of gauze of sufficient size and carefully securing them by sutures to the sides of the trephine wound or otherwise.

\section{POLL EVIL OPERATION.}

PLATE VII.

Instruments. Clipping shears, razor, sharp scalpels, probe-pointed bistoury, probe, Lner's bone forceps, bone gonge, curette, suture and dressing material.

Technic. Confine the animal in lateral decubitis preferably upon the operating table, place under complete anaesthesia and remove the halter or other headgear. Clip the foretop and mane and shave the forehead and the top of the neck bask to a distance of 8 or ro cm. and behind the supposed extension of disease, and disinfect the area. With a sharp scalpel make a longitudinal incision on the median line of the head and neck beginning at a point presumably posterior to the diseased area and carrying it over the poll down onto the forenead for a distance of 4 or $5 \mathrm{~cm}$. below the foretop. Continue this incision through the skin, the subcutem, the adipose tissue, A', Plate TII, and either through or passing around alongside the neck ligament, LN, into the diseased area beneath the latter. Dissect the ligamentum nuchæ away from the adjoining tissues as far back as diseased and divide obliquely upward and backward as indicated at A A, Plate VII and detach anteriorly from the base of the occiput. Be careful to remove every portion of the ligament in the area indicated and remore all calcareous deposits or diseased tissues. With Luer's forceps groove a channel about $2 \mathrm{~cm}$. wide from behind to before through the occipital protuber- 


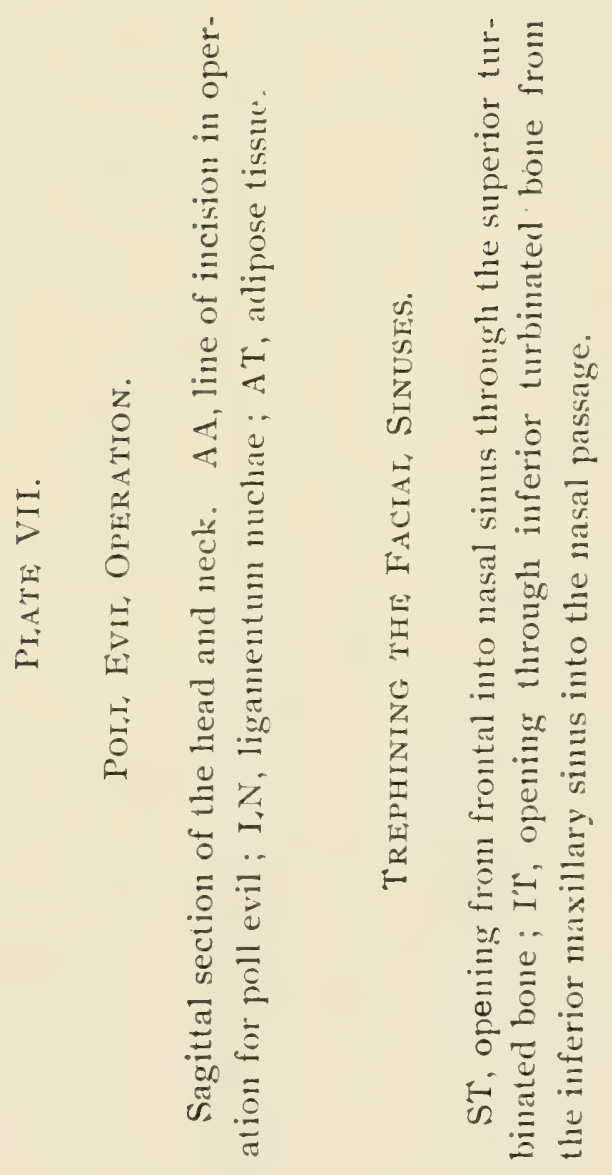




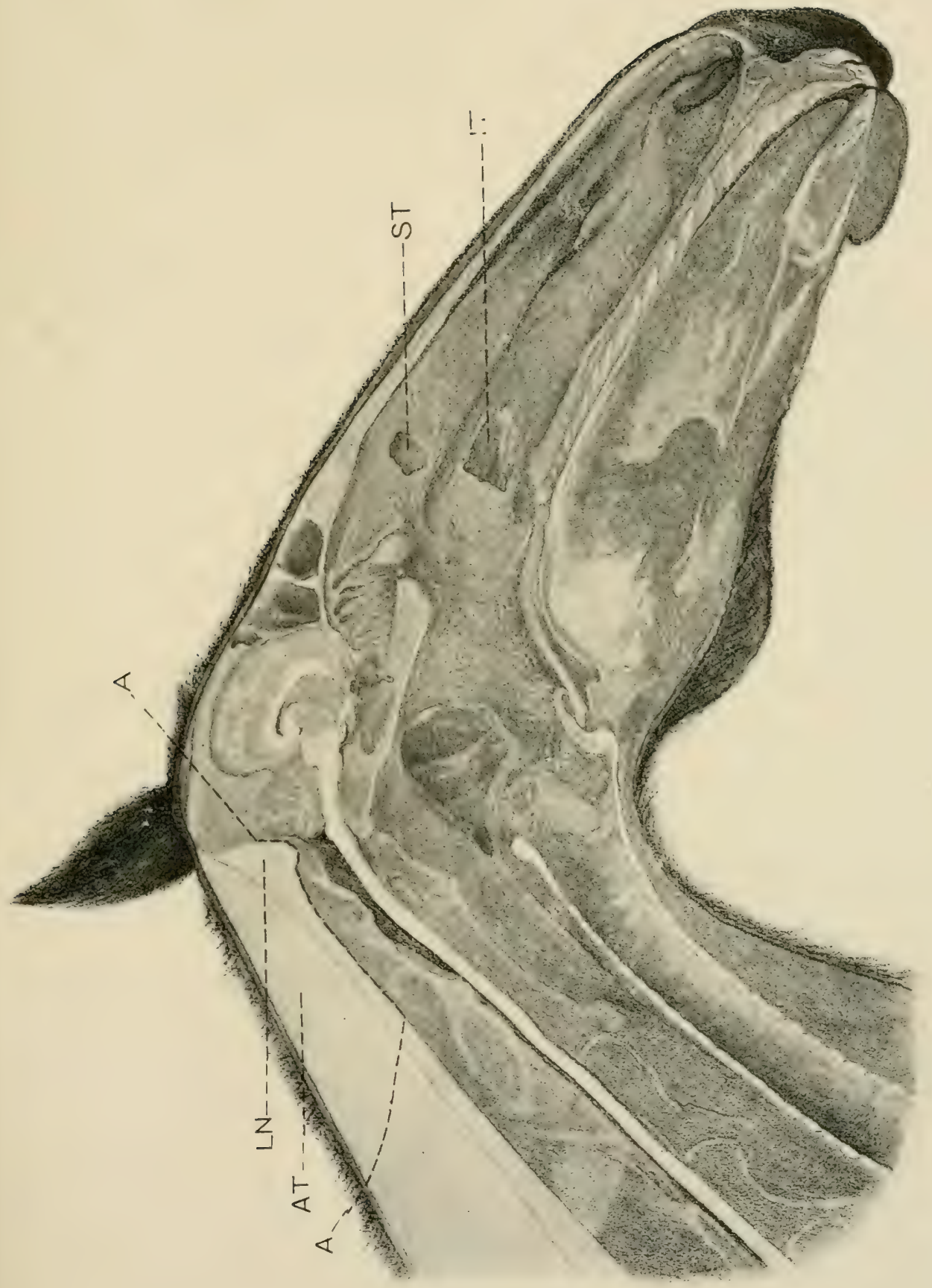



ance to the depth of about 2 cm. making the bottom of the groove as near as possible on a level with the bottom of the wound in the soft tissues as indicated by the dotted line, AA, Plate VII. Using Luer's forceps as a curette detach all restiges of the neck ligament from the base of the occiput and leave the bone bare and smooth. Be careful to avoid penetrating the cranial carity or the occipito-atloid articulation. Control the hemorrhage, cleanse and disinfect the wound, pack with iodoform gauze and sutue for its entire length except the anterior part where the packing should slightly protrude and dust the margin of the wound over with iodoform and tannin. Remove the pack after fortyeight hours and dress antiseptically daily. The sutures may or may not be removed according to conditions. In carrying out this operation our chief aim should be to remove all diseased parts, to afford perfect drainage anteriorly, to secure and maintain asepsis, and to keep the wound directly on the median line from which no visible scar will result.

\section{LIGATION OF THE PAROTID DUCT.}

PIATE VIII.

Objects. The destruction of the parotid gland in case of fistula from wounds or abscesses.

Instruments. Razor, convex scalpel, straight probepointed scalpel, tenaculum forceps, ligation forceps, tenacula, needle holder, probe, suture and dressing material.

Technic. In case of salivary fistula insert a probe through the fistula into the duct toward the gland and with a sharp scalpel lay the parotid duct free for a distance of from I to $2 \mathrm{~cm}$. On the glandular side of the fistulous opening. If the fistula has its location on the side of the cheek, cast the horse and shave and disinfect the region on the inferior maxilla where the artery, vein and parotid duct turn around its inferior border. When the operator glides his finger over the vascular region from before backward 
Plate VIII.

Ligation OF The PaRotid DUCT.

Fig I. Segment of the left ramus of the inferior maxilla of the horse seen from the right and beneath. sp, usual operative field; $a$, external maxillary artery; $v$, external maxillary vein ; st, st, parotid duct.

Fig. 2. Life size of operation field at $s p$, fig. I ; $a$, external maxillary artery ; $v$, external maxillary vein ; st, parotid duct ; $m$, mass eter muscle. 


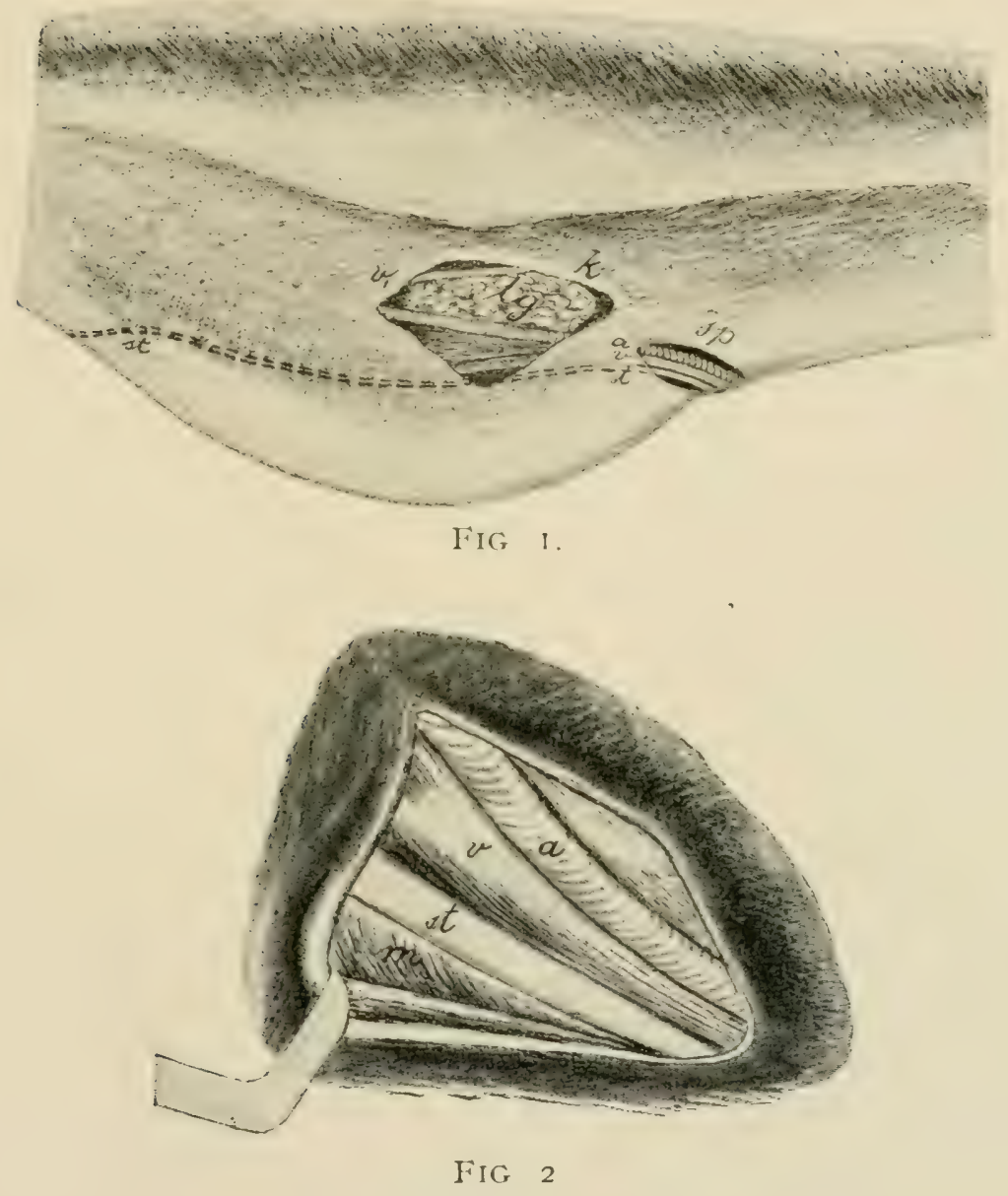



there is felt a resistant cord, the external maxillary artery about $3 \mathrm{~mm}$. in dianeter, pulsating in the living animal. Between this and the oral border of the masseter muscle make an incision about + cm. long parallel with the artery through the skin and skin muscle. This incision is more readily made by gathering up a fold of skin about $2 \mathrm{~cm}$. high and cutting through this. Pick up the loose connective tissue with a pair of forceps and excise it. Immediately behind the external maxillary artery, $a$, Figs. I and II, Plate VIII, is the external maxillary rein ${ }^{\prime}$ and behind this and immediately on the border of the masseter muscle lies the parotid duct, st. In case of salivary calculi which cannot be removed through the month and cystic dilation of the parotid duct, make the cutaneous incision at the affected point, open the parotid duct, and after the remoral of the calculus, etc., close the duct wound by means of intestinal sutures in such a way that the exterual surfaces of the lips of the wound in the wall of the duct are brought in contact, or ligate the duct on the proximal side of the point of operation. Ligation is accomplished by passing a strong silk thread behind the duct by means of a curred needle carrying it around the duct and tying with a surgeon's knot. The parotid duct can also be previonsly split and an internal wound made at the point of ligation. Close the skin wound by means of a continuous suture and cover the operative surface with iodoform collodion or with wound gelatine. 


\section{ENTROPIUM OPERATION.}

Instruments. Razor, convex scalpel, tenaculum and ligation forceps, tenacula, needle holder, needles, thread, absorbent cotton.

Technic. Quiet adult horses may be operated upon in the standing position with the aid of local anaesthesia, other horses and small animals should be secured in lateral recumbency preferably upon the operating table. Shave and disinfect the skin of the inverted eyelid. Grasp the skin of the eyelid midway between the inner and outer canth either with the fingers or the forceps and elevate a skin fold parallel with the border of the eyelid to such a height that the inverted member assumes its normal position. Pass

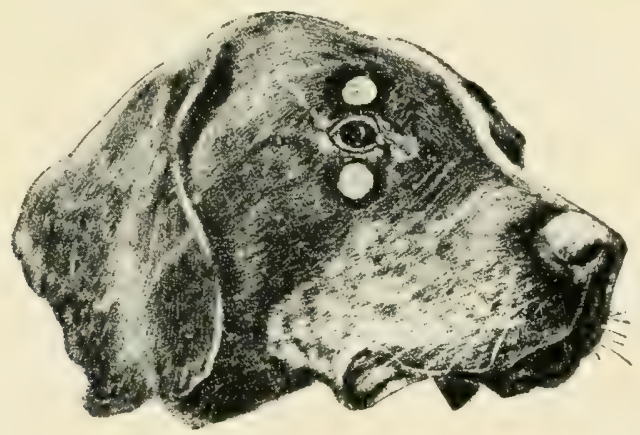

FIG I.

Entropium operation on the superior ant? inferior eyelids of the dog. one finger into the conjunctival sac to make sure that the conjunctiva is not drawn into the skin fold. Clip the fold off with the scissors immediately below the forceps, removing an oblong piece. Between the border of the eyelid and the border of the wound the skin should be left intact for at least $.5 \mathrm{~cm}$. Ligate any bleeding vessels and close the wound by means of interrupted sutures. The wound may be covered with iodoform collodion or wound gelatine or dusted over with iodoform-tannin. It is usually unnecessary and inadvisable to cover the parts with hood or other appliance since so long as the wound is healing properly the animal will not disturb it. 


\section{STAPHYLOTOMY.}

Object. An operation devised by Dr. M. H. McKillip for making a mantual exploration of the Eustachian tubes, guttural ponches, phirynx and posterior nares; and for operations upon these structures. The form and extent of the soft palate of the horse is such as to render it extremely difficult to make a manual exploration of the parts above and behind it, and impossible to make a risual examination except with the aid of the expensive and complicated rhino-laryngoscope, which only aids in diagnosis while staphylotomy combines with this operative advantages, permitting the free introduction of the land into the laryngopharyngeal region.

Instruments. Mouth speculum, short curved probe pointed bistoury with a ring to fit the middle finger.

Technic. Cast the patient or secure on the operating table in lateral recumbency and turn the nose upward. Adjust the mouth speculum and open the mouth as wide as possible; draw the tongue well out with the left hand while the right carrying the knife on the middle finger is passed carefully through the fances until it hooks over the posterior border of the soft palate. The knife is then gently drawn forward making an incision along the median line of the soft palate from its posterior, free border to its attachment on the palatine bone. The hand is then withdrawn and the speculum removed for a few minutes to permit the patient to rid its pharynx of any blood clots or mucus that may have accumulated. Readjusting the speculum as before, the right hand is again passed through the fances and now that the palate is divicled a digital exploration will perfectly reveal the presence of any abnormality in the region. 


\section{IO. TRIFACIAL NEUROTOMY.}

PLA'TE IX.

Object. The relief of involuntary shaking of the head.

Instruments. Razor, scissors, convex scalpel, tenacula, aneurism needle, compression artery forceps, needles, thread, absorbent cotton, a strong piece of muslin I $2 \mathrm{~cm}$. square.

Technic. Secure in lateral recumbency, preferably upon the operating table, and produce complete anaesthesia. Remove the halter, bridle, or other head gear. Shave and disinfect an area 8 to $I 0 \mathrm{~cm}$. square over the infra-orbital foramen. Locate hy touch the infra-orbital foramen, IOF, Plate IX, below the levator labii superioris proprius muscle and displace the latter, LL, downwards toward the inferior maxilla until the foramen can be felt above the muscle. By pushing this muscle downward the branches of the glosso-facial ressels which lie chiefly below it are pushed downward with the muscle so that the incision can be made without wounding them. Begin the incision I cm. above the foramen and carry it down directly over the middle of the nerve a distance of 5 or $6 \mathrm{~cm}$., through the skin, subcutem and the levator labii superioris alaque nasii muscle, laying bare the nerve NF, where it emerges from the foramen. Let an assistant hold the lips of the wound apart and the levator muscle downwards with two tenacula, dissect away the connective tissue surrounding the nerve until the latter is clearly defined, pass the aneurism needle beneath the nerve from above downwards being especially careful to include the uppermost or dorsal tivigs, and passing a curved probepointed scalpel or the blade of a pair of scissors underneath it, divide the nerve at the foramen, grasp the distal end with forceps and excise a piece at least $3 \mathrm{~cm}$. long being careful to include all branches. Control the hemorrhage very carefully. Cleanse the wound, sprinkle with iodoform and close 
with continuous sutures. Place the square piece of muslin centrally over the wound and fix it securely to the skin by means of strong sutures at each corner, in order to protect it while the other nerve is being cut. Turn the animal to the opposite side and repeat the operation on the other nerve except the application of the square piece of muslin which is here nnnecessary. As soon as the animal stands, remove the protective piece of muslin from the first wound, disinfect both wounds, dust them over with iodoform and tannin or cover with wound gelatine and leare undisturbed to heal by primary union. Aroid halter, bridle or other fixtures which might injure the wounds after the operation.

Dangers. 'The chief danger in the operation is from infection, which sets up a severe neuritis in the proximal end of the nerve, aggravates the symptoms and causes much suffering. In order to prevent infection the aseptic precautions need be unusually strict in every detail and the anaesthesia profound. Carefully aroid wounding the neighboring ressels and control completely any hemorrhage that occurs in order to aroid a lematome in the wound, which would invite infection.

Literature. Involuntary twitching of the head relieved by trifacial neurectomy. W. L. Williams, Jour. Comp. Med. and V. A., vol. XVIII, p. 426. Involuntary shaking of the head and its treatment by trifacial neurectomy. do. Am. Vet. Rev., vol. XXIII, p. 32I and Esst. Monatsch. Thierheilkunde, Bd. XXIV, s. 2II. 
PLATE IX.

Trifactal, NeURotomy.

LL, Levator labii superioris proprii displaced ventralwards toward inferior maxilla. It originally rested at end of dotted line from IOF; IOF, infra-orbital foramen; NF, superior maxillary division of the trifacial nerve. 


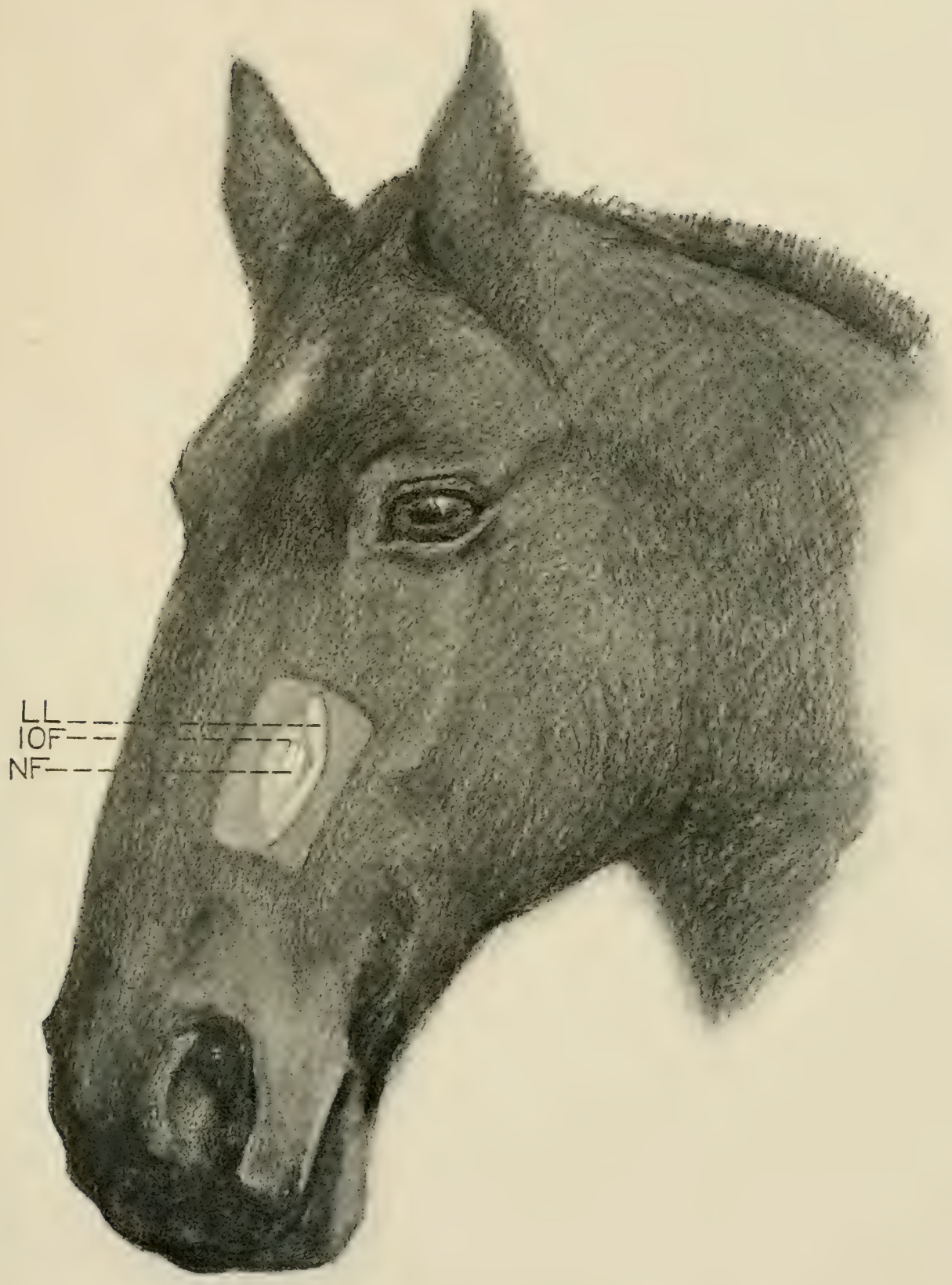





\section{OPERATIONS ON THE NECK.}

\section{OPENING OF THE GUT'TURAL POUCHES.}

\section{PLATE X.}

Instruments. Razor, scissors, convex pointed and straight probe pointed scalpels, artery forceps, tenacula probe, trocar, curette, drainage tubing, suture and dressing material.

Technic. I. Tiborg's method. 'The operation is possible on the standing animal, but generally the patient must be cast or placed on the operating table and secured in lateral decubitis with the head extended. By extending the head and compressing the jugular rein there is brought ont the triangle immediately belind the posierior border of the inferior maxilla and below the parotid gland comprised between the posterior angle of the inferior maxilla, the terminal tendon of the sterno-maxillaris muscle and the external maxillary vein. In this so-called Viborg's triangle after the removal of the hair and the disinfection of the skin which is maintained stretched, make a $5 \mathrm{~cm}$. long incision throngh the skin and skin muscle immediately beneath the aforementioned tendon and parallel to it. In case of pronounced swelling in Viborg's triangle the operator must determine the location for the incision by the position of the sternomaxillaris muscle. The skin and subcutem having been incised to a sufficient extent, force a passage with the finger or with probe pointed scissors closed or other blunt instrument through the loose connective tissue on the median side of the parotid gland, which area is free from large vessels and nerves, to the guttural pouch and penetrate it at its lowest point with the finger or trocar. In order to open the empty guttural pouch it is desirable to grasp a portion of its wall by means of forceps. Through the operative 
PLATE X.

Opening of the GutTural, Pouches (HyoVERTEBROTOMY) ACCORDING TO VIBORG

AND CHABERT.

Head and neck of recumbent horse viewed from the side. $s m$, Stylo maxillaris muscle ; $p$, parotid gland; $l$, guttural pouch; $k$, larynx; st, sterno-maxillaris muscle; $r$, rectus capitus anticus major muscle ; $c$, external carotid artery ; $e$, external maxillary artery; $i$, internal maxillary artery; $v$, external maxillary vein; $s$, probe ; $a$, wing of atlas. 


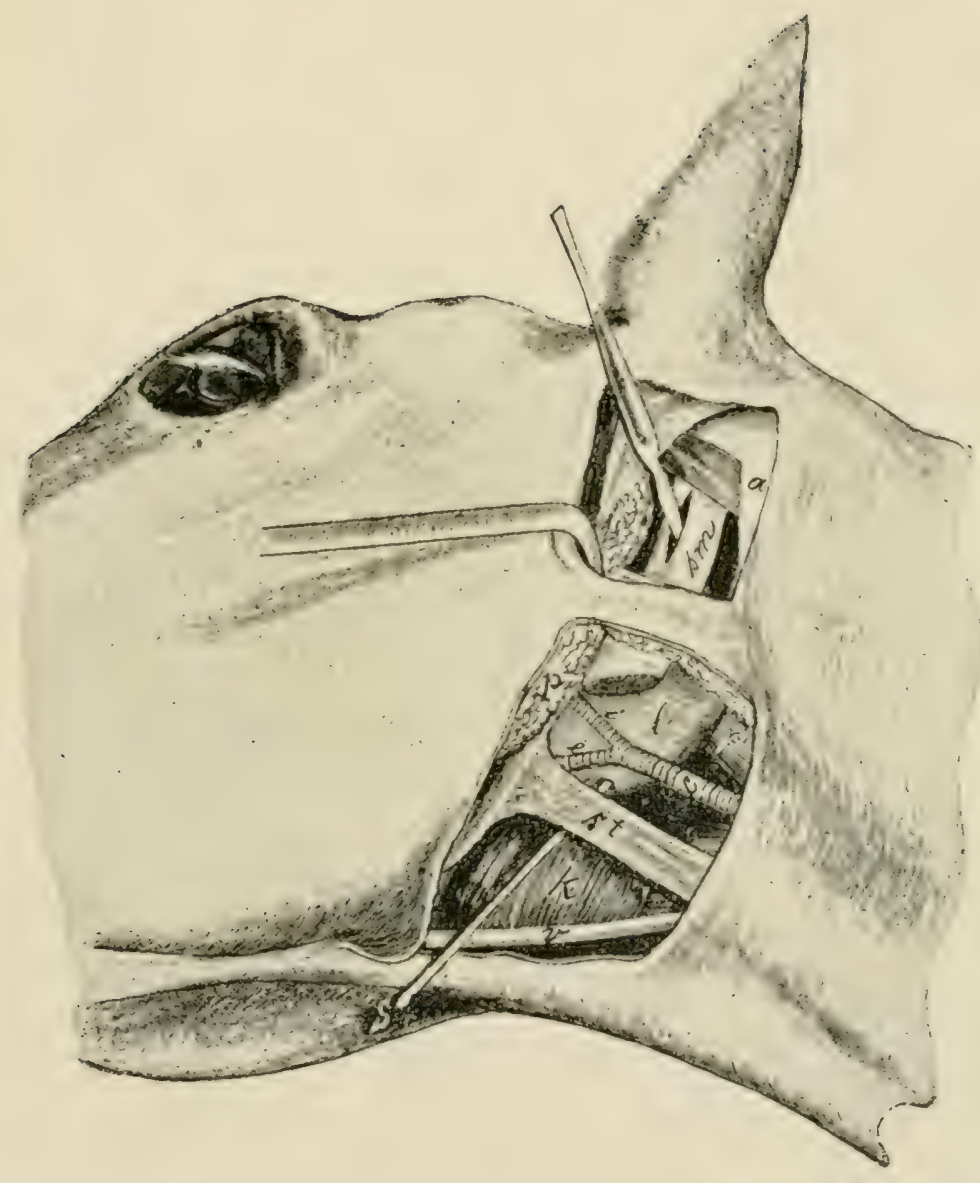



wound a drainage tube can be introduced into the pouch, and fixed in its position by sutures. The opening can be enlarged in an anter-posterior direction to the extent of 5 to $8 \mathrm{~cm}$.

A far more common operation in reterinary practice than the opening of the guttural pouches, is the opening of abscesses of the sub-parotid lympl glands, lying between the inner face of the parotid and the external face of the guttural pouch. The operation here used is the same as Viborg's for the guttural pouch but does not penetrate that cavity because the inner wall of the abscess has pushed the external wall of the pouch inward so that the former largely occupies the usual location of the guttural pouch. The dyspnoea generally prohibits casting the animal and necessitates operating in the standing position. In some cases the dyspnoea is so severe as to demand tracheotomy before the opening of the abscess can be undertaken because the excitement aggravates the difficult respiration to the point of suffocation.

II. Chabert's method. Secure the horse in the lateral recumbent position, remore the hair and disinfect the skin beneath the wing of the atlas. Make an incision about I $\mathrm{cm}$. in front of the lower half of the wing of the atlas and paraliel to it, about $6 \mathrm{~cm}$. long extending through the skin and skin muscle down to the parotid gland. The incision is facilitated by rendering the skin tense with the left hand and care is to be taken not to wound the auricular nerve which passes directly along the atlas. Then draw backward the posterior lip of the wound and separate with blunt instruments the posterior border of the parotid gland from the atlas, to which it is bound by loose connective tissue, and draw the gland forward with tenacula. At the bottom of the opening thus formed there is seen the stylomaxillaris muscle, sm, Plate $\mathrm{X}$, lying against the median side of the parotid gland corered only by the aponeurosis of the mastoido-humeralis muscle. With the handle of the 
scalpel inclined toward the wing of the atlas penetrate in the direction of their fibers the aponeurotic expansion of the mastoido-humeralis muscle and the sterno maxillaris muscle. The puncture is thus located between the ninth and tenth nerves on one side and the internal carotid on the other. Since the wall of the guttural pouch rests against the median side of the digastricus muscle it is opened by this incision. 'The operator inserts an index finger along the blade of the knife at first and then withdrawing the instrument passes the other index finger also in the penetrant wound and by forcibly parting these dilates it. The abnormal contents are then removed by means of forceps, curetting and irrigation. In order to prevent adhesion of the wound lips in the firmly stretched stylo-maxillaris muscle, introduce a strong drainage tube into the pouch and fix it to the external borders of the wound by a suture.

III. Dieterich's method. This combines the operations under I and II, with the difference that the superior opening of the ponch is made immediately behind the stylo-maxillaris. In order to accomplish this the cutaneous wound over the wing of the atlas must be prolonged below it. After detaching the posterior border of the parotid gland the operator searches in the loose areolar tissue with the index finger of the left hand for the rascular angle which is formed by the occipital, internal carotid and external carotid arteries which may be detected by pulsation-the same is located at a depth of somewhere from 8 to $10 \mathrm{~cm}$. Place the volar surface of the finger in the vascular angle and push a sharp scalpel along the dorsal surface of the finger to the pouch which here becomes opened on its posterior lateral surface.

This method has the advantage over Chabert's that for the removal of hard contents (chondroid) the opening can be readily dilated, even to such an extent that the entire hand can be passed into the air sac and the opening of the Eustachian tube be explored. 


\section{I2. TRACHEO'TOMY.}

FIG. 2.

Instruments. Razor, scissors, convex scalpel, tenacula, tenaculum and ligation forceps, trachea tube, and suture material.

Technic. In the superior third of the neck, in the region of the fourth to the sixth tracheal ring, shave and disinfect the skin on the anterior surface of the neck to the extent of ro cm. long by $5 \mathrm{~cm}$. wide. The operation is best performed upon the standing animal with the head extended In lateral decubitis of the horse the operation is carried out with some difficulty, and generally the operator fails to get the incision on the median line. The operator stands before the

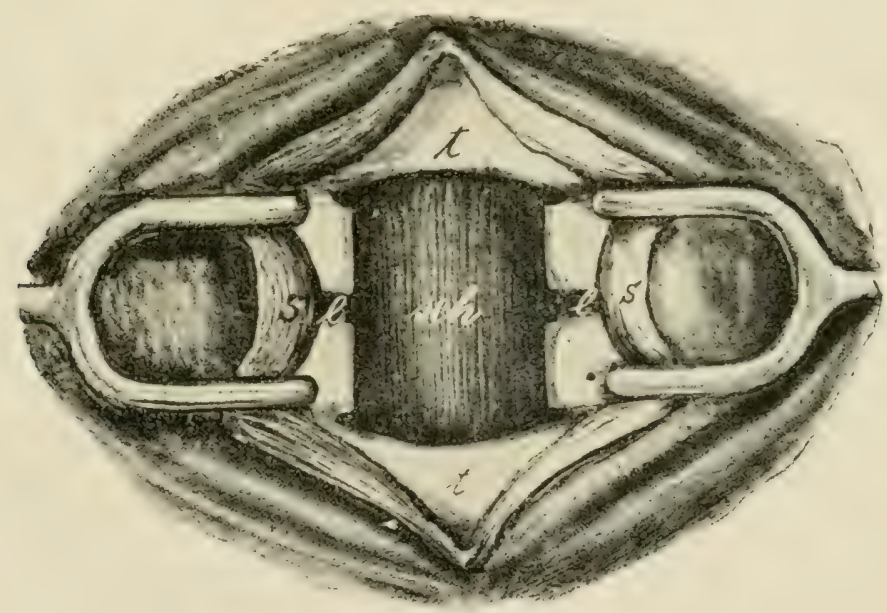

FIG. 2.

TRACHEOTOMY. $s$, sterno-thyro-hyoïdeus muscle; $t$, trachea; sch, mucous membrane of the posterior wall of the trachea; $l$, interannular ligament.

right shoulder of the horse and the assistant opposite him. On the shaved area the operator and his assistant takes up a transverse fold of skin 3 to $4 \mathrm{~cm}$. high, and divides the same by an incision. The 6 to $8 \mathrm{~cm}$. long wound in the skin then 
lies in the median line of the anterior face of the neck. Or the incision may be made by rendering the skin tense along the median line of the trachea with the left hand, then making a drawing cut from above to below with the scalpel. After the skin muscle is cut through, in order to avoid hemorrhage, separate the two sterno-thyro-hyoidens muscles by means of tenacula along the median line in the white strip of connective tissue. The opening into the trachea may be made in a variety of ways. The quickest and most crude method is to slit the trachea which has been laid bare from above downwards; through three or four tracheal rings, and pressing the severed ends apart insert the tube through the opening. Since the tracheal rings are incomplete, being open on their dorsal surfaces, cutting through the ventral portion divides each ring into two separate parts and their being pushed apart, distorts them and tends to the causation of chondritis and collapse of the trachea, a danger which increases with the duration of time that the tube is maintained in position. It is therefore most suitable for hurried operation in impending suffocation where the tube will probably be needed for a short time only.

A second method of operation, illustrated in Fig. 2, consists in making a transverse incision through the inter-annular ligament between the two last exposed tracheal rings the length of the diameter of the tube to be inserted. Make a perpendicular incision upward from each end of this at a point I to $\mathrm{I} .5 \mathrm{~cm}$. from the median line through one or two tracheal rings, according to the size of the tube. With forceps or tenaculum grasp the segments of partially detached cartilage and remove them by cutting through the inter-annular ligament.

A third and to us preferable method is to insert a scalpel transversely at about the lower third of the lowermost bared tracheal ring and cutting outwards and upwards in a curved line, pass through the first inter-annular ligament and continue the incision into the succeeding tracheal ring, curving 
the incision upward and inward until the ring is cut about 23 in two, when the incision is turned downward to eventually reach the starting point, the isolated section of the trachea being securely grasped by a pair of forceps before its excision is completed. By this method no tracheal ring is severed.

The trachea tube is to be removed and cleansed daily as long as its use is necessary, and when finally remored the wound should be left open and dressed antiseptically.

\section{I3. ARYTENECTOMY.}

PLATE XI.

Object. The relief of roaring or laryngismus paralyticus. Instruments. Razor, scissors, scalpel, razor shaped knife with long handle, long curved sharp pointed scissors, long curved uterine dressing forceps, double tenaculum forceps, trachea tube, retractors, reflecting lamp, absorbent cotton and dressing material.

Technic. Secure the animal in lateral recumbency preferably upon the operating table and induce complete anaesthesia. Shave and disinfect the skin over the laryngeal region and also over the trachea at the usual point for tracheotomy. Place the animal upon its back with the head extended and remove the halter or other head gear. Perform tracheotomy in the manner described abore, insert the trachea tube and if necessary continue the administration of chloroform through this by means of a funnel the small end of which is inserted in the trachea tube while the chloroform is dropped on a towel spread over the larger end. The operator takes his place on the right side of the animal and the assistant on the lett. Make a longitudinal incision through the skin and subcutem beginning at the anterior part of the thyroid cartilage and extending backward on the median line to the 3 rd or $4^{\text {th }}$ tracheal ring. Control the cutaneous hemorrhage. Continue the incision through the 
PLATE XI.

ARYTENECTOMY.

$\mathrm{E}$, epiglottis; TT, thyroid cartilage; $\mathrm{CC}$, cricoid cartilage; TRI, first tracheal ring; V, left vocal cord; A, left arytenoid cartilage surrounded by dotted line of incision; CTL, cricothy-roïdean ligament. 


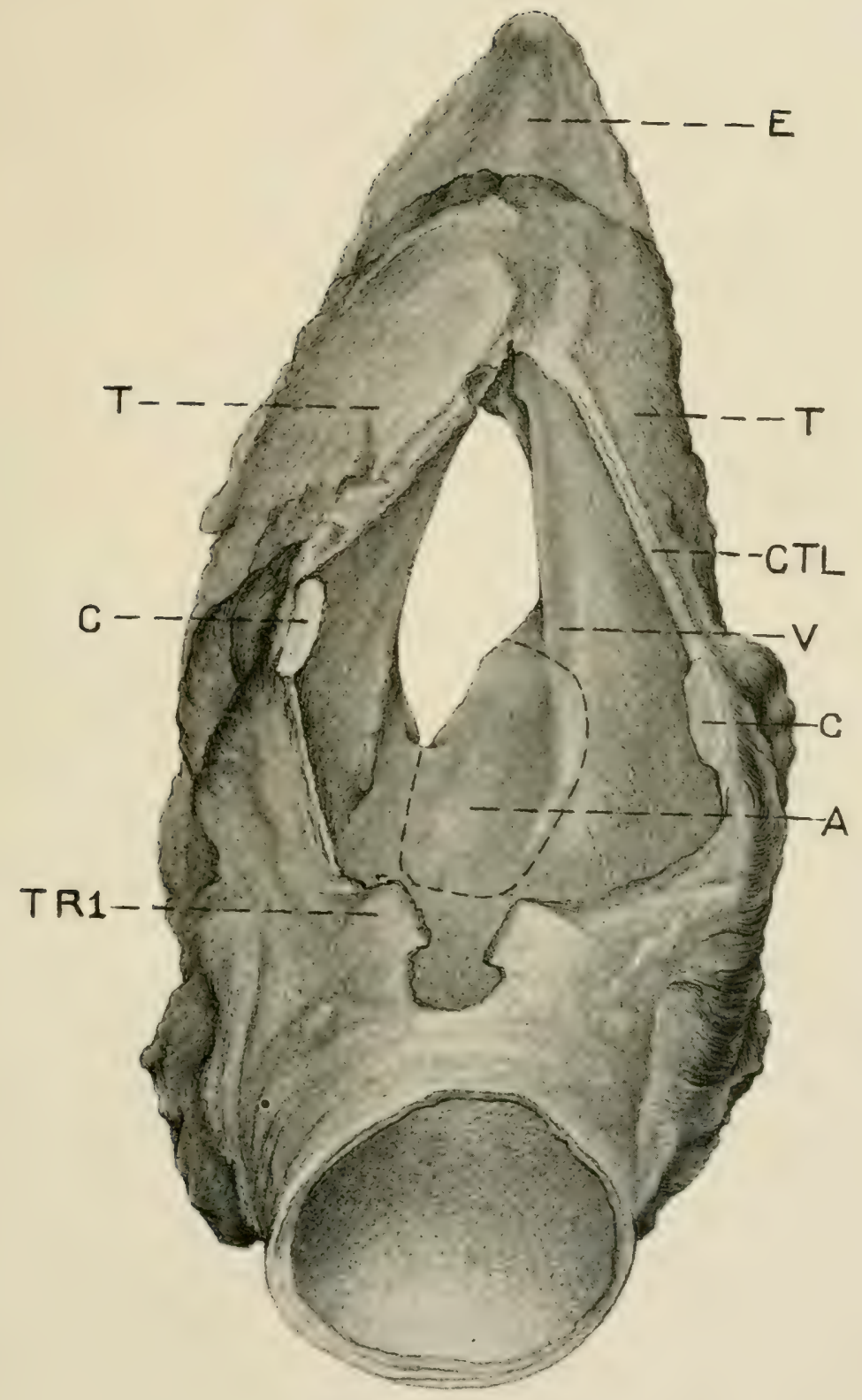



subjacent muscular tissue being careful to follow the median line exactly until the crico-thyroidean ligament, CTL, Plate XI, the cricoid cartilage $\mathrm{C}$, and the first tracheal ring TRI, are laid bare. Again control any hemorrhage. Plunge the scalpel with its cutting edge directed backward through the crico-thyroidean ligament on a level with the dotted line $T$ and extend this backward along the median line serering the cricoid cartilage, $C$, and the first tracheal ring. 'TRI. Insert the retractors and have the larynx held well open by assistants. Illuminate the larynx by means of a reflecting lamp as may be required. After controlling any hemorrhage caused by tine foreguing make an incision through the mucosa and the intervening connective tissue between the two arytenoid curtilages, A, beginning at the anterior part and extending backward to the cricoid, thence turning upward and lateraily, incise the mucosa across the posterior end of the arytenoid thence forward along its lateral border through the rocal cord, $r$, and turning downward as the animal lies, that is toward the dorsal part of the larynx, continue the incision to the point of beginning. In making this incision cut as closely as possible to the margin of the cartilage so that a minimum amount of the mucous membrane will be removed. Grasp the lateral border of the cartilage with the long tenaculum forceps and with the razor-shaped knife or the scissors separate the lateral and anterior portions of it from the adjacent tissues keeping always immediately against it in order to produce as clean a wound as possible and to avoid injuring adjacent vessels from which hemorrhage would occur.

When the cartilage has been detached over the greater part of its surface locate the crico-arytenoid articulation and disarticulate or cut through the arytenoid as close to the articulation as possible with the razor-shaped knife or the scissors. Remore all blood by means of pledgets of absorbent cotton securely held in the long dressing forceps, or the clots may 
be pushed into the pharynx when they will generally be swallowed. Carefully remove any cartilaginous remnants or tissue shreds and control the hemorrhage from any risible ressels. Dust the wounds thoroughly with iodoform and tamin and if the capillary hemorrhage is great pack the larynx with a single strip of iodoform ganze and secure it by sutures through the margin of the skin wound. Remove this tampon after twelve to twenty-four hours. Wash and disinfect the laryngeal wounds daily. Remove and cleanse the trachea tube and wash the tracheal wound daily and keep the trachea tube in position for five to seven days according to conditions. After about eight days the retractors should be placed in the laryngeal wound, the wound dilated and the interior of the larynx examined with the aid of a reflecting lamp and any unhealthy granulations or other untoward conditions given proper attention.

\section{I4. INTRA-TRACHEAL IRRIGATION.}

Objects. The washing of irritant or septic substances from, and the disinfection of, the trachea and bronchi.

Instruments. Same as for tracheotomy, and a gravity irrigating apparatus fitted with $3 \mathrm{~m}$. of rubber tubing about I cm. in diameter, 5 liters of .6 per cent. soda bicarbonate or chloride solution at a temperature of 37 to $39^{\circ} \mathrm{C}$.

Technic. Operate on the standing animal. Perform tracheotomy. Eilevate the gravity apparatus containing the irrigating fluid I to $2 \mathrm{~m}$, above the patient, have the animal's head slightly elevated, insert the free end of the rubber tubing in the trachea tube and let the fluid flow into the trachea in a moderate stream until it is filled and the animal makes expulsive efforts. when the inflow is stopped and the animal permitted to lower his head and expel the fluid, then raise the head again and repeat until the fluid is expelled clear. Repeat the operation according to requirement. In cases of suppurative bronchitis, peroxide of hydrogen may be added to the solution. 
I5. INTRAVENOUS INJECTION.

Fig. 3 .

Instruments. Scissors, hypodermic syringe.

Technic. The operation is performed on the standing animal on either jugular vein at about the juncture of the upper and middle thirds of the neck; to most operators the right jugular is the more convenient. At the place designated the subscapulo-hyoideus muscle lies between the jugular rein and the carotid artery. After clipping the hair, the skin should be carefully disinfected. The rein lies in

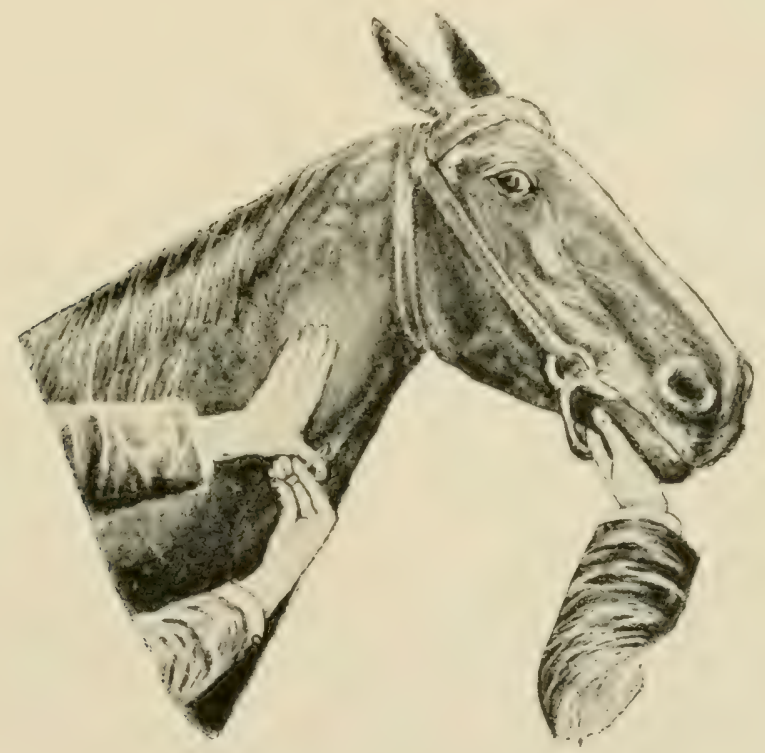

Fig. 3. Intravenous Injection.

the jugular groove between the mastoido-humeralis and the sterno-maxillaris muscles covered only by the skin and skin muscle. Stand by the shoulder of the horse and compress the jugular with the thumb as shown in Figure 3 or with the second to the fourth fingers, in which case the ball of the thumb rests on the mastoido-humeralis muscle, in a way that the vein becomes filled above the point of compression in the 
shorn area and stands out as a swollen cord. In the case of fleshy necked horses this compression is more readily attained if the head is somewhat elevated and extended by an assistant. If the vein can not be made prominent in this way the compression should be alternately applied and withdrawn suddenly, the course of the vein then reveals itself by a wave-like movement along the jugular groove. Just above the point of compression the rein is the most fully distended and firmly fixed. After testing the hypodermic needle to see that it is open hold it between the second and third fingers while the thumb covers its posterior opening and thrust it through the skin, cutaneous muscle and jugular wall, in the direction of the vein obliquely forwards and upwards 1 to $2 \mathrm{~cm}$. deep, so that the point of the needle enters the vessel at its most distended part. In this way it is easy to prevent injury to the median wall of the vein. If the vein has been properly punctured blood will flow from the needle upon the removal of the thumb. If the vein is not entered at the first attempt the needle should be partly withdrawn and then pushed in again in a slightly different direction. The compression is then remored and the hypodermic syringe in which no air is contained is connected and the contents slowly discharged into the vein. In withdrawing the needle be careful to press the skin firmly against the underlying part. The omission of this precaution frequently results in the formation of a subcutaneous hematome. 


\section{I6. PHLEBOTOMIY.}

FiG. 3.

Instruments. Razor or scissors, fleams, lancet, phlebotomy trocar, spring lancet, pins, suture material.

Technic. a. Phlebotomy with fleams may be performed on either jugular rein. The operation is preferably carried out on the standing animal, but is not difficult when the patient is recumbent. The point of operation is at about the boundary line between the unper and middle cervical regions. because it is here that the subscapulo-hyoideus muscle which separates the jugular vein from the carotid artery is most roluminous and consequently affords the greatest protection to the latter. At this point clip or shave and disinfect the skin. Grasp the extended blade of the fleam at the joint with the thumb and index finger of one hand, while the third and fourth fingers compress the jugular rein at a point far enough below the shared part that the fleam blade rests upon it. In fleshy-necked animals the course of the vein may be clearly made out by causing its repeated distension and relaxation. It is well to be careful that the point of the fleam blade is not allowed to prick the skin prematurely and render the animal restless, and that the fleam blade is held perpendicular to the surface and parallel to the long axis of the vein. The most elevated point of the vein should be struck by the blade in suclı a way that the skin, subcutaneous muscle and jugular wall are penetrated parallel to the long axis of the vessel. Drive the fleam blade into the vein by a short, sharp blow with a light wooden stick. The extension on the fleam blade prevents its being driven too deeply. The size of the blade to be used depends upon the thickness of the skin and other tisstues covering the rein. If the rein is opened, dark red blood escapes from the wound in a large stream. If the operation does not succeed at the 
first effort, one should select an undamaged portion of the skin for a second attempt so that the opening into the vein may be direct and clean. When the vein is opened lay the instrument aside, the compression of the vein being continned in order to prevent aspiration of air into it and also that the lips of the wound shall not become overlapped by which the escape of blood would be impeded or stopped. The flow of blood may be favored by inducing masticatory movements by the animal. The amount of blood withdrawn varie:s between 3 and 8 liters, according to the size of the animal and the object to be attained. The wound may be closed by an interrupted or a pinned suture. For the latter, relieve the compression on the rein and grasp the lips of the skin wound between the finger and thumb and stick the pin perpendicularly through the middle of it a few mm. from its borders. Apply a noose of silk ligature previously prepared over the pin and close and tie the loop. In applying the pin and loop, take care not to elevate the skin from the underlying part, which tends to the production of a hematome.

b. With the lancet the operation is preferably performed on the right side of the neck. Compress the vein as illustrated in Fig. 3, and hold the lancet between the thumb and index finger with the blade at right angles to the handle, the thumb and finger being so placed on the blade that it can barely penetrate the vein, and then push it in quickly just in front of the compressing thumb through the skin, subcutem and venous wall as deep as the fingers holding the lancet will permit.

Hold the blade perpendicular to the long axis of the vein, and avoid directing the point dorsalwards, which would endanger the superior wall of the vessel or cause the lancet to glide over the wall and not enter the vein. When the lancet has entered the vein extend the wound somewhat toward the head by flexing the hand dorsally. In cattle it is necessary to compress the vain by means of a cord tightly 
drawn around the neck, the operator taking the same position as in the horse while an assistant holds the animal by the horns or nose. Close the wound as in a.

Phlebotomy with the spring lancet is carried ont in a similar mannet, the jugular being compressed in the same way, and the lancet with the spring set placed over the vein in such a way that the opening wiil be made in the same direction and manner as with the fleams. The lancet blade is then released and penetrates the vein. The compression below is continued as in other cases.

c. Phlebotomy with the trocar is performed in the same manner as has been described for intrarenous injection. So long as the flow of blood continues the compression of the vein must not be intermitted. The phlebotomy trocar should be about $5 \mathrm{~mm}$. in diameter.

\section{I7. LIGATION OF THE CAROTID ARTERY.}

PLATE XII.

Objects. The control of hemorrhage from wounds or the prevention of hemorrhage during the remoral of tumors or other operations in the parotid region.

Instruments. Scissors, scalpel, tenacula, aneurism needle, mouse-toothed forceps, ligation forceps, suture material.

Technic. The operation is possible on the standing animal with the aid of cocaine or other local anaesthetic but it is preferable to confine the patient in lateral recumbency and anaesthetize.

The operation is made at the same point as for phlebotomy and the same cutaneous wound, $a$, Plate XII, may be used for this purpose. The incision should be at least io $\mathrm{cm}$. long extending through the skin, fleshy panniculus and 


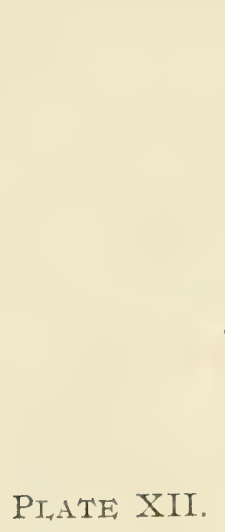

FIG. 1. - $a$, Ligation of the common carotid artery ; $b$, Esophagotomy.

FIG. 2.-Ligation of the common carotid artery. $c$, common carotid artery $; j$, jugular vein ; $v$, vagus nerve ; $s$, sympathetic nerve; $r$, recurrent nerve; $p$, cervical panniculous carnosus muscle: $m$, sternomaxillaris muscle; st, levator humeri muscle.

FIG. 3.-Cisophagotomy. c, com1mon carotid artery; $j$, jugular vein ; $o$, $o^{\prime}$, œesophagus; $s$, sympathetic nerve ; $t$, trachea; st, mastoïdo humeralis (lavator humeri) muscle.

Fig I. 

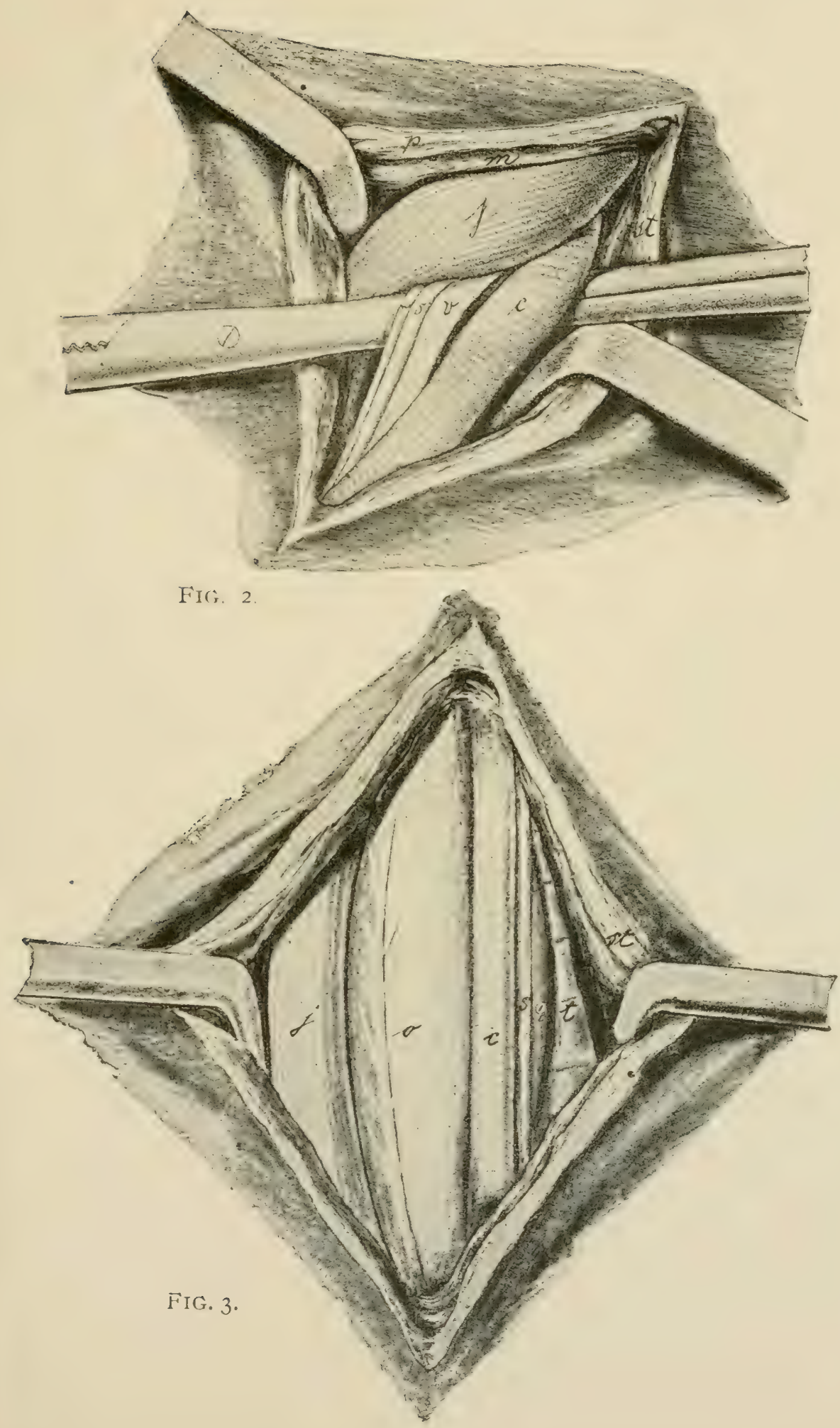

subscapulo-hyoideus muscles and then force a passage with the fingers, with the cautions aid of the knife, to the trachea. At the region of the neck indicated, the carotid passes along the border between the lateral and dorsal surfaces of the trachea, accompanied dorsally by the ragus and sympathetic nerves and ventrally by the recurrent. In Figure 2, Plate XII the vagus and sympathetic nerves, $v$ and $a$, are pushed out of their normal position and appear ventrally to the carotid. Pass the index finger over and behind the carotid until the trachea is reached, and encircling the inner and lower sides of the artery, force a way through the surrounding areolar tissue and draw the ressel out through the operation wound. As a rule the carutid is still surrounded by the lamellar fascia, which comes from the deep fascia of the neck in which also the three above mentioned nerves are fonnd. These nerves must be carefully separated from the carotid and must on 110 account be included in the ligature. Ligate the carotid twice with an interval of abont $2 \mathrm{~cm}$. between the two ligatures and divide the artery midway between the two. The second ligature is necessary in order to prevent hemorrhage from the distal end through collateral anastomoses and it is essential to sever the artery in order to aroid its rupture by the stretching of the undiricied carotid during morements of the neck where the nutrition has been cut off at the point of ligation. Proride drainage for the wound and suture the muscle and skin. 


\section{IS. GESOPHAGOTOMY.}

\section{PLATE XII.}

Instruments. Razor, scissors, convex scalpel, straight probe-pointed bistoury, tenacula, artery forceps, absorbent cotton, suture material.

Technic. The operation can be carried out on the standing or the recumbent animal. At its origin the osophagus lies above the trachea, generally somewhat to the left of the median line and gradually deviates farther to the left until toward the lower cervical region it lies down along the left side of the trachea.

The operation is performed at any point between the pharynx and chest where the lodgment of a foreign body or other condition may demand it. When the cesophagus is empty the operation is best performed in the lower third of the neck at $b$, Figure I, Plate XII.

An incision ro $\mathrm{cm}$. long through the skin and skin muscle is made on the left side between the anterior border of the mastoido-humeralis muscle and the jugular vein. With one finger each of the left and right hand divide the loose connective tissue down to the osophagus, which lies between the left scalenus muscle, trachea and the jugular vein. Along the supero-external border of the trachea rums the carotid, accompanied dorsally by the vagus and sympathetic and ventrally by the recurrent nerves. The osophagus feels like a round muscle within which one can feel a firmer cord, the mucous membrane, and has a pale red color. Esophagus and trachea are surrounded by the deep fascia of the neck. Pass one finger around the cesophagus from behind, draw it away from the trachea, force a passage through the deep fascia of the neck and draw the oesophagus out through the external wound. After making an incision through the muscle and mucous membrane introduce a probe pointed 
scalpel or a scissors blacie into the lumen of the cesophagus and split its wall. The mucous membrane is white and lies in thick longitudinal folds. When there is a foreign body in the cesophagus the operation is performed at the point where it is lodged in the manner described and the incision should be made only large enough to permit its removal. In diverticuli of the oesophagus an elliptical piece of the mucous membrane which has been overstretched is cut out. The œsophageal wound is closed by a laminated suture, that is, the mucous membrane is united by means of an intestinal suture and the muscular wall closed over this. The skin and muscular wound may either be left open or closed with the Bayer suture and bandaged with a drainage tube in the lower angle of the wound. 
III. OPERATIONS ON THE TRUNK AND GENITAL, ORGANS.

19. PUNCTURE OF THE CHEST.

FIG. 4.

Objects. The relief of hydrothorax or pyothorax.

Instruments, Razor, scissors, trocar, I $\mathrm{m}$. of rubber tubing of the same size as the trocar, vessel for receiving the escaping fluid, dressing material.

Technic. Operate upon the standing animal, the point of operation being the seventh intercostal space on the left side, and the sixth on the right. Dogs may be laid upon

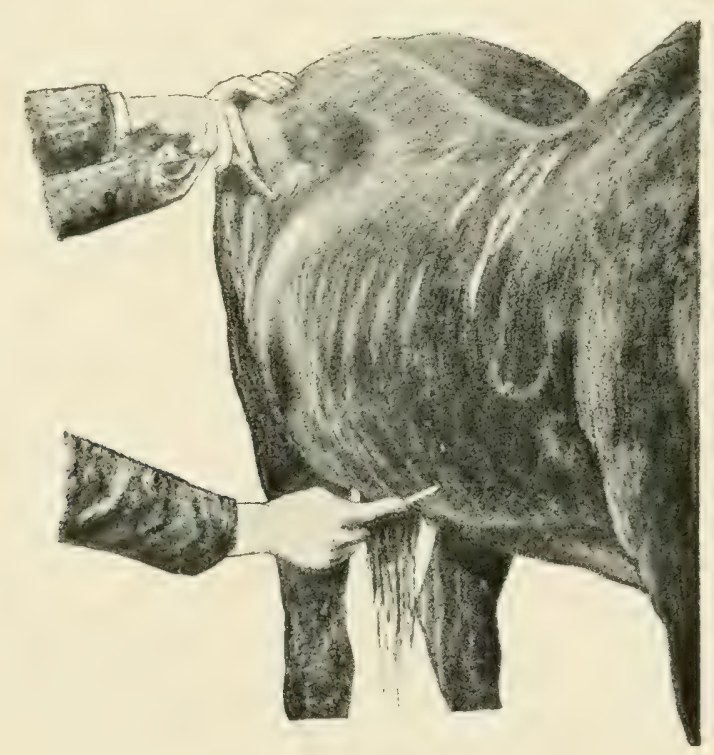

FIG. 4.

Puncture of the chest; puncture of the intestine.

the table. The ribs are enumerated from behind forward, counting eighteen for the lorse and fourteen for the dog. Clip or shave the designated intercostal area immediately above the thoracic vein. Grasp the trocar firmly with the 
thumb and index finger of one hand at a distance from the point which will permit the canula to enter the chest. After the skin over the seat of operation has been drawn aside by the hand place the trocar at the anterior border of the rib with the point inclined slightly forward and with a sharp blow with the palm of the other hand drive the instrument through the skin, skin muscle, intercostal muscles, internal thoracic fascia and pleura into the pleural sac. When the resistance ceases, the thoracic cavity has been entered. Remove the stilette and permit the pus, lymph, or other fluid to escape. This escape is at first continuous, but later becomes rythmic, synchronous with respiration. The intermission of the outflow during inspiration permits air to enter the pleural cavity muless precautions are taken against it; this is most readily obriated by slipping one end of the rubber tubing orer the exposed end of the cantula and placing the other extremity in the receptacle for the fluid where it will be submerged. This will not only prevent aspiration of air into the chest but will act as a syphon to aid in the aspiration of the fluid from the pleural carity. In the absence of the tubing the entrance of air may be aroided by closing the canula with the finger after each expiration.

FIGS. 4, 5 .

Object. The relief of intestinal tympany.

Instruments. Razor, scissors, trocar, disinfectants.

Technic. Puncture of the intestine is preferably performed on the standing horse but may be carried out on the recumbent animal. The point of operation is in the right flank about equi-distant from the last rib, the extremities of the transverse processes of the lumbar vertebrae and the external angle of the ilinm in the standing horse, at the uppermost point of the abdomen in the recumbent animal, that is, 
at the most prominent part of the distension. After the skin at this place has been clipped or shaved and disinfected grasp the trocar with the index finger and the thumb of the left hand and holding the instrument perpendicular to the skin, give it a firm quick blow with the palm of the right hand and drive it through the abdominal walls into the intestine. With a properly constructed trocar of the dimensions suggested in Figure 5 no preliminary puncture with the lancet is required or advisable. The cutting end of the stilette should be very long, tapering and sharp so that it will cut as freely as the lancet. By performing the operation as directed the trocar ordinarily punctures the caecum.

FIG. 5 .

Intestine trocar with sheath. Outside diameter of canula $3 \mathrm{~mm}$., length of canula, $16 \mathrm{~cm}$.

Withdraw the stilette and permit the gas to escape through the canula. The canula may become occluded by particles of ingesta entering it and these should be remored by reinserting the stilette. The intestine first punctured may collapse and the flow of gas cease while the tympany continues in other parts; this may be orercome by reintroducing the stilette and pushing the trocar through the distal wall of the bowel and into the next section of intestine beyond. If this does not succeed the trocar may be withdrawn and reinserted in a neighboring area or if need be on the opposite side of the animal. In withdrawing the canula replace the stilette and press the skin against the abdominal with the thumb and finger of one hand while the trocar is drawn out with the other. This tends to prevent particles of ingesta 
from following the cantla out of the intestine and becoming lodged at some point in the track of the wound to set up inflammatory processes there. Before introduction, the trocar should always be rendered sterile but should not bear irritant antiseptics, which becoming lodged in the wound tend to irritate the tissues and produce abcesses. Puncture of the intestine is so often extremely urgent that deliberate aseptic precantions are not always practicable and trocarization only too frequently results in abscesses in the abdominal wall. Its prevention must depend chiefly upon the disinfection of the skin and instrument. It becomes important to use an instrument which is clean in advance. If the one shown in fig. 5 is well disinfected after using and the sheath is filled with alcohol before it is screrred on, the instrumient will remain sterile until it is again musheathed and then the alcohol will quickly evaporate and leave it aseptic.

\section{I. SUBCUTANEOUS CAUDAL MYOTOMY.}

FIG. 6.

Object. The correction of curved tail.

Instruments. Sharp straight tenotome, bandage.

Technic. The point or points of curvature and their extent are to be carefully noted by haring the animal trotted away from the operator. The curvature is generally due to nnequal derelopment of the two levator or extensor muscles Fig. $6 e$, though quite rarely the depressors, $f$, may be implicated. Confine the animal in stocks, or in default of these, control by means of a twitch and sideline. Cleanse and disinfect the tail and have it sharply bent by an assistant in the opposite direction to the curvature. Locate the longitudinal furrow between the levator and depressor muscles on the convex side and at the lower margin of the levator and just above $\approx$, Fig. 6, insert the tenotome at the 
most prominent part of curvation, the incision being parallel with the muscular fibers, and push the instrument entirely through the muscle to the rertebra, then turning the cutting edge upwards, at the same time advancing the point of the tenotome toward the median line, sever the entire muscle. The superior lateral caudal artery, $s$, Fig. 6, bleeds profusely if severed, and wounding of it may usually be avoided by withdrawing the tenotome a trifle in passing that point. IVounding the skin over the muscular incision is avoided by

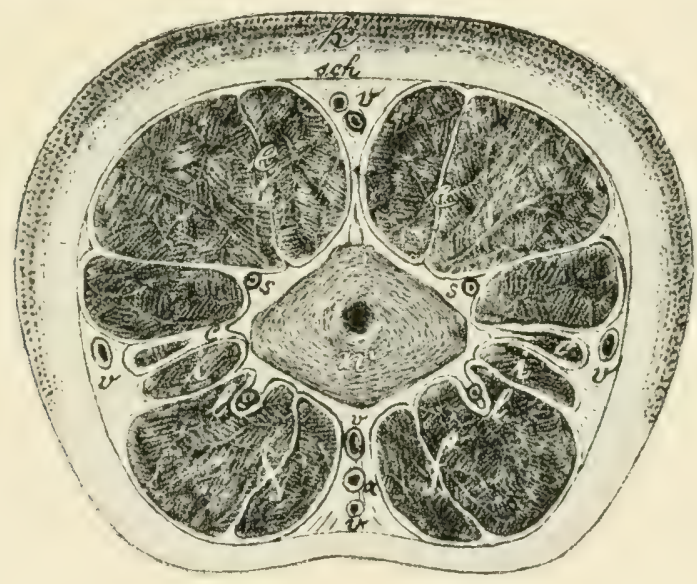

FIG. 6.

Transverse section of the tail. $n$, caudal vertebra ; $c$, sacrococcygeus lateralis muscle; $e$, sacro-coccygeus superior; $f$, depressor longus and brevis muscles (sacro-coccygeus inferior) ; $i$, intertransversales muscles ; $a$, coccygeal artery ; $s$, supero-lateral coccygeal artery ; $l$, infero-1ateral coccygeal artery ; $v$, caudal veins (dorsal, ventral, lateral); sch, caudal fascia; $h$, skin.

placing the thumb of the left hand over the line of incision so the knife will be recognized as soon as the muscle and caudal fascia are cut through. Remove the knife in the sane manner as introduced. Release the horse and have him trotted again. If the operation is sufficient the tail should curve in about the same degree as before, but in the opposite direc- 
tion. If this has not been attained examine carefully and sever any remaining bundles of muscle, and this not sufficing repeat the operation as before at another point 5 or $6 \mathrm{~cm}$. above or below the first, severing the muscle again. Or if the depressor appears implicated, serer it in a similar manner. In extreme cases the entire lateral half of muscles, tendons and aponeurosis may be serered. Apply an antiseptic pad to the wound and retain it by a moderately firm bandage, which serves at once as an occlusire dressing and effective hemostatic. Remove the bandage after 24 hours.

\section{CAUDAL MIYECTOMY.}

FIG. 6 and PLATE XIII.

Objects. For the prevention of the gripping of the reins by the tail.

Instruments. Flastic bandage, elastic ligature, straight bistony, tenacula, absorbent cotton, bandages, disinfecting material.

Technic. Confine the animal in lateral decubitis or in stocks, cleanse and disinfect the tail, ap1)ly the elastic bandage tightly to it beginning at the apex and continuing to its base and then apply the elastic ligature as close as possible to the root of the tail. Have an assistant hold the tail upwards, i.e., dorsalwards, and tightly stretched. Make an incision I 5 to $20 \mathrm{~cm}$. long, over the middle of the inferior surface of each depressor longus muscle, beginning close against the elastic ligature and extending toward the apex, severing at once the skin and caudal fascia down to the muscle. Let an assistant retract the lips of the incision with tenacula while the operator dissects the depressor longus muscle, DC, Plate XIII, from the adjacent tissues at either side, sever it by a transverse incision close against the liga- 
PLATE XIII.

Caudal Myectomy To Prevent Gripping of THE REINS.

DC, Depressor coccygeus longus muscle; ' $T$, tourniquet. 


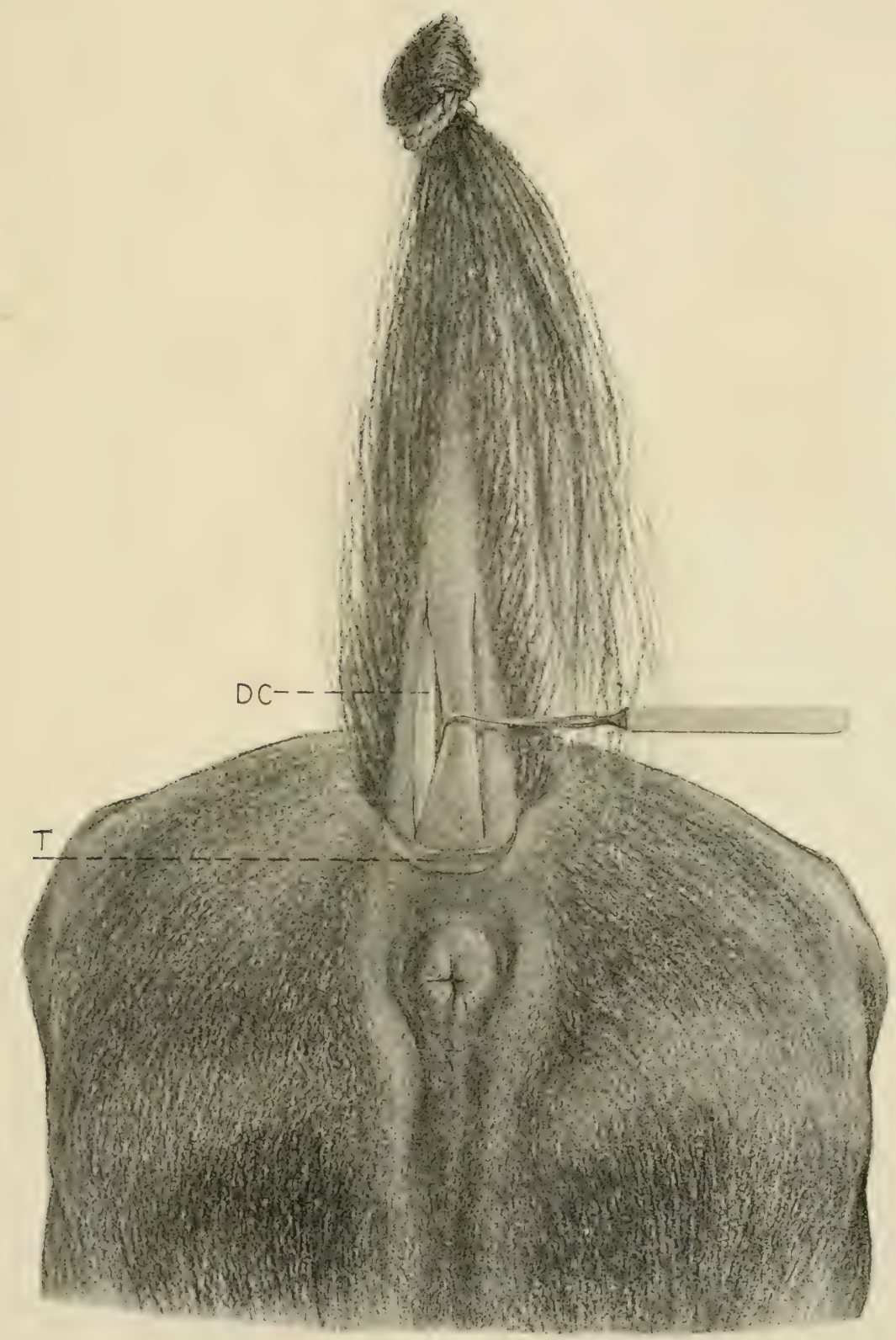



ture and dissect away the entire muscle down to the lower end of the wound and there excise it. 'The small depressor brevis, lying on the median side of the longus need not be removed, thus preserving a limited depressor power. Repeat the operation on the opposite depressor. Make two elongated tampons of absorbent cotton, of the size and form of the muscles remored, saturate these in r-1000 sublimate solution, insert neatly in the wounds and apply a moderately firm bandage as closely as possible to the elastic ligature. Remore the ligature, upon which hemorrhage ensues, which is to be controlled by the application of a second bandage extending higher up on the tail orer the previons location of the elastic ligature. Remore the bandage in 24 hours, wash the parts and saturate the tampons again with I-IOoO sublimate solution and apply a fresh bandage, allow it to remain for another 24 hours, remore the bandage and tampons and treat as an open wound. Care should be taken to not apply the bandage too tightly or leave it in place for more than 24 hours, since otherwise necrosis of the tail is liable to occur and necessitate amputation. 


\section{AMPUTATION OF THE TAIL.}

\section{FIG. 6 AND 7 .}

Objects. Malignant or incurable diseases of the tail.

Instruments. Docking shears, ring cantery iron, docking chisel, mallet, a block of wood, suture material.

Technic. I. Docking with the shears. Operate on the standing animal secured in the stocks or with the aid of the twitch and one fore foot held up or the side line applied to

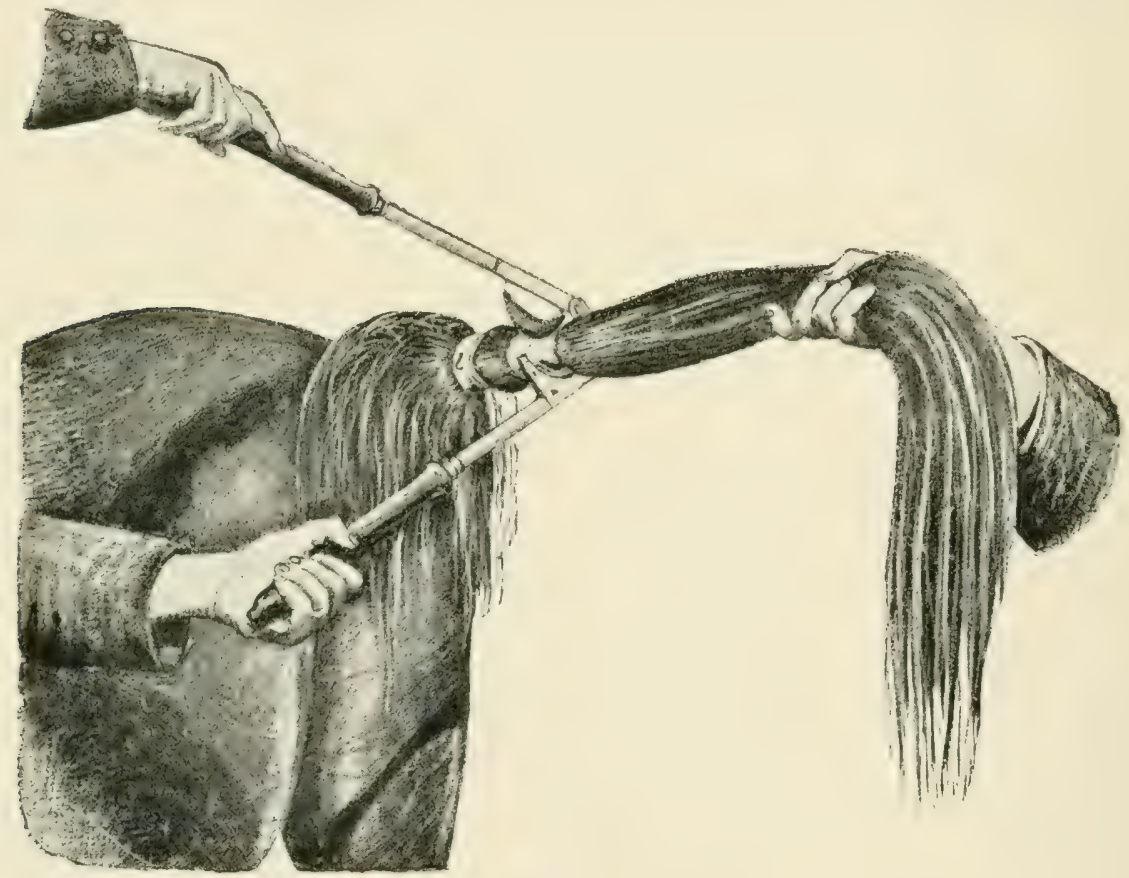

FIG. 7 .

Amputation of the tail. $l$, ligature for binding the hair of the tail upwards.

a hind foot. The point of amputation is determined by the location of the disease. At this point the hair is parted around the organ, turned upwards and bandaged to the root of the tail with a compression bandage which at the same time serves to retain the hair out of the operator's way and to make the operation bloodless. Beneath the part clip the 
hair away for a space of 3 to $4 \mathrm{~cm}$. around the tail, have an assistant hold it horizontally, stand at the side, behind the left leg and apply the docking shears in such a way that the clipped portion of the dock rests in the semi-circular depression in the shears. By quick and powerful closing of the handles of the docking shears cut, if possible, between two caudal vertebrae at one stroke through the entire organ. Grasp the stump of the tail with the left hand and press the red-hot ring iron against the parts between the skin and vertebrae for from ten to twenty seconds in order to stop the hemorrhage so that a dry and firm necrotic scab covers the wound surface. In cattle and logs the tail is amputated in a similar manner between two rertebrae; a straight knife will answer for operating instrument. Hemorrhage is likewise most promptly controlled by cantery. Ligating the arteries and applying a bandage is more æsthetic.

II. Amputation with the chisel. Prepare for the operation in the same manner as in I. Have an assistant hold a block of rood against the rentral surface of the tail at the point for amputation. Place the chisel on the dorsal surface of the tail at the point desired, with its conrex side directed towards the base of the organ, and with a vigorous blow with the mallet drive the chisel through it against the wooden block held below. In cases of extensive melanosis the chisel may be far too narrow to cut off the entre organ at one blow in which case the instrument is still to be placed centrally and driven through the candal vertebrae and the latera! parts may then be severed with a scalpel. There is now left a triangular wound, the rertebra constituting the apex. Ligate any risible vessels and draw the lateral flaps together on the median line by means of strong silk sutures passed through the two flaps at their thickest parts and unite the edges of the wound by frequent interrupted sutures. Apply antiseptics and remove the bandage. This operation is preferable in point of blemish and sensibility of the stump to $\mathrm{I}$. 


\section{URETHROTOMY. LITHOTOMY.}

FIG. S, 9.

Objects. For the removal of calculi from the bladder or urethra or performing other operations on these parts.

Instruments. Catheter, convex scalpel, scissors, artery and compression forceps, tenacula, lithotone, lithotomy forceps, lithotrite, absorbent cotton, drainage tube, suture material.

Technic. Urethrotomy may be performed on horses in a standing position, the hind feet being secured with hobbles.

It is best, however, to operate under anaesthesia with the patient in lateral or dorsal recumbency, either on the operating table or cast, being careful to secure as gently as possible, having first emptied the bladder if practicable, since rupture of an orerdistended viscus may readily occur during violent struggles by the animal.

The point of operation will depend upon the location of the calculus or other obstacle. If it is found in the pelvic portion of the wethra or in the bladder, the operation is made at the ischial notch, Fig. 8. First the penis is drawn out from the prepuce and the catheter introduced into the urethra and pushed upward until it has passed the ischial notch. After disinfection of the skin, render it tense and make a $5 \mathrm{~cm}$. long incision on the median line at the ischial arch through the skin, bulbo-cavernosus muscle, spongy portion of the urethra, and the urethral mucous membrane down to the catheter, Fig. 9, k. In order to prevent infiltration of urine after the operation, special care is to be taken to make the lower end of the wound slanting in such a manner that the inner margin is higher than the outer.

After the catheter has been drawn back away from the ischial arch, introduce the lithotomy forceps into the urethra or bladder, grasp the stone and draw it ontward in its natural direction. The grasping of the stone by the forceps is materially aided by means of the left hand introduced into 
the rectum. One must aroid grasping, along with the stone, the mucous membrane of the bladder. Partial filling of the bladder with a tepid aseptic solution will aid in grasping the calculus and in aroiding the implication of the bladder walls. By careful rotary movement and pushing the forceps backward and forward the operator can determine before the extraction of the stone if the forceps can be withdrawn easily and without much resistance through the neck of the

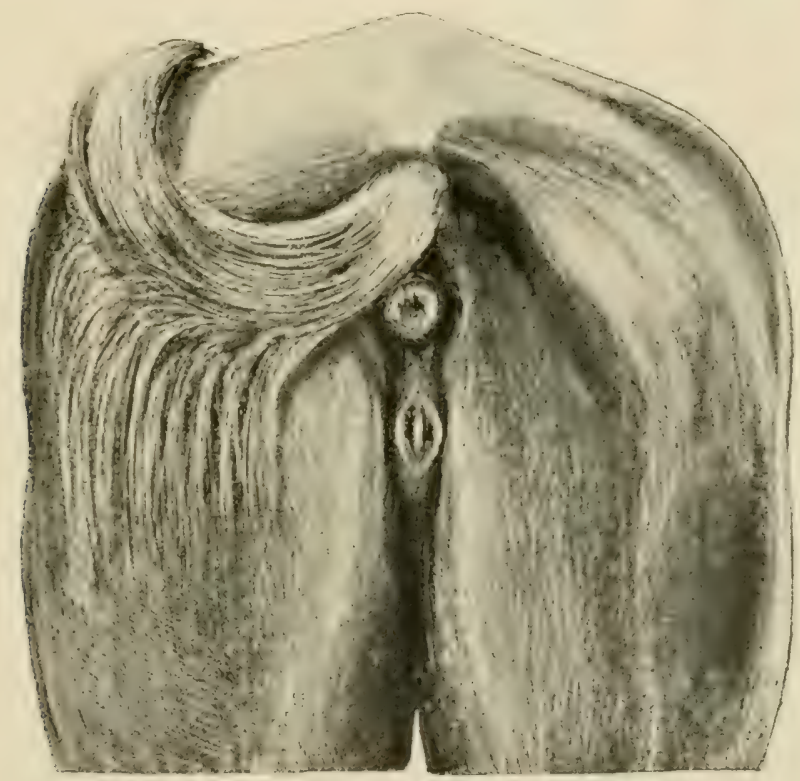

FiG. S. Urethrotomy at the ischial notch.

bladder. If the stone is so large that it can not pass the neck of the bladder lithotripsy must be performed. This operation requires time and patience, since as a rule it is not possible to encompass the entire calculus with the forceps. That is, the narrowness of tine neck of the bladder prevents the sufficiently wide opening of the forceps. The stone consequently must be gradually broken off at its periphery and the individual pieces of calculus remored. The character of the surface of the stone has an erident bearing upon the practicability of lithotripsy.

When this operation is impossible, the operative dilation 
of the neck of the bladder with the lithotome can be undertaken as a last resort. Introduce the instrument closed into the bladder, it is then opened and the neck of the bladder divided upward and laterally as the instrument is withdrawn. In order to prevent injury to the rectum it should be emptied before the operation is undertaken. After the removal of the stone, push the catheter again over the ischial arch and unite the lips of the wound in the urethral mucous mem-

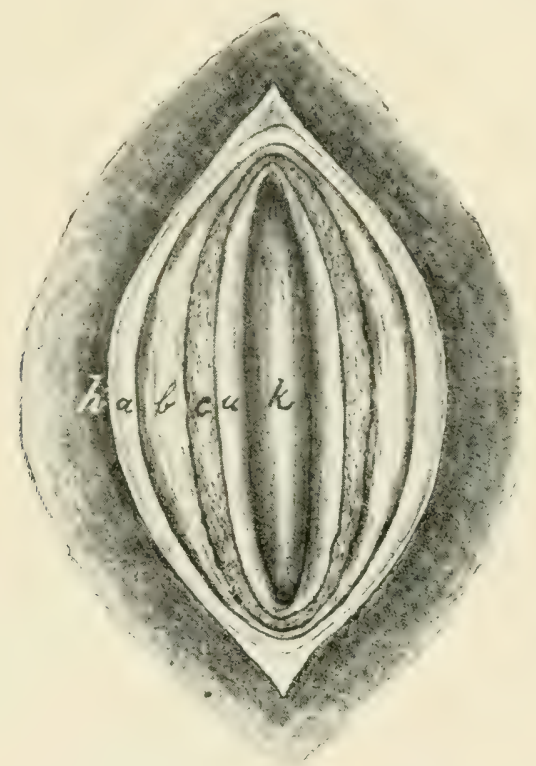

FIG. 9. Urethrotomy (life size). $h$, skin ; $a$, retractor penis muscle ; $b$, bulbo-cavernous muscle; $c$, spongy urethra; $u$, urethra; $k$, catheter.

brane by means of intestinal sutures. Flush the bladder or urethra by means of a warm 3 per cent. boric acid solution injected throngh the catheter and then withdraw the latter. Finally, suture the skin wound and insert a drainage tube or iodoform gauze in the lower angle of the wound. The whole wound may be left entirely open and be dressed daily with antiseptics. For student practice, on an anaesthetized horse, introduce a stone into the bladder through the urethral wound and practice grasping and removing it with the lithotomy forceps. 


\section{AMPUTATION OF THE PENIS.}

\section{PLATE XIV.}

Instruments. Scalpel, elastic ligature, strong silk thread, strong piece of tape I $\mathrm{m}$. long, artery and compression forceps.

Technic. The operation is carried ont on the recumbent animal under complete anaesthesia, the upper hind foot being drawn forward or otherwise so fixed as to not obstruct the field of operation. The point of operation is determined by the character of the disease and the object to be attained. It may be made at any point from the glans penis to the attacinment of the corpus carernosum to the ischium. If possible amputate in front of the preputial ring. After the penis is drawn ont, and the preputial region is carefully cleansed with brush and soap, an assistant grasps it just behind the preputial ring with the hand and holds it firmly. A temporary elastic ligature, $p$, is then applied in front of the liand around the penis, or the piece of tape is looped around it above the hand and it is made to serve both as a tourniquet and as a means for holding the penis, and it is then excised by a circular incision about $5 \mathrm{~cm}$. in front of the elastic ligature, or immediately in front of the preputial ring. The dorsal blood ressels of the penis are ligated separately. 'The urethra, $u$, lying on the ventral side of the penis, covered by the corpus cavernosum of the urethra, is dissected out of the urethral groore for a distance of about $2 \mathrm{~cm}$. its dorsal wall slit and the mucous membrane sutured, spread out fan-like to the surrounding tissues. The urethra can also be slit dorsally and rentrally and the halves sutured to the left and the right. A silk ligature, $l l$, is applied to the corpus carernosum, $c$, just above the point of excision of the penis and the elastic ligature then remored. After a few days the silk ligature is also removed. 


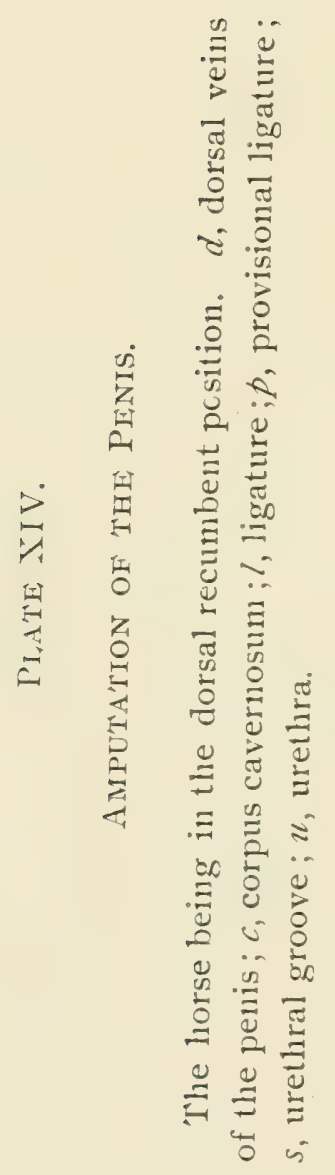




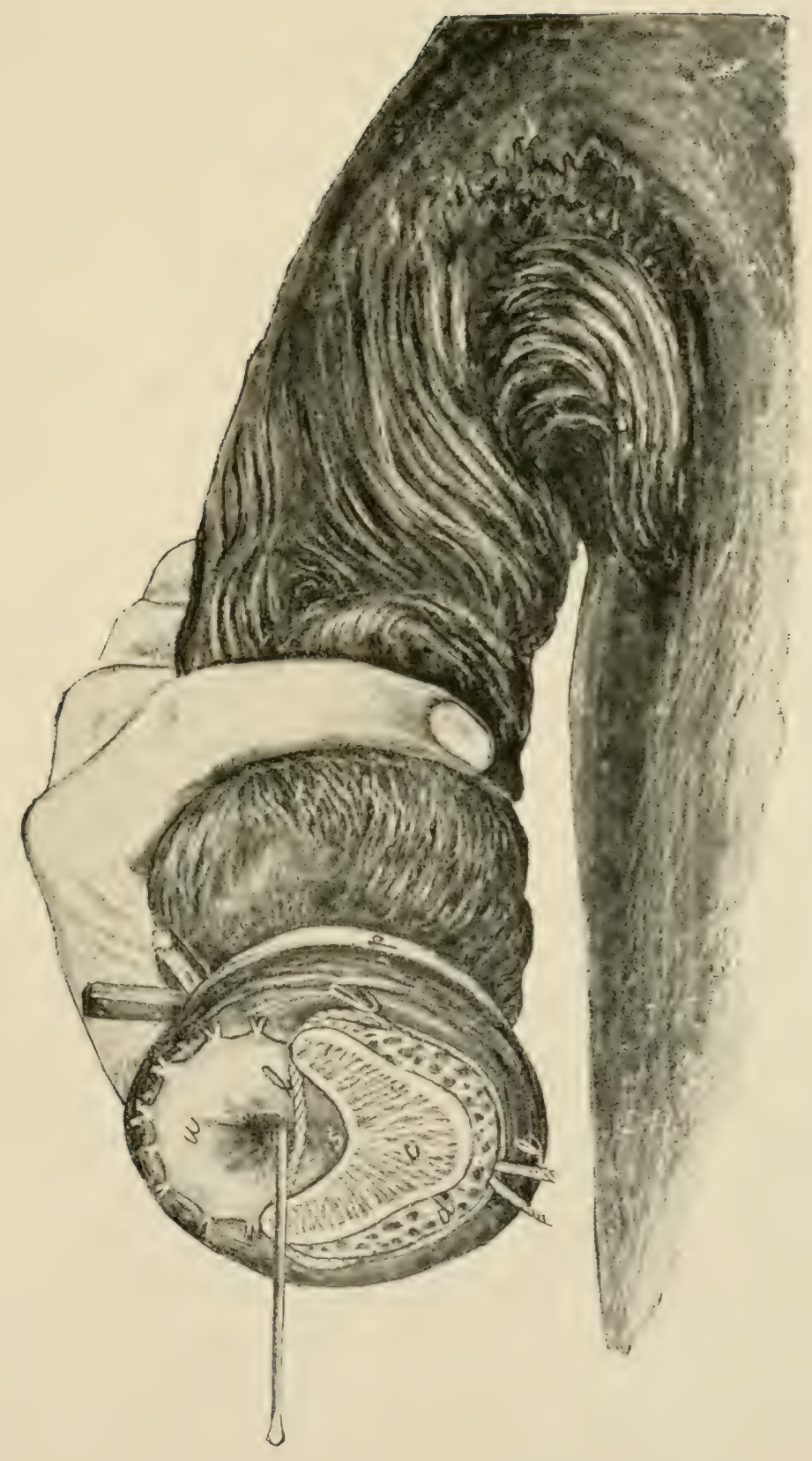


- 
26. VAGINAL OVARIOTOMY IN THE MARE.

Figs. IO, II AND PLATE XV.

Objects. The alleviation of vice when related to ovarian irritation or disease.

Instruments. Colin's scalpel, ratchet ecraseur, $55 \mathrm{~cm}$. long.

Technic. The vulvo-vaginal canal of the mare is unique in its physiological behavior. Under venereal excitement or the introduction of the operator's hand or of tepid water the organ has the power of " ballooning "' or dilating to a degree not seen so far as we know in other animals; the walls become erected, hard, and stand apart from each other, filling the pelvic cavity, the vaginal walls resting firmly against the
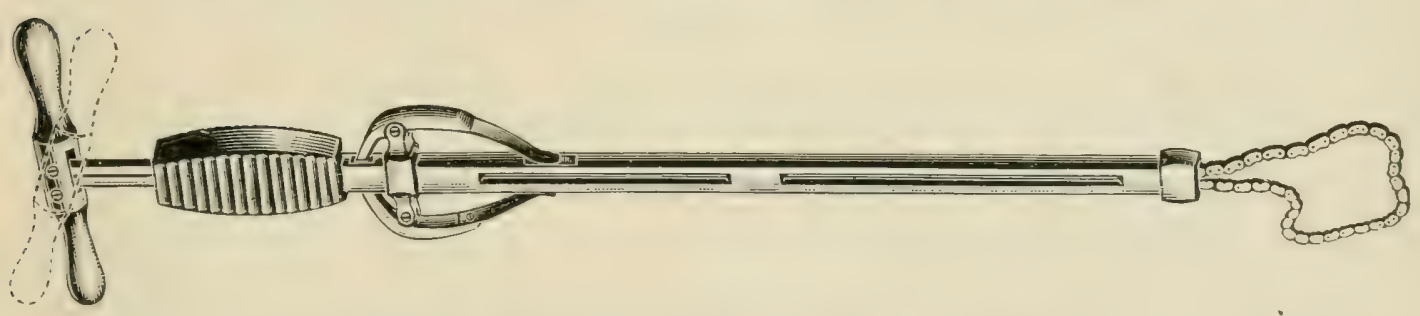

FIG. IO. Special spraying ecraser, $55 \mathrm{~cm}$. long.

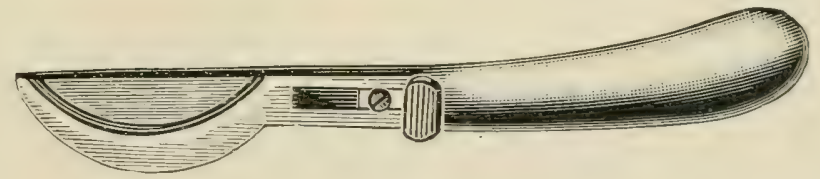

FIG. II. Colin's scalpel.

pelvic bones at every part except at the points where the bladder and rectum intervene and these organs are pressed out flat and occupy a minimum space. In the quiescent state the vaginal walls are in contact and from the perinaem forward to within about Io cm. of the uterine os, the vulva and vagina are connected above with the rectum by the pelvic connective tissue, while anterior to this point the vagina is covered by peritonemm, and it is in this area that the incision needs 
PLATE XV.

VAGINAL OVARIOTOMY IN THE MARE.

Diagrammatic sagittal section through the "ballooned" vagina. $\mathrm{V}$, vagina: $\mathrm{OA}$, operative area ; I, point of incision ; U, uterus ; R, rectum ; $A$, aorta with dotted lines posteriorly to indicate location of the iliacs. 


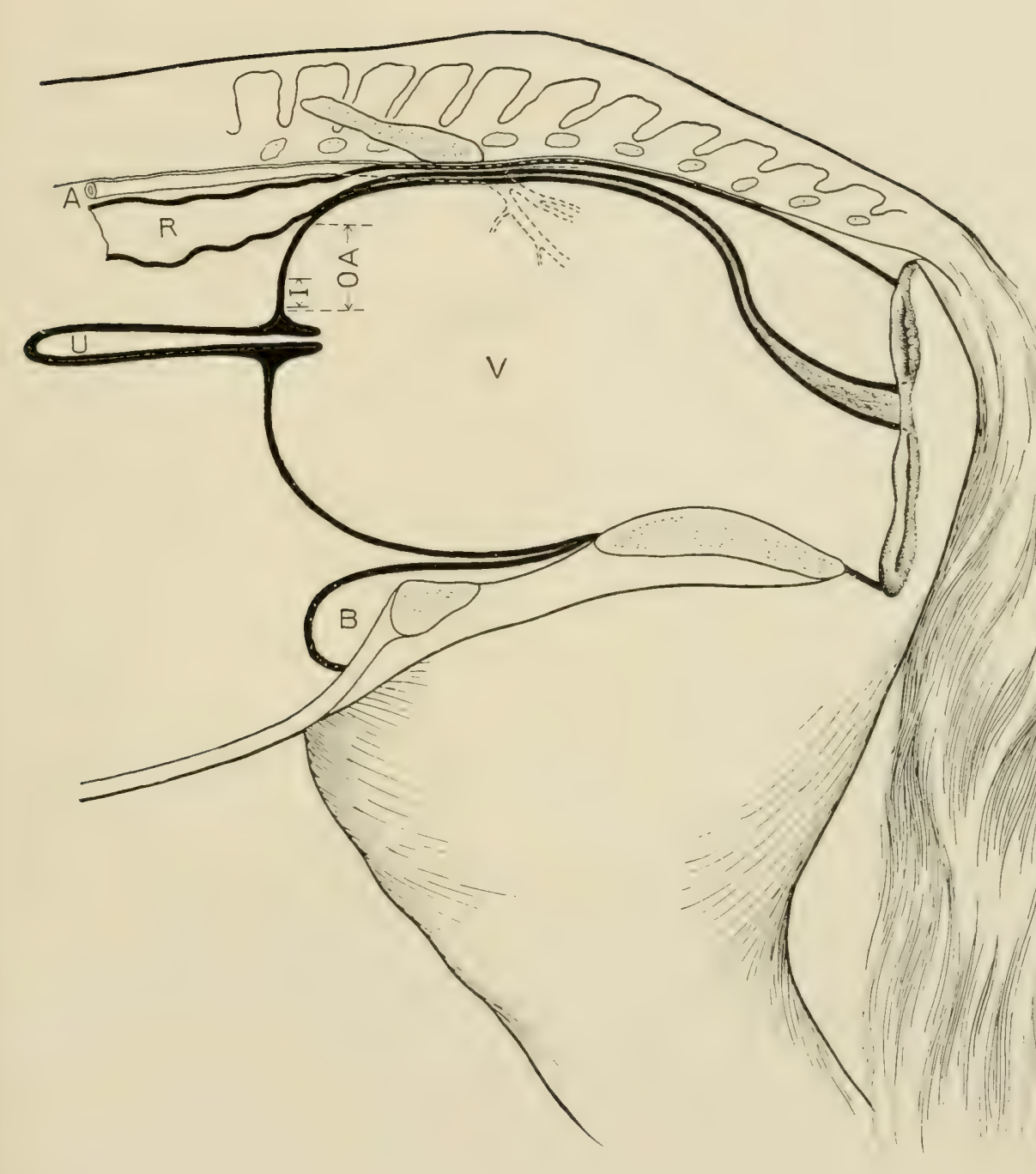



be made in the operation. The ballooning of the vagina profoundly alters the relation of this operative area, OA, Plate $\mathrm{XV}$, and changes it from the horizontal in the quiescent organ to the perpendicular in the ballooned conditioned. These variations permit two methods of operation, on the quiescent organ where the incision must be upwards, and on the "ballooned" or erected, where it must be directed forwards. We follow the latter, because since the "ballooning "' can always be induced, the operation can thus be made uniform in all cases, and we believe it safer and more readily performed. The operation should always be performed on the standing animal, and stocks constitute the proper form of restraint. It can be performed under other means of restraint, even in the recumbent animal, but it is inadrisable and greatly increases the difficulties and dangers. Secure in the stocks with the head elevated, a rope orer the back to prevent rearing, straps beneath the body to prevent lying down, straps or ropes before and behind the animal to prevent backward and forward movements, all four feet pinioned to the floor, and the tail firmly secured and stretched to a beam above.

With soap, water and brush cleanse the tail, perineum and rulva thoroughly, being especially careful to remove all detachable masses of sebum ; 50 per cent. alcohol may be used sparingly to aid in removing this. Too free a use of alcohol excoriates the delicate skin. Cleanse the clitoris carefully. Follow the washing with a free application of I: rooo aqueous sublimate solution to the external parts and for a short distance inside the vulvar lips and to the clitoris. Do not introduce disinfectants into the healthy vagina nor deeply into the rulva as it will cause severe straining during and subsequent to the operation and by injuring the vulvovaginal mucosa favor subsequent infection of the vaginal wound. Wash away the sublimate solution with a tepid .6 per cent. soda bicarbonate solution, and fill the vulvo-vaginal 
canal with the same. After thorongh disinfection of the hands and arms remove the disinfectants by washing in sterile soda solution, which at the same time renders the hand unctuous and readily introduced through the vulva. Armed with the guarded sterilized scalpel, Fig. Io, introduce the right hand into the vagina promptly and when it is well "ballooned" "unsheath the knife and placing it just above the os uteri at I, Plate XV, parallel to the long axis of the uterus and a few mm. to the right or left of the median line, in order to avoid a loose fold of mucous membrane generally existing directly on the median line, the blade being held vertical, that is the cutting surface parallel to the longitudinal muscular fibers of the ragina, and guarding the possible extent of its introduction with the thumb and fingers, push it directly forward in a straight line with a quick thrust through vaginal mucosa, the muscular walls and the peritoneum, until the disapp zarance of resistance indicates that the peritoneum has been penetrated. This is the most critical step in the operation.

If the hand is introduced immediately after the injection of the sterile saline solution the vagina will generally be found "ballooned" or will quickly become inflated under movements of the hand. If the solution is thrown out the vagina may collapse and closely invest the hand, in which case more soda solution should be injected when it will again dilate. If the hand is introduced without the knife, withdrawn and then introduced with the knife it will be frequently found that the vagina has collapsed and needs a second filling with the fluid. Patience until dilation is accomplished and promptness to act when attained are prime requisites to success. The knife should be pushed through the ragina quickly making a clean wound the width of the knife blade, when the latter is to be withdrawn and laid aside. It should be remembered that in this "ballooned" state, the anterior wall of the vagina is but 2 or $3 \mathrm{~mm}$. thick and easily penetrated. Introduce the hand again, push one finger into 
incision, then a second and third finger, and eventually holding all the fingers in the form of a cone push the entire hand into the peritoneal cavity. Immediately below the incision and continuous with the tissues involved in the wound lies the uterus with a transverse diameter of 4 to $6 \mathrm{~cm}$. With the palm of the hand downwards, trace the uterus, $\mathrm{U}$, Plate XV, forward a distance of $\mathrm{I} 5$ to $\mathrm{I} 8 \mathrm{~cm}$., where it ends abruptly in two cornua of about the same size as the uterus, which are given off horizontally at almost right angles. 'Trace these to the right and left for a distance of I 4 or $15 \mathrm{~cm}$., where they end obtusely, and 3 or $4 \mathrm{~cm}$. beyond this in a direct line, resting upon the anterior border of the broad ligament is the dense oral ovary varying in size from 2.5 to $7 \mathrm{~cm}$. in diameter. Withdrawing the hand, carry the ecraseur enclosed within it through the vaginal wound to the region of the orary, release the ecrasenr and retrace the parts if necessary, and locating the orary drop the chain over it from above and either grasp it with the fingers through the chain from above and draw it into the loop or passing one or two fingers around beneath the ovary push it up through the loop to be grasped by the thumb and index finger abore. The chain loop should be of barely sufficient size to admit of the easy passage of the ovary. Holding the orary with one hand tighten the chain quickly with the other, examine to make sure that a loop of intestine is not canght, draw the orary well through and get a large portion of the oviduct, and cut off promptly, holding to the ovary until carried out through the vulva. Remove the other ovary in the same way. Generally it is most convenient to remove the left ovary with right hand and viceversa but both may be removed with either hand. IVash away any blood from external parts, apply sublimate solution freely to the vulva, perineum and tail. Keep the patient quiet for fire or six days, and feed lightly on a laxative diet. 
DANGERS.

Wounding of the rectum is scarcely possible if care is taken not to attempt the incision until the vagina is well " ballooned," and then making the stab wound directly forward. If made upwards when the organ is so erected the accident is highly probable, and with the undilated vagina where it is necessary to cut upwards the danger is ever present. Its prevention demands that the operator await the complete "ballooning", and then make his incision as directed. If the wound in the rectum passes through the pelvic connective tissue behind the peritonem it is of little consequence, but the operation should be abandoned; if the bowel is opened into the peritoneal cavity the accident is fatal.

Wounding of the iliac arteries, which produces prompt death from hemorrhage, results from the incision being made upwards instead of forwards either when the vagina is "ballooned" or collapsed. It is most likely to occur with timid operators who become nervous, especially when the vagina does not "balloon" promptly or the mare is not well secured. The accident is wholly munecessary if the operator will await the "ballooning" and favor it if need be by repeated injections of tepid soda solution. When it has occurred it is generally beyond remedy.

Wounding of the uterus may occur when the incision is directed downward and may greatly embarrass the operator and confuse him by passing the hand through the incision into the nterine cavity. It is to be avoided by carefully directing the incision straight forwards; when the accident occurs it is of little consequence beyond the embarrassment and may be overcome by again dilating the vagina with fresh injections of the soda solution and making a new incision, or if preferred the first incision may be corrected by placing an index finger against the peritoneum at the upper part of the wound, and with a sudden and vigorous thrust 
break through the peritonemm into the carity. Great care must be exercised to make the thrust quickly and vigorously or the peritoneum will separate from the adjoining tissues and a large cavity be formed between the peritoneal and muscular walls of the vagina with a large area of yielding membrane which it is difficult to penetrate. It is not very safe in such cases to attempt continuing the incomplete incision with the scalpel, as it is rery yielding and pushes against neighboring organs before it is penetrated and affords no signal to the hand by cessation of resistance when it has passed through.

Incomplete penetration of the vaginal wall is liable to occur if the scalpel is dull or the ragina incompletely " ballooned " and flaccid, or if the operator is unduly timid. It is best prevented by aroiding the canse as related, and once it has occurred it is generally best to again "balloon" the organ and make a new incision either to the right or left of the first. It may be overcome also by thrusting the index finger through the peritonem as described in the preceding paragraph.

The mistaking of a ball of feces for the ovary has occurred to inexperienced operators and the fatal error of remoring the portion of the rectum surrounding the fecal pellet committed. The blunder is uncalled for; the fecal ball is movable in the bowel, the intestine is far more massive than the broad ligament, and the ovary is to be definitely identified by its being lodged in the broad ligament just beyond the end of the oriduct, which is continuous with the uterus and coruna. If, therefore, one traces the uterus forward to the coruna, thence along these to the oviducts, and thence along the border of the broad ligament to the ovary, as above directed, the error will not occur.

The incision may readily be made too low and pass beneath the broad ligament. It is to be avoided by being careful to keep close to the median line and above the os uteri. 
If it occurs the operation may be completed from beneath without very great difficulty only that the ovary now lies above the hand and must be drawn down from on top the broad ligament in order to fix the ecraseur upon it.

Infection constitutes always the most serious danger and is to be avoided by proper securing of the animal, by the avoidance of irritant antiseptics in the vagina, by rigid antisepsis at every stage, and by carrying out the mechanical parts of the operation deliberately, vigorously and neatly. If infection should occur it will generally take the for:u of pelvic cellulitis with abscesses and rectal stricture. Enemas of a normal salt or soda solution affords the surest relief of the stricture and impaction in front of it. The abscesses must be watched and opened early into the vagina or rectum, and the case treated internally and locally according to general surgical principles. 


\section{VAGINAL OVARIOTOMY IN THE COW.}

Objects. Increasing the fat or milk-producing qualities and the cure of nymphomania.

Instruments. Colin's scalpel, raginal dilator, Miles' spaying shears.

Technic. Confune the cow in the standing position in the stocks, securing the head firmly and passing two boards beneath the abdomen and sternum to prerent lying down, and a rope over the middle of the back to prevent arching of the spinal column and straining.

Wash and disinfect the tail and the perinaemm and flush ont the vagina with a .5 per cent. solution of carbolic acid or lysol at a temperature of abont $100^{\circ} \mathrm{F}$. Insert the vaginal dilator with one hand and push the prolongation at the anterior end into the os uteri. With the other hand elevate the handle of the dilator and depress and push forward the uterus, thus rendering the roof of the ragina tense and pushing it downward away from the rectum. Carry the scalpel into the vagina with the right hand and resting it in the oval of the dilator make an incision throngh the roof of the vagina, beginning at a point 8 to $\mathrm{IO} \mathrm{cm}$. posterior to the os nteri and extending backward on the median line for a distance of 2 or $3 \mathrm{~cm}$. Be careful to make the incision entirely through the mucosa, muscle and peritoneum at the first cut, since any failure to complete the incision tends to cause the peritoneum to separate from the muscular coat and form a pocket between them, while the peritoneum being very elastic renders it difficult to complete the incision. Introduce two fingers through the incision, and reaching over the side of the vagina to the right or the left, the right or left ovary respectively is recognized lying immediately against the vagina somewhat below it, just at the anterior border of the pubis, in a mass consisting of the cord-like Fallopian tube and the fimbriæe of its pavilion. The ovary 
may be distinguished as a firm oval mass 2 to $4 \mathrm{~cm}$. in length and I to $2 \mathrm{~cm}$. in its lesser diameter attached to the broad ligament. If not promptly recognized by the sense of touch, trace the vagina and uterus with the fingers forwards from the vaginal incision to the cornua and follow them as they bend upward and then backward to the Fallopian tubes, and trace each of them until the ovary is reached, where it is attached to the broad ligament, just beyond the fimbriated end. Grasp the ovary between the index and middle fingers and draw it through the incision into the vagina. Introduce the scissors with the other hand, and when the ovary is reached open them barely sufficient to admit the broad ligament between the blades and cut away the ovary along with a considerable amount of the broad ligament. It is essential that plenty of the broad ligament and Fallopian tube be removed with the ovary in order to insure the entire removal of the latter, because the accidental leaving of the smallest particle of ovarian tissue will cause a development of these into abnormally large Graafian follicles, and will tend to increase rather than decrease nymphomania. Should the animal be pregnant the ovary on the gravid side is dragged downward and forward ont of reach of the operator's fingers, and if it is desired to complete the operation it may be necessary to enlarge the vaginal wound and introduce the entire hand, when the ovary can be reached and removed. No after care is generally necessary.

The Dangers are similar to those of the mare. The iliacs may be wounded in the same manner as in the mare and is preventable by being careful to push the vaginal roof wel downwards away from the rectum and pelvic roof.

A new danger appears in the presence of the rumen, the supero-posterior portion of which projects into the pelvic cavity when filled with food and if the cut is directed forwards a stab wound readily penetrates its walls with fatal results. Make the cut upwards and backwards. 


\section{OVARIOTOMY IN 'IHE COW BY THE FLANK.}

Instruments. Clipping shears, convex scalpel, spaying shears, heavy needle and thread.

Uses. Same as the preceding, applicable to heifers or to cows when the vulva is too small to admit the operator's hand or in case of diseased vagina or uterus.

The animal may be secured as in the preceding or confined in lateral recumbency with the hind legs extended backward and the anterior limbs forward. T'o accomplish this loop a rope about the two fore feet, another about the two hind feet, and drawing upon these, cast the animal and secure it in recumbency with the legs extended and body stretched by fastening the ropes to two strong posts about $\mathrm{s}$ to $\mathrm{r}$ $\mathrm{m}$. apart. 'The operation may be performed in either flank.

Clip the hair from the upper part of the flank, disinfect an area $I_{5}$ to $25 \mathrm{~cm}$. square and make an incision about I 2 cm. long beginning at a point equi-distant from the anterior tuberosity of the ilium, the ends of the transverse processes of the lumbar rertebrae and the last rib and extend it downward perpendicularly severing the skin and subcutaneous muscle. Diride the external oblique muscle in the direction of its fibres by means of the scalpel handle or the fingers and repeat the process upon the internal oblique muscle after which puncture the peritoneum either with the scalpel or by means of a sudden thrust with the index finger. Force one hand through the opening into the peritoneal cavity and search for the ovaries at the same point and by the same method as in the preceding operation, that is, locate the uterus within the pelvic cavity, between the rectum and bladder and trace the former and thence the cornu, oviduct and broad ligament to the ovary. The uppermost ovary can be drawn out through the wound and cut off with the scissors; the lower one must be held with one hand and the 
scissors introduced closed along the arm and when the ovary is reached, opened barely sufficient to pass over the broad ligament and clip it off. The beginner must always remember that the positive means for identifying the ovaries is by tracing the uterus from the vagina along its cornua to the Fallopian tube and thence to the ovary in the broad ligament. Cleanse the wound and close the skin incision with continuous sutures.

29. OVARIOTOMY IN THE BITCH BY THE FLANK.

\section{PLATE XVI.}

Instruments. Spaying knife, suture material.

Technic. Confine the animal in lateral recumbency, preferably upon the right side for a right handed operator, the head somewhat depressed, the limbs extended and the body well stretched. Clip, shave and disinfect a sufficient area in the exposed flank at a point just anterior to and beneath the external angle of the ilium. With one hand grasp the skin fold of the flank and render the skin of the region tense, while with the other holding the spaying knife likea pen make at first a drawing $i_{1}$, cision from below upward about 2 to $3 \mathrm{~cm}$. long, ending above at a point slightly below the external angle of the ilium, the incision extending through the skin and subcutaneous tissues; without removing the knife from the wound elevate the handle and with a quick thrust make a stab wound extending through the external and internal oblique muscles and peritoneum at a single cut. The operator can determine when the peritoneal cavity has been entered by the disappearance of resistance. Introduce an index finger into the peritoneal cavity, and as soon as this has been entered follow directly along the peritoneum upward and backward toward the angle of the ilium where the uterine cornua lie covered over by the broad ligament. The internal generative organs of the bitch are unique among 
our domesticated animals. The uterus, U, Plate XVI, is rery small and physiologically umimportant, the cornua, RUC and LUC, are ample in size and constitute physiologically the uterus, the Fallopian tube between LUC and $O$ is very short and surgically could almost be said not to exist, the ovary OO is rery small, smooth and completely hidden in the pavilion which here constitutes a sac having a very small longitudinal opening of 2 to $5 \mathrm{~mm}$. The most remarkable feature of the apparatus from a surgical standpoint is the great derelopment of the broad ligament which is broader than the distance from the lumbar region to the abdominal floor, while the nterus and uterine cormua are stretched between the vagina, $\mathrm{V}$, and the ovary, $\mathrm{O}$, so that they are suspended in the sub-lumbar region with the double fold of the broad ligament hanging down like a curtain between the parietal peritonemm and the uterus and cornua on either side. The broad ligament of the bitch is consequently suspended at one point from the sub-lumbar region, at the other from the uterus, so that instead of the uterus being suspended by the ligament the relation is reversed and the ligament is suspended from the uterus, or rather uterine cormua.

In Plate XVI the right broad ligament BL' is laid ont "pon the side exposing the right uterine cornu $\mathrm{RUC}$, while on the left side the ligament is divided at about its center and the posterior portion BL' is laid ont on the flank, while the anterior BL is left in its normal position concealing a portion of the cornu LUC. Unlike onr other domesticated animals, the broad ligament is hearily loaded with fat which gires it an appearance very similar to the omentum, but the net-work is far less conspicuous or wanting. The omentum also extends back into this region so that the two are in contact. The ovary being indistinct and hidden is difficult to identify directly, and the cornua being covered over by the duplinature of the broad ligament is not readily reached, so that the finger generally comes in contact first with the broad ligament of the uppermost cornu hanging loose in the peri- 


\section{PLATE XVI.}

OVARIOTOMY IN THE BITCH.

Abdomen of a non pregnant bitch lying on the back with the abdominal floor removed and the omentum pushed away. T'T, the two posterior teats; $\mathrm{B}$, bladder; $\mathrm{V}$, vagina ; $\mathrm{U}$, uterus : LUC, LUC, left uterine cornua with a portion of its broad ligament, BL, lying across it : RUC, right uterine cornua with its broad ligament, $B L^{\prime}$, turned outwards exposing the full length of the cornua. On the left side the ligament is divided so that the anterior half rests in its normal position while the posterior half, $B L^{\prime}$, is turned back; OO, ovaries; $\mathrm{R}$, rectum; $\mathrm{K}$, left kidney; $\mathrm{AA}$, a line indicating the level of the external tuberosities of the ilia. 


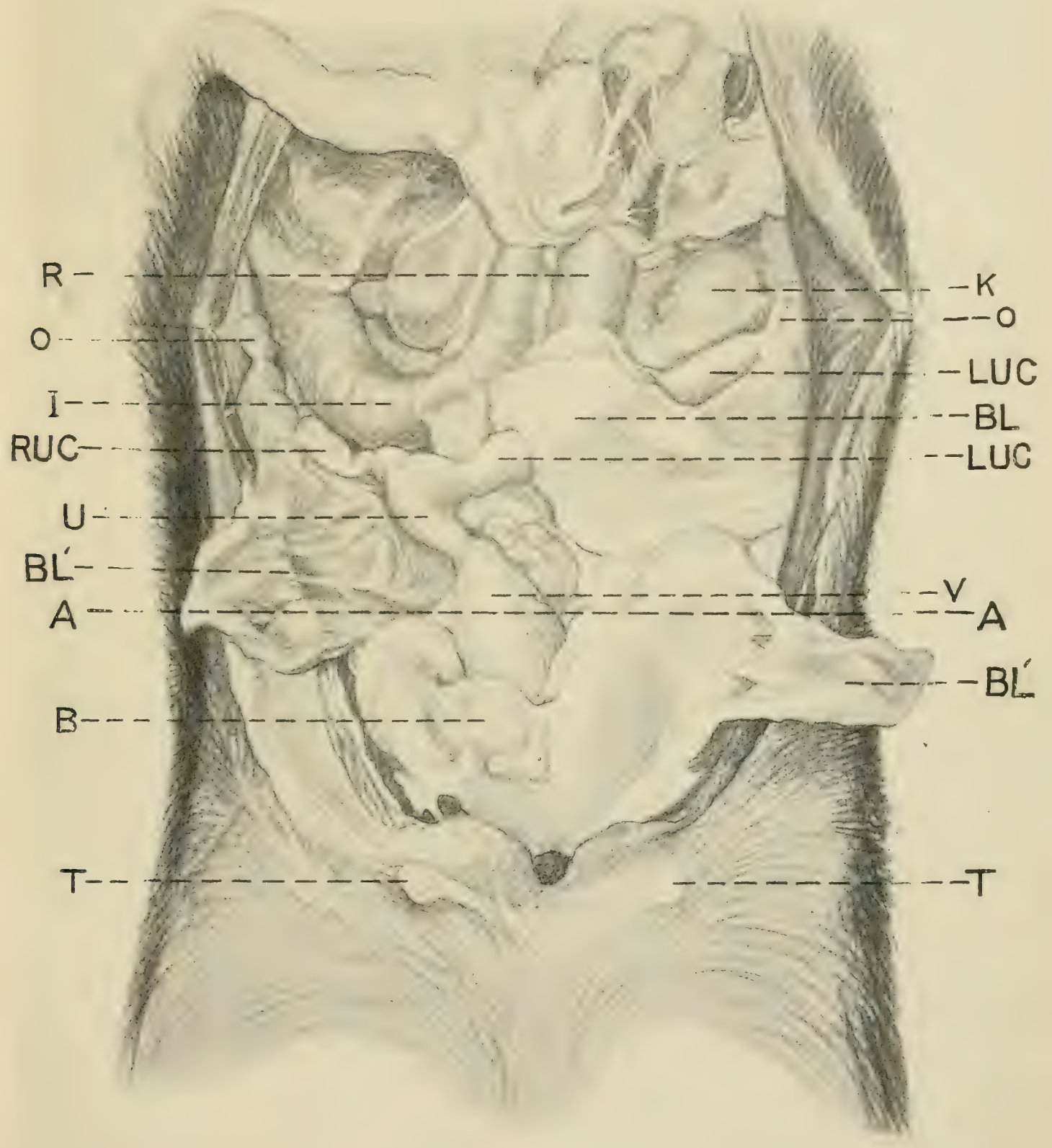



toneal cavity ; engage this between the end of the finger and the abdominal wall and draw it out through the wound, grasp it and continue drawing upon the folds of the ligament, especially upon the median or molermost portion until the naked cornu appears through the opening, seize it and draw out the anterior portion until the ovary follows, then grasp the orary firmly with the thumb and index finger of one hand and the orarian ligament with the same members of the other hand and tear the ligament through between them by linear tension. Extend the tear through the broad ligament as high toward its lumbar attachment as is convenient and backward to the neighborhood of the uterine bifurcation. Draw upon the exposed cormu until the bifurcation appears, when the other cormu is to be grasped and drawn out through the opening. In young puppies the securing of the seconci cornua is rery difficult and requires great care to prevent its rupture. The object may be facilitated by pressing the upper flank of the bitch downward, thereby greatly diminishing the transverse diameter of the abdomen.

The succeeding operation, 30 , avoids this difficulty in a large measure. Should the distal cornu be ruptured and with its ovary drop away from the operator, it becomes necessary to turn the animal over and make a second incision on the opposite side, somewhat further forward. When the second cornua has been secured draw it out as far as practicable and holding it tense insert an index finger along it nutil the ovary is reached, which is recognized by its slightly greater size and density succeeding the brief neck representing the Fallopian tube between the end of the cornu and ovary which are slightly larger, while beyond it, can be felt, the ovarian ligament. Engage the ligament between the end of the index finger and the abdominal wall, and with a firm and vigorous movement, using the finger end and nail as a curette, rupture the ovarian ligament by drawing the finger toward the incision, and with the aid of tension upon the 
cornu draw the ovary out through the abdominal incision and divide the broad ligament as in case of the other cornu. Remove the cornua with the attached ovaries by rupturing them transversely near the bifurcation by means of linear tension.

If the bitch be pregnant and especially if far advanced the uterine coronna will lie upon the abdominal floor, much enlarged and very much more flaccid than the nongravid nterus and feeling very much like intestines. The change in the position of the uterus has caused the unfolding of the duplicature of the broad ligament so that it no longer covers the cornu. In such cases the operation is performed in the same way except that rupturing the blood ressels by linear tension does not insure against hemorrhage and it is necessary to ligate the ovarian and uterine arteries with catgut or silk. In cases of pregnancy the entire comna should be drawn ont and a strong ligature placed around the uterus or vagina ; and the ovaries, uterine cornua and their contents be removed en masse. Release the upper posterior limb and close the cutaneous wound by a continuous suture.

Dangers. Rupture of the uterine cormu alluded to above.

The ureter may be mistaken for the cormu but is smaller, is closely attached to the abdominal walls, and does not have the broad ligament with its large deposit of fat. The kidney is far larger than the ovary, more exposed, and located more anteriorly.

The iliac arteries are at times caught and ruptured by the finger but the blunder is uncalied for except through nervousness of the operator.

Unanthentic instances of puncturing the bladder in making the incision have been reported and may be possible. If the bitch has been led ont and caused to urinate prior to operating, the accident is made practically impossible. 
30. OVARIOTOMY IN THE BITCH BY THE LINEA ALBA.

$$
\text { PlaTE XVI. }
$$

Instruments. Same as in the preceding.

Technic. Confine in the dorsal position with the head sharply declined. Share and disinfect an area on the median line about $6 \mathrm{~cm}$. square extending forward from the pubic brim. Make an incision on the median line abont $4 \mathrm{~cm}$. long beginning just in front of the pubic brim and extending forward cutting entirely through the skin, the linea alba and peritoneum at a single stroke. Insert an index finger and identify the uterus or broad ligament by its location and form. The finger usually comes in contact first with the urinary bladder which may more or less obstruct the passage to the uterus according to its degree of distension. When empty as shown at $B$, it offers practically no obstruction. When very much distended it may be evacuated by gentle pressure with the fingers. 'The operator should be careful not to draw the hladker ont through the incision as its replacement may prove difficult and its puncture with the hypolermic needle or an enlargement of the incision may be necessary in order to bring about its return. Push the bladder aside if necessary and just above it and below the rectum the uterus should be readily distinguished and either it or the broad ligament canght by the finger and brought out through the incision after which the operation proceeds in the same manner as by the flank method. It has a distinct adrantage orer the flank method in that in puppies there is not so much difficulty in bringing out the ovaries, nor the danger of the rupture of the cornua and the ovary dropping back. By the use of retractors in the abdominal incision the operator is enabled to ;ee the uterus in position and grasp it by means of forceps, obviating the necessity of introducing the finger into the peritoneal cavity. The sutures must extend entirely through the abdominal wall and be carefully placed in order to prevent hernia. Interrupted sutures are preferable. If the operation has been properly 
performed no bandage is necessary and the patient will not disturb the sutures. If asepsis has not been strictly followed infection may occur and the consequent irritation cause the patient to tear the sutures out, which may lead to protrusion of the intestines or other abdominal viscera. If the sutures do not include the deeper layers of the abdominal wall hernia is liable to occur and require a second operation.

\section{I. OVARIOTOMY IN THE CAT.}

Instruments. Same as for the bitch.

Technic. The cat may be spayed by either the flank method or through the linea alba. The point of incision in either case is the same as in the bitch but owing to the smaller size of the animal it is necessary to make the wound quite small. The abundance of hair or fur in the region renders it essential that an ample area be shaved and the surrounding hair be saturated with a disinfectant and carefully brushed away from the operative area. The cat being more subject to infection than the bitch the aseptic precantions must be of the strictest possible character. 'The operative area must be thoroughly disinfected and cleansed and equal care must be taken not to introduce irritant disinfectants into the wound. A great danger also exists in the tendency of the abdominal muscle layers to readily become separated by pressure from the finger and form a pocket in which wound discharges accumulate and constitute a dangerous seat for infection. Great care must therefore be taken to make a clean incision directly into the peritoneal cavity and to avoid separating the peritonem from the muscles or the muscular layers from each other. The uterus and oraries of the cat are naked and far more easily distinguished than in the bitch, there being no extra deposit of fat in the broad ligament. The sutures are to be applied to the wound in the same manner as in the bitch. 


\section{OPERATIONS ON THE EXTREMITIES.}

32. TENOTOMY OF THE FLEXOR PEDIS TENDONS.

PIATE XVII.

Objects. The relief of contraction of the flexor tendons of the foot.

Instruments. Razor, scissors, sharp tenotome, bandage material.

Technic. 'T'enotomy is generally performed on the deep, or flexor pedis tendon, seldom on the superficial, or flexor of the os coronae of the foot.

Confine upon the operating table with the affected nember undermost and the foot fully extended. In default of a table confine in lateral recumbency and apply an extension splint to the foot as shown in Plate XVII.

On the median side at the middle of the metacarpus the skin is shaved and disinfected over the tendon of the flexor pedis muscle. The location named lies between the lower extremity of the great carpal sheath above and the superior extremity of the tendonous sheath of the fetlock below, so that neither of these is wounded during the operation, but the tendon is serered at a point where it is invested by loose connective tissue which retains the divided ends in their normal hme of direction, somewhat fixed, and favors their ultimate reunion.

Grasp the metacarpus in this area from above and behind in such a manner that the thumb rests upon the median or upper surface of the metacarpus, and the index and second fingers on the lateral or under side of the flexor pedis tendon. While the left thumb pushes the skin toward the metacarpal bone, that is, forward, a sharp pointed tenotome held perpendicularly in the right hand is introduced with the cutting edge toward the hoof through the skin, subcutem and anti- 

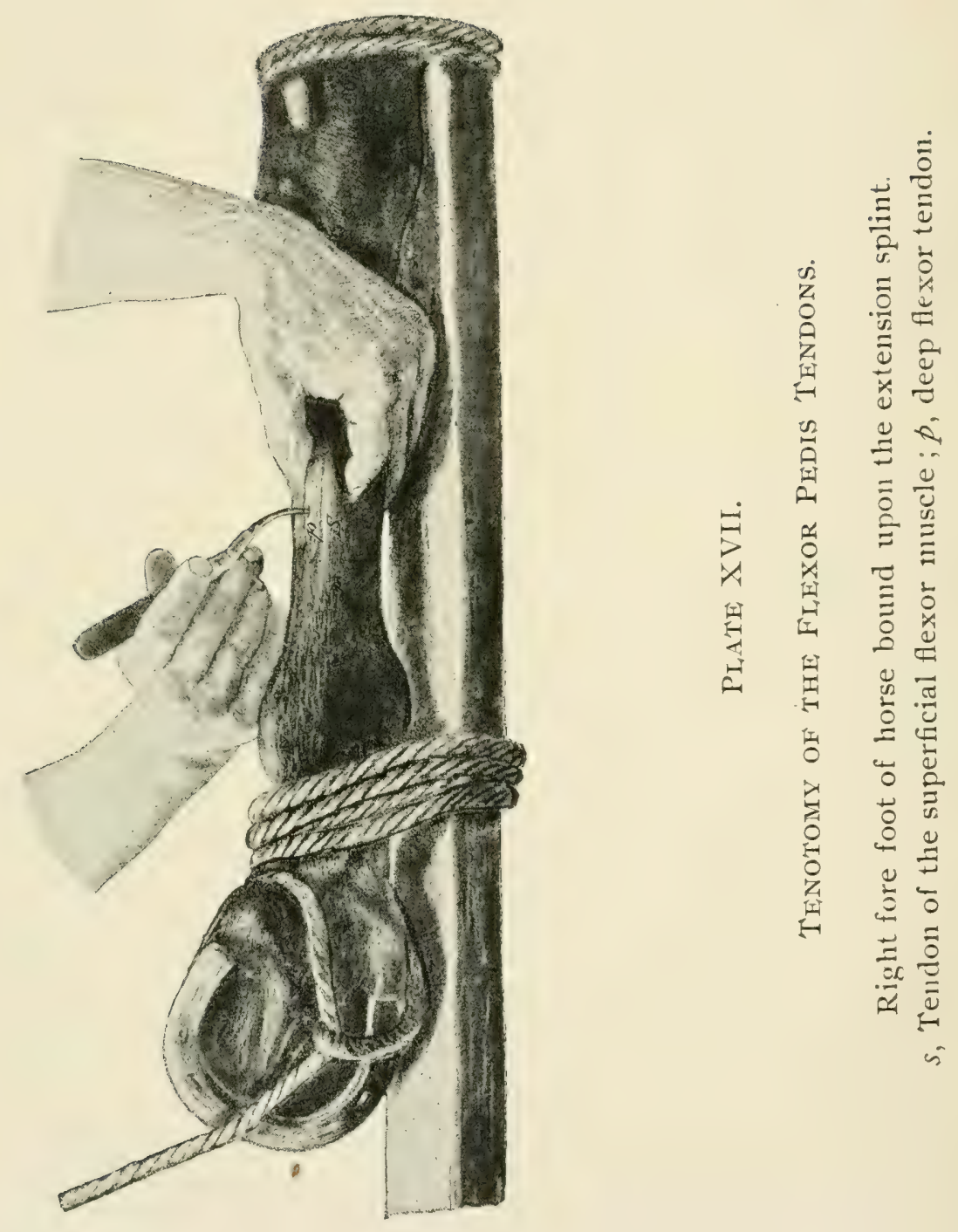
brachial fascia down to the flexor pedis tendon. Immediately on the anterior border of the tendon insert the tenotome so far that the point of it can be felt on the lateral or outer side through the skin with the left hand. The cutting edge of the knife is then turned against the tendon of the flexor pedis, that is, it is directed backward, the foot is extended by an assistant with the aid of a rope bound around the pastern and looped over the hoof, and the extensor pedis tendon is cut through under light pressure, by the operator pressing downward on the handle of the knife, using the metacarpus or suspensory ligament as a fulcrum upon which the back of the tenotome rests as a lever. A lond crackling as well as the disappearance of resistance by extension shows that the tendon is severed. By keeping as close to the anterior border of the tendon as possible we can aroid injury to the common digital artery, the internal cutaneous rein, and the internal and external interosseous veins which run between the flexor pedis and the suspensory ligament.

After the removal of the knife and after seeing that there is a wide space between the ends of the tendon, the foot is unbound from the splint and a bandage applied to the metacarpus, which rests upon the fetlock joint and remains in position for eight days. Healing of the cutaneous wound by primary union.

\section{PERONEAL TENOTOMY.}

PLATE XVIII.

Object. The relief of Stringhalt.

Instruments. Razor, scissors, sharp tenotome.

Technic. On the lateral side of the metatarsus a triangle, $d$, opening toward the tarsus is formed by the tendons of the extensor pedis longus muscle, $l$, and the lateral extensor of the foot, $e$, which unite on the anterior surface of the middle of the metatarsus. The synovial sheath of the extensor 
PLATE XVIII.

Peroneal Tenotomy For StringhalT.

Right hind foot seen from the external side. The skin covering the lateral extensor of the foot is laid back in the form of a flap, the crural fascia divided. $e$, Peroneal tendon; $f$, crural fascia; $l$, tendon of the anterior extensor pedis muscle; $d$, the triangle formed by $l$ and $e$. 


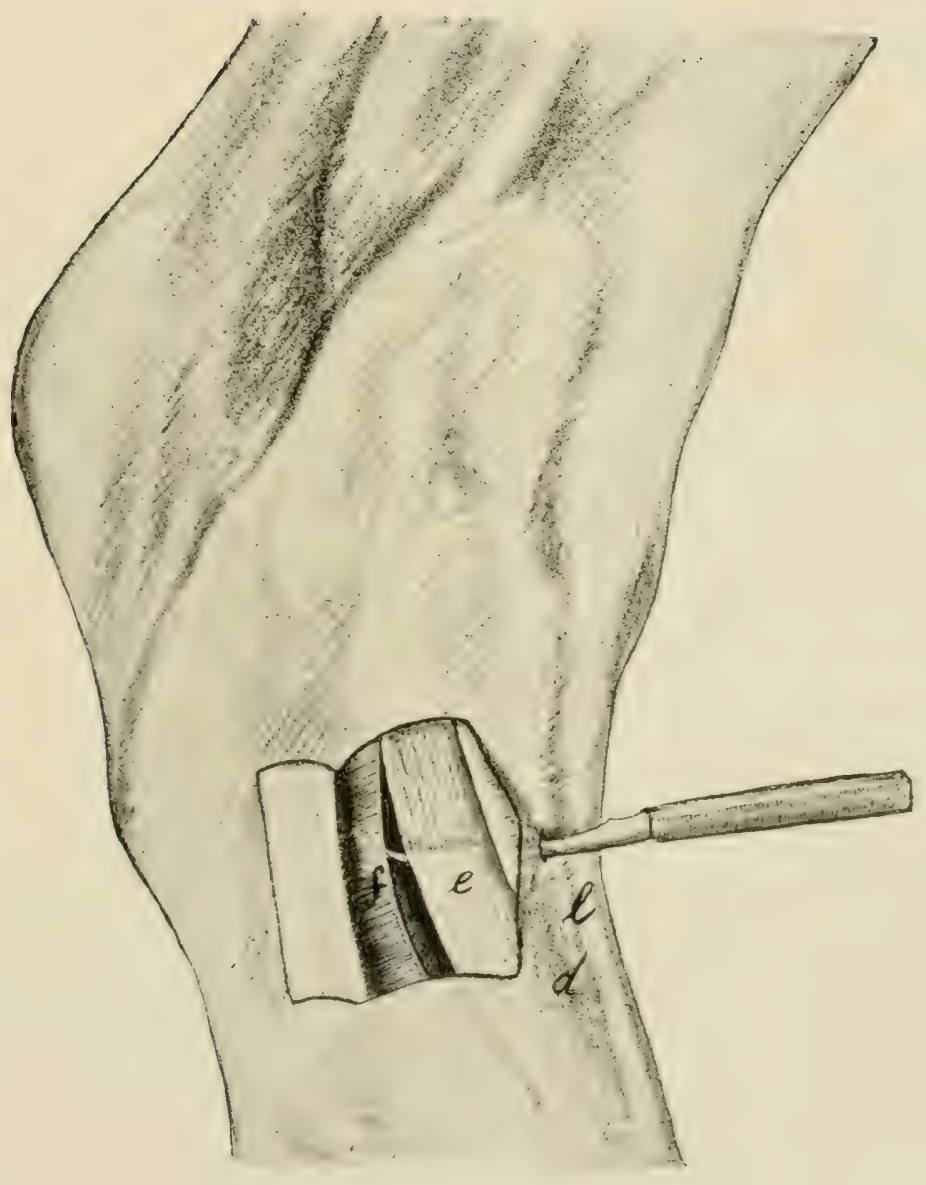



pedis longus muscle extends inferiorly to near the point of juncture of the two tendons; the sheath of the lateral extensor ends below 3 to $4 \mathrm{~cm}$. above the point of union. In the middle of this space without a sheath, which is 3 to 4 cm. long, and below the annular ligament of the hock the operation is carried out. After the skin has been shaved and disinfected, confine in the stocks or operate upon the standing horse, with the aid of local anaesthesia, a twitch being applied to the nose and the opposite hind foot held up with the side-line. The tendon of the lateral extensor is easily felt under the skin as a hard cord abont .7 to I cm. in diameter. Stretch the skin and with the back of the hand toward the hock grasp the tendon with the thumb and index finger of one hand, insert the tenotome with the cutting edge toward the foot perpendicularly upon the tendon through the skin, subcutem and aponenrosis derived from the crural fascia ; push it from before backward under the tendon, turn the cutting edge against it, and with the hock extended sever the tendon as well as the fascia through to the skin. In accomplishing the section of the tendon the knife is to be used as a lever of the first class with the anterior border of the metatarsus acting as a fulcrum. If the tendon has been completely severed its retracted ends may be felt under the skin I to $2 \mathrm{~cm}$. above and below the wound. After the operation an antiseptic bandage is applied, resting upon the fetlock. The bandage should remain eight days and the cutaneous wound heal by first intention.

\section{CUNEAN TENOTOMY.}

PlaTE XIX.

Objects. The relief of spavin lameness and as an adjunct to peroneal tenotomy for stringhalt.

Instruments. Razor, scissors, straight scalpel.

Technic. Most horses can be operated on standing, with the aid of cocaine, otherwise cast, or secure on the operating 
PLATE XIX.

CUNEAN TENOTOMY.

For the relief of spavin lameness, and as an adjunct to peroneal tenotomy in stringhalt. CT, cunean tendon. The dotted line crosses the ergot. 


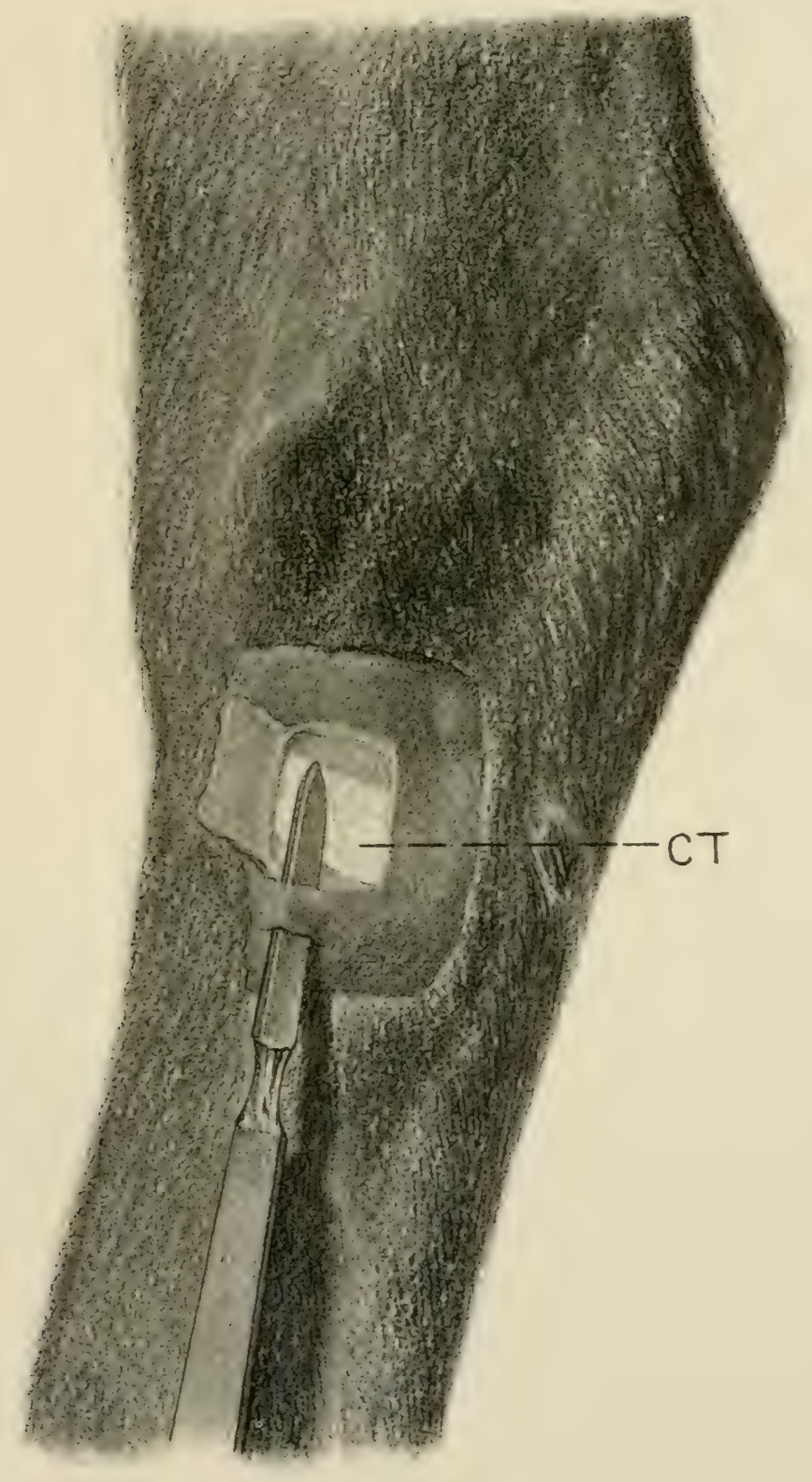


table, on the affected side and extend the tarsus. Shave and disinfect an area 5 to $6 \mathrm{~cm}$. square on the inferior median surface of the hock orer the course of the cunean tendon of the chief flexor of the metatarsus, as indicated in Plate XIX. Locate the tendon, C'T, by palpation as it passes obliquely downward and backward and make a transverse incision about I cm. below the inferior border of the tendon at a point midway between the anterior and posterior borders of the hock, or slightly anterior thereto, the width of the scalpel blade. Push the tenotome flatwise between the skin and tendon, as shown in the plate, force it upwards to the superior border of the tendon, then turn the cutting edge toward it and elerating the handle, using the superior border of the wound as a fulcrum, cut the tendon through from without inwards. By firm pressure upon the tenotome in the latter method periosteotomy is simultaneously accomplished. The completion of the operation is eridenced by the separation of the cut ends of the tendon leaving a well-marked depression at the point of operation. Disinfect the wound, apply an antiseptic bandage resting upon the fetlock and allow to remain undisturbed for six days. Healing by primary union.

\section{NEUROTOMY.}

General Remarks. Neurotomy is performed for a rariety of objects, such as the relief of pain in a sensitive nerve itself, as in trifacial neurotomy, i I, p. 48, the relief of pain or lameness in a par: supplied by a sensory nerve, or the inhibition of motor power, as in the "cribbing" operation.

The following neurotomies are designed to relieve pain and the consequent lameness dependent npon a pathologic condition of some part or tissue on the distal side of the point of operation and to which the divided sensory nerve is destined. 
Nenrotomy of a sensory nerve is always a painful operation, and its performance without anaesthesia is unjustifiable from a humane standpoint, and cannot be so well done either from the view of mechanical correctness or the carrying out of antiseptic standards. Some nemrotomies can be well performed on the standing animal if it is quiet and the operator is experienced, the parts being rendered insensitive by means of cocaine or other local anaesthetics ; in the greater neurotomies general anaesthesia is called for, whether viewed from the humane or operative standpoint.

The confinement of animals for neurotomy on the sensory nerves of the extremities for the relief of lameness is always to be viewed as a critical procedure for the reason that the operation is generally made because of the local manifestation of a more or less general disease which is accompanied by fragility of the skeleton, and as a result most casting accidents occur in cases of confining for neurotomy or firing in cases of lameness belonging to the great group of dry arthritis or spavin family. Casting must, therefore, be done with the greatest possible care, a id the operating table is to be constantly and greatly preferred.

Neurotomy is properly a last resort in lameness and should not otherwise be performed. It has two great and ever present dangers. If the part deprived of sensation is too badly diseased to bear the weight and resist the insult resultant upon the part being called to do its normal or even an extra amount of work, it must ultimately give way, the bones become fractured, the tendons separate from the bone, the intra-ungular tissues lose their integrity and the hoofs become detached (exungulation) or other degenerative changes take place as a result of causing a part to do a work for which its condition unfits it.

The second great danger occurs from wounds or other tranmatisms to the tissues distal to the operation when the nunerved parts are not rested as they would be in natural 
conditions when injured and as a result reparative changes are prevented and supplanted by retrograde processes with ultimate death of the part and of the animal.

Nerves are generally accompanied by satellite arteries and veins which are always liable to be wounded during the operation and are nore embarassing because of the hemorrhage clonding the operation field and inviting error than dangerons because of the loss of the blood itself. It is essential to a good operation that the hemorrhage be kept under control throughout so that each tissue will stand ont in good relief and the nerve reveal its identity in addition to its location, size and relations, by its intensely white, nacrons, striated character, The test of compressing the nerve in order to identify it by the resultant pain is unsurgical and unnecessarily cruel.

Sepsis holds an important place in considering the dangers of neurotomy becanse the infection of a sensitive nerve causes very great pain and if considerable tends to cause a false neuroma or fibroma in the connective tissue of the nerve trunk, calling for a second operation in order to remove the tumor, and resultant laneness.

Neurotomies should consequently be performed only in properly selected cases, the smallest possible trunk that will sufficiently relieve the pain should be selected for the operation, it should be performed with due regard for suffering and for asepsis, should be performed quickly and neatly, the incisions being free, laying the nerve trunk bare withont tearing up the tissues and clonding them and at every point aim at celerity, accuracy and neatness. 


\section{DIGITAL NEURO'TOMY.}

\section{PI.ATE XX}

Objects. The relief of navicular lameness in cases where plantar neurotomy is not deemed necessary or adrisable.

Instruments. Razor, scissors, scalpel, probe pointed bistoury, tenacula, aneurism needles, bandages.

Technic. Digital neurotomy may generally be performed on the standing animal, the operative area having first been anaesthetized by means of cocaine or otherwise, a twitch applied to the upper lip and the affected foot held up by the assistant. If necessary because of restlessness of the animal or inexperience of the operator, confine on the operating table or cast the animal and apply the extension splint to the foot to be operated on as shown in Plate XVII, except that the lower binding cords rest on the metacarpus instead of the pastern. Extending downwards from the fetlock joint toward the coronet, between the posterior border of the phalanges and deep flexor tendon there is a slight furrow, at the posterior part of which, close to the external margin of the tendon, lies the median or principal digital nerve accompanied in front by the digital artery, A, anterior to which lies the digital vein, V. Inmediately behind the nerve and generally lying a trifle deeper, is quite commonly found a second venous trunk of considerable size. Near the middle of the first phalanx the nerve is crossed externally in an oblique direction from above to below and from behind to before by a white liganentous band, L, slightly broader than the nerve extending from the base of the ergot of the fetlock to the retrossal process of the pedal bone. This must not be mistaken for the nerve, $\mathrm{N}$, and need not be if it is remembered that the latter is accompanied on the same plane and in a like direction by the satellite artery, A, and vein, V, enclosed with it in a fibrous sheath. At the uppermost part 
of the first phalanx the nerve lies in front of this ligament, a short distance inferiorly it passes beneath it, while from the middle of the pastern downwards the nerve lies behind the ligament.

The operation is practicable at any point over the line of the nerve from the top to the bottom of the shaved area in Plate XX or from the superior end of the first phalanx down to a level with the superior border of the lateral cartilage, but perhaps preferably at about the middle of the pastern. At the desired point and orer the groore between the flexor pedis tendon and the phalanges shave and disinfect an area 4 to $5 \mathrm{~cm}$. square. In the center of this area at the anterior border of the flexor tendon, with the scalpel held perpendicular to the skin, make an incision from above downwards a distance of from 2 to $3 \mathrm{~cm}$. cutting cleanly through the skin and subcutaneous fascia down upon the nerve. The incision is farored by tensing the skin between the thumb and index finger of the left hand, but care should be taken not to displace it backwards or forwards. Dilate the wound by pressure with the thumb and index finger or otherwise and carefully incise longitudinally the fibrous sheath enveloping the nerve and artery. Pass an aneurism needle beneath the nerve, and follow with a second aneurism needle immediately beside the first. Draw the two apart, one toward the toe, the othar toward the fetlock, and separate thereby the nerve from the surrounding tissues. Remove one aneurism needle, insert a probe pointed scalpel, or scissors beneath the nerve, and divide it at the upper angle of the wound and excise a section of nerve $3 \mathrm{~cm}$. long. Disinfect and bandage with or without suturing the wounds. Leave the bandage in place 6 to 8 days. 


\section{PLATE XX.}

Digital Neurotomy.

$\mathrm{V}$, digital vein; $\mathrm{A}$, digital artery; $\mathrm{N}$, digital nerve; L, ligament. 


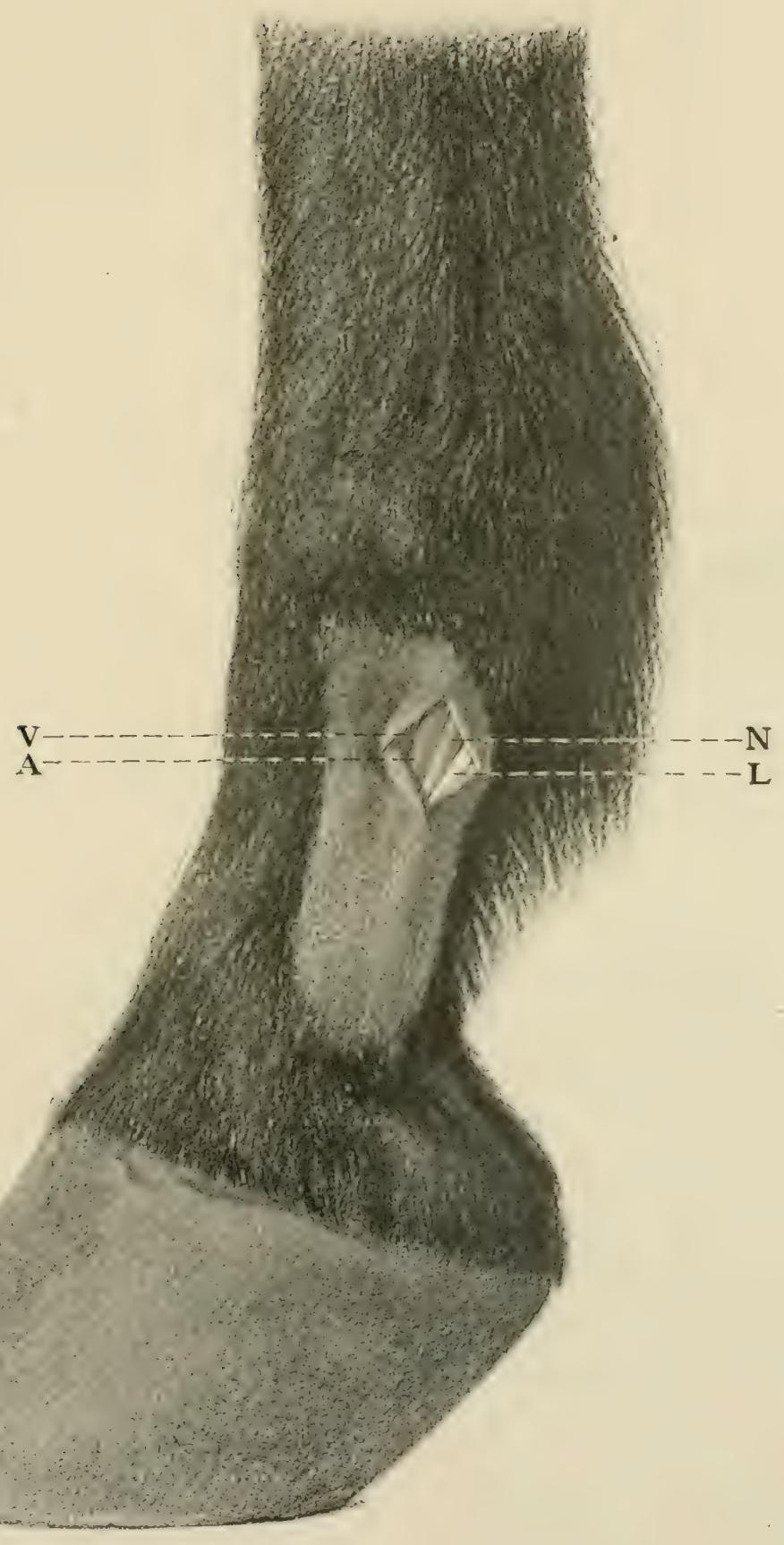





\section{PIAATAR NEUROTOMY.}

PI,ATE XXI.

Objects. The relief of navicular lameness or other painful non-suppurating diseases of any parts below the fetlock joint.

Instruments. Razor, scissors, conrex scalpel, compression artery forceps, tenacula, aneurism needles, suture material, elastic ligature.

Technic. It is well to apply a bandage saturated with sublimate or creolin solution to the fetlock joint 24 hrs. before the operation in order to secure thorough disinfection.

Confine the animal and fix the limb as in the preceding operation. After the removal of the bandage, shave the site of operation and thoroughly disinfect the region of the metacarpus and fetlock with soap, brush, and sublimate or creolin solution and 50\% alcohol. Passing the fingers from before to inehind with light pressure over the region of the fetlock joint, there is felt just in front of the flexor pedis tendon a channel-like depression extending from above the fetlock downward over it. In this lies the threadlike cord of the nerve, $n, 3 \mathrm{~mm}$. thick, which glides forward underneath the fingers with a distinct recoil. The site of operation lies immediately above the fetlock in tie posterior third of the metacarpus or one may operate at any point higher up as far as beyond the middle of the metacarpus or metatarsus so long as care is taken to include the anastomosing branch given off by the median plantar nerve at about the middle of the metacarpus and bending obliquely around behind the tendons to join the lateral nerve somewhat lower down. At this point stretch the skin between the thumb and index finger of one hand and make an incision 3 to 5 cm. long, the lower angle of which is just above the fetlock joint, cutting directly through the skin, subcutem and con- 
PLATE XXI.

PiantaR NeURótomy.

$a$, lateral digital artery ; $v$, lateral digital vein ; $n$, common lateral digital nerve; $d$, anterior branch; $o$, posterior branch ; $s$, superficial flexor tendon; $p$, perforans tendon; $i$, suspensory ligament of fetlock ; $m$, metacarpus. 


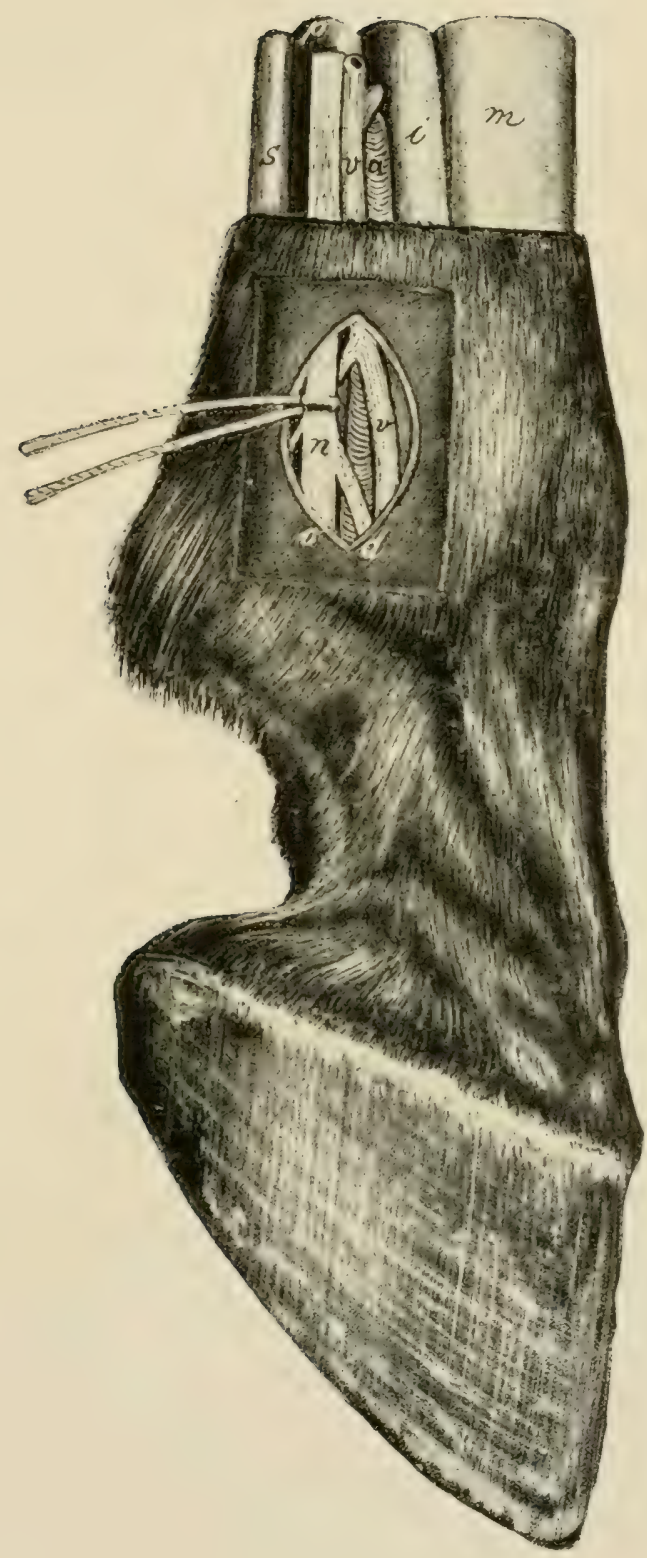



nective tissue sheath down on to the nerve, laying it bare. The borders of the cutaneous wound are held apart with tenacula and by palpation with the fingers or by vision it is determined if the nerve lies in the middle of the wound. If necessary continue the dissection with the scalpel until the nerve is clearly revealed; it is distinguished by its faintly yellowish color, its fine longitudinal strixe and its location behind the metacarpal artery. Immediately above the fetlock joint the median metacarpal or metatarsal nerve divides into an anterior smaller, $d$, and posterior larger, $o$, branch. This division should be laid bare in order that the operator may not erroneously cut one branch only. Immediately above this point of division the aneurism needle is passed under the nerve, then a second needle is inserted beside it and the two pulled apart separating the nerve from the adjacent tissues, the scissors or a small probe-pointed bistoury is passed beneath and it is cut through quickly at the superior angle of the wound. The distal end of the nerve is then dissected free as far as possible downward and hoth branches excised at the lower angle of the wound so that a section 3 to $5 \mathrm{~cm}$. long is removed. 'The cutaneous wound is united by a continuous suture and a temporary bandage applied. The extension splint, if it has been used, is then removed, the foot replaced in the hobble and the horse turned to the other side. Neurotomy of the opposite metacarpal nerve is carried ont in the same way after which a sterile bandage is applied and allowed to remain eight days. Healing by primary union.

37. NEUROTOMY OF THE MEDIAN NERVE.

\section{PLATE XXII.}

Objects. The relief of lameness due to disease so located in the anterior limb that it cannot be overcome by plantar neurotomy. 
Instruments. Razor, scissors, convex scalpel, artery and compression forceps, tanacula, aneurism needles, suture material.

Technic. The operation is performed on the median surface of the anterior limb immediately below the humeroradial articulation on the recumbent horse after the affected foot has been fully extended on the operating table or in default of this removed from the hobbles and bound upon the extension splint as shown in Plate XVII. Anaesthetize. The foot is drawn out firmly from the shoulder, inclined somewhat forward. The operator places himself between the neck and the forearm and, after the median region of the elbow joint has been washed with soap and water, searches for the median nerve where it glides over the posterior part of the joint to disappear behind the radius. Shave the skin at and below this point, disinfect it with soap, sublimate or creolin solution and $50 \%$ aclohol. The nerve, $n$, lies as a rule somewhat in front of the middle of the median side of the forearm against the postero-internal margin of the radius and can be felt, about 5 to $6 \mathrm{~mm}$. in diameter, lying somewhat deeply. The position of the nerve varies with the different attitudes of the forearm. In fat and fleshy horses the identification of the nerve is more difficult. It may be felt upon the standing animal.

With the nerve lying between the thumb and index finger of the left hand, at the point where it begins to disappear behind the radius after having passed over the humero-radial articulation stretch the superposed skin and immediately upon and parallel to it make an incision $5 \mathrm{~cm}$. long, first through the skin, then through the sterno-aponeuroticus muscle. Any hemorrhage from the skin, subcutis, or muscle, is checked. The tenacula are inserted cautiously in the lips of the wound, and these being drawn apart the white anti-brachial fascia is brought into view and a search is made with the index finger to determine the exact location 
of the nerve, and the fascia is divided with the scalpel and an oral piece excised with the scissors immediately orer it. If much fatty tissue is found between the layers of fascia it may be dissected away carefully with the scalpel or cut away with the scissors. There now comes to view a delicate reddish colored fascia-like membrane, the nerve sheath, behind which a blue cord, the brachial rein, $\mathrm{V}$, is visible, the latter being intimately connected with the nerve sheath. The rein lies mostly behind and beneath the nerve and may project ont from beneath the anterior border of the same. The operator needs be careful not to prick this vein with the tenacula, as the hemorrhage therefrom is exceedingly annoying during the operation. It is best to avoid the use of tenacula after penetrating the fascia and retract the wound lips cantionsly with the aneurism needles instead. Still further forward and deeper may be felt the pulsating brachial artery. Incise the nerve sheath carefully and divide it upward and downward with the scalpel or scissors, wherempon the yellowish and distinctly fibrons nerve comes into plain view. Pass an aneurism needle b neath the nerve then pass another alongside the first and drawing the two apart separate the nerve from the adjacent tissues throughout the length of the wound. Be careful to not cut the nerve too high and erroneously include the motor nerve of the flexor of the metacarpus and the flevors of the foot, which are generally given off posteriorly just below the humero radial articulation. Lift the nerve up and cut it through at the superior angle of the wound by a sudden clip with the scissors or with the probe pointed scalpel. Lay the peripheral end of the nerve bare to the lower angle of the wound, and excise at least $3 \mathrm{~cm}$. of it. Tamponade the wound with dry iodoform ganze and approximate the skin with a continuous suture. The tampon and sutures remain from I to 2 days.

Since sensation of the lower part of the limb is partly maintained by the deep branch of the nhar nerve which at 


\section{PLATE XXII.}

\section{MEDIAN NEURECTOMY.}

Median surface of the right humero-radial articulation. $a$, brachial artery; $n$, median nerve; $v$, brachial vein ; $f$, antibrachial fascia; $p$, sterno-aponeuroticus muscle. 


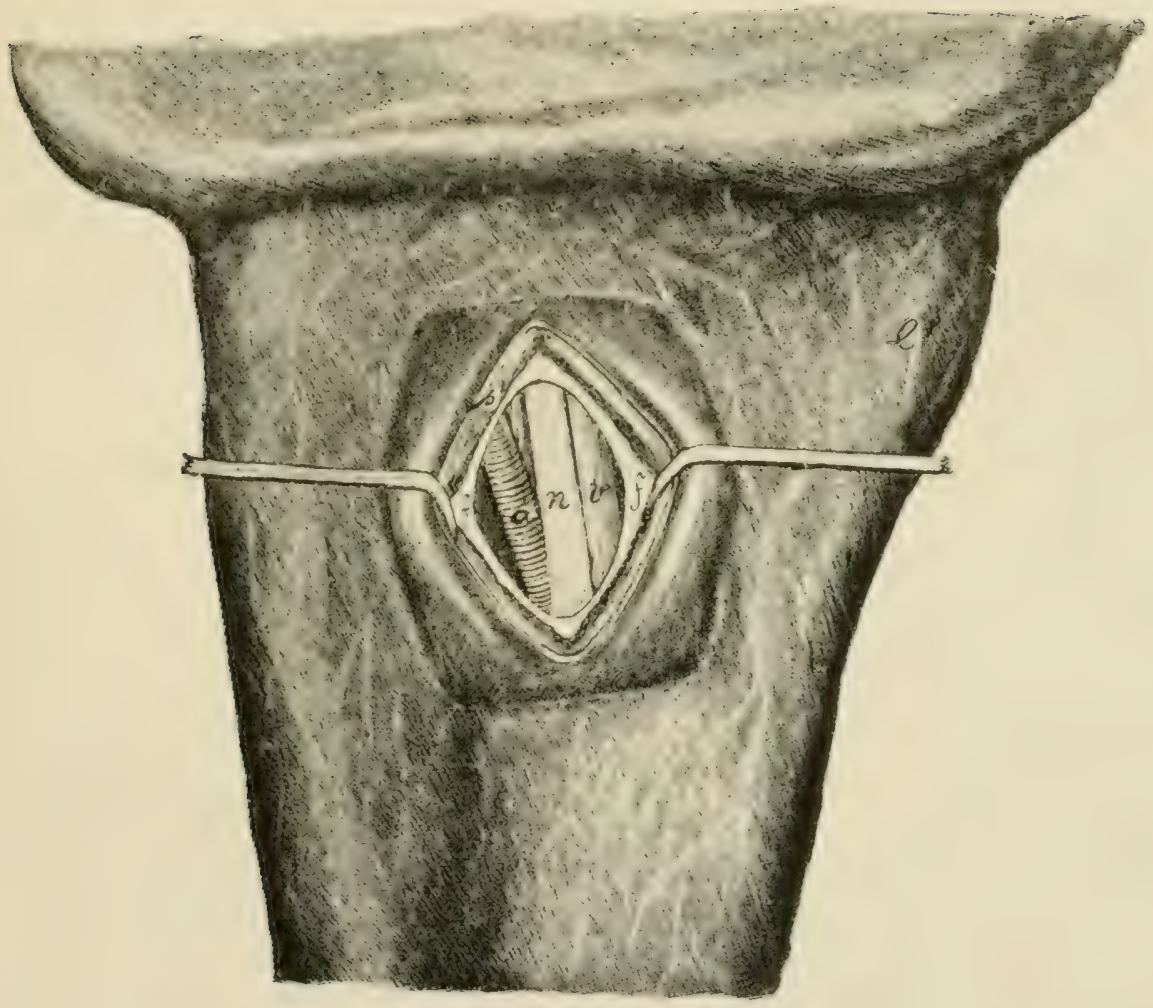



the lower part of the carpas, covered by the tendon of the oblique flexor becomes the lateral plantar nerve, neurotomy of the median nerve does not completely effect the desired end. In order to produce complete anaesthesia, therefore, from median, it is necessary at the same time to perform uluar neurotomy.

38. NEUROTOMY OF THE ULNAR NERVE.

\section{PLATES XXIII AND XXIV.}

Objects. An adjunct operation to the preceding by which the enervation of the carpus and foot is completed.

Instruments. Same as in the preceding.

Technic. Above and behind the carpus there may be felt a groove between the external and middle flexors of the carpus, EF and OF, Plate XXIV. At this point $10 \mathrm{~cm}$. above the pisiform bone the skin is shaved and disinfected and an incision $6 \mathrm{~cm}$. long made throngh the skin and antibrachial fascia. This incision extends just ontside the median line of the posterior surface of the radius in such a way that the superior angle of the wound is about $\mathrm{I} \mathrm{cm}$. farther ontward than the lower. Beneath the fascia between the aforesaid muscles is seen the ulnar nerve, Plate XXIII, n, Plate XXIV, NU, on the median or inner side of it the collateral ulnar vein, Plate XXIII v, and between the two and somewhat deeper the collateral ulnar artery, $a$. The nerve, about $3 \mathrm{~mm}$. in diameter is picked up with the aneurism needle, severed at the upper and lower angles of the wound, the lips of the wound united by a continuous suture and a bandage applied. Healing by first intention. 
PLATE XXIII.

ULNAR NEUROTOMY.

Right forearm seen from behind. $e$, external flexor of the carpus; $f$, oblique (middle) flexor of the carpus ; $a$, collateral ulnar artery $; b$, antibrachial fascia; $n$, ulnar nerve. 


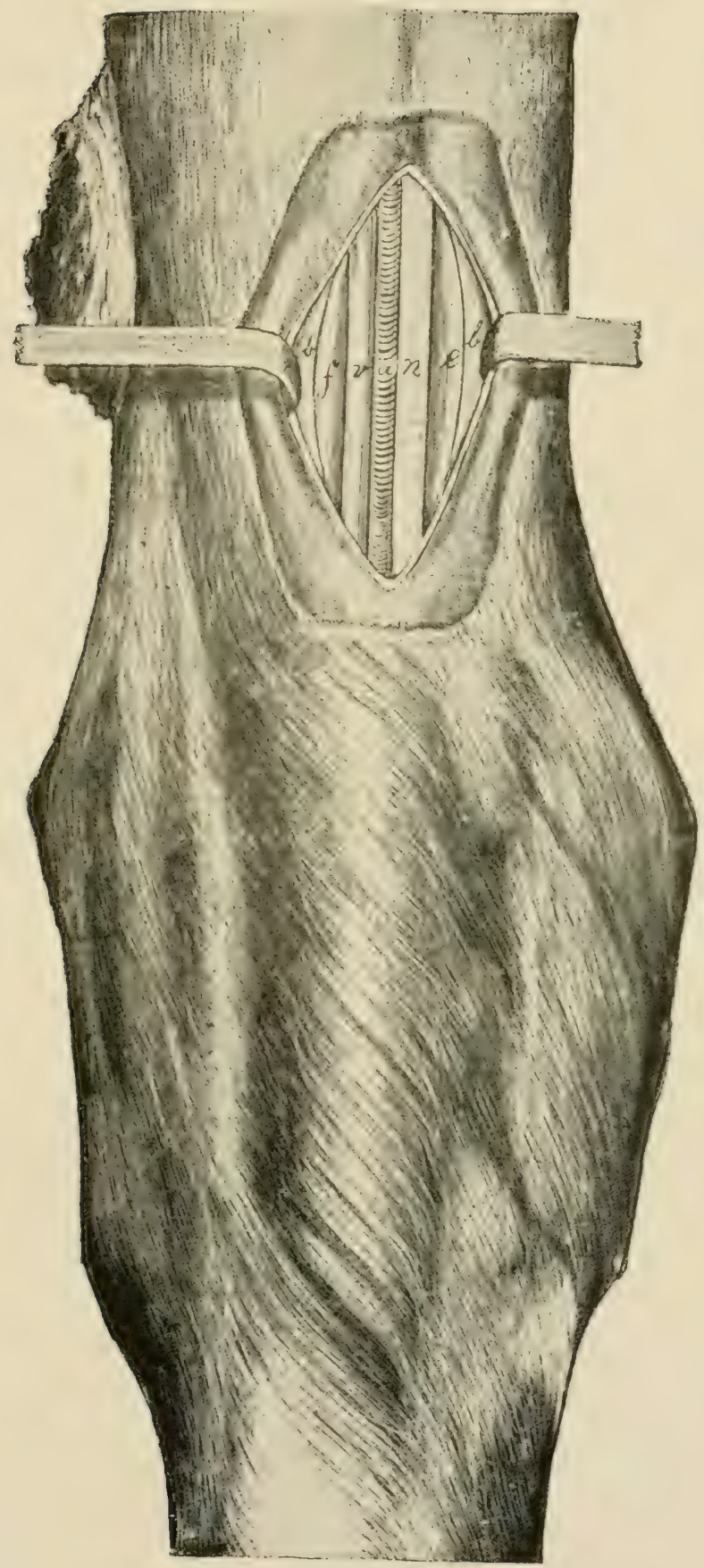


PIATE XXIV.

\section{ULNAR NEUROTOMY.}

Cross section through the radius of the limb about Io $\mathrm{cm}$. above the pisifurm bone, viewed from below. EF, external flexor of the carpus; OF, oblique flexor of the carpus; NU, ulnar nerve; NM, median nerve. Lying on its median side is the ulnar artery, the satellite vein of which is not shown. 


. 


\section{SCIATIC NEUROTOMY.}

\section{Plates XXV AND XXVII.}

Objects. The destruction of sensation in the tarsus and parts beyond for the relief of otherwise incurable spavin lameness, diseases of the tendons, etc.

Instruments. Same as in the preceding.

Technic. Place the animal on the operating table on the diseased side, extend the affected limb and draw the upper leg forward and secure it out of the way. Produce complete general anaesthesia. The posterior tibial or sciatic nerve $n$, Plate XXT, and XS, Plate XXVII, is then songht by grasping the leg with the left hand from behind in such a manner that the thumb rests above and the fingertips below it. Reaching forward with the fingers to the deep flexor of the foot grasp the leg with moderate firmness and draw the hand slowly backward. Immediately behind the perforans muscle and between this and the tendo-Achilles the nerve nearly I cm. in dianeter glides away forward from between the fingers with a distinct recoil. If the nerve can not be found in this manner the hock should be strongly extended, by which means it is caused to recede from the perforans muscle, so that it can more readily be felt near the middle of the groove extending between it and the tendo-Achilles. At this point the skin is shaved, disinfected and an incision made through it $5 \mathrm{~cm}$. long, parallel to the tendo-Achilles. The white rigidly-stretched crural fascia is now divided in the same direction after which it should be determined by palpation that the nerve lies in the middle of the wound. Excise with the scissors an elliptic or oral piece of the fascia or hold apart the fascia along with the lips of the cutaneous wound by means of the tenacula. In poor horses the contour of the nerve covered only by loose connective tissue stands out prominently, in fat horses it is surrounded 
PIATE XXV.

SCIATIC NEUROTOMIY.

Right hind leg viewed from the median side. $f$, crural fascia; $n$, sciatic (tibial) nerve; $v$, plantar vein. 


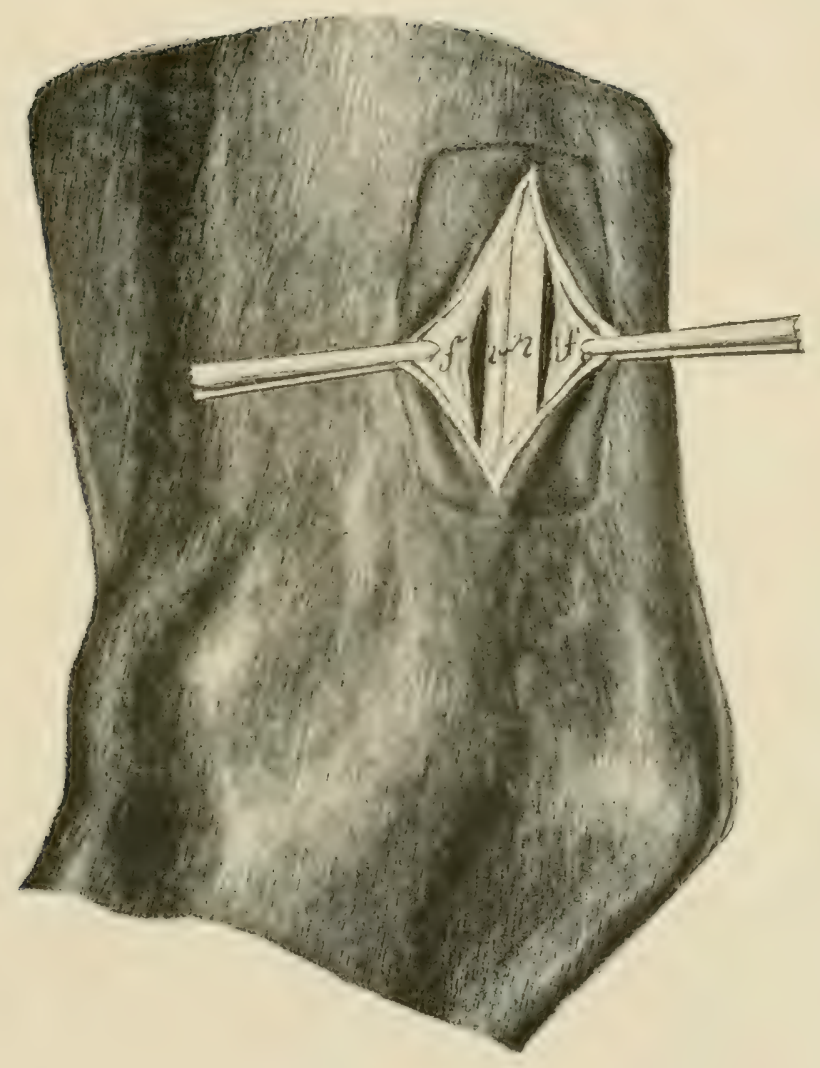





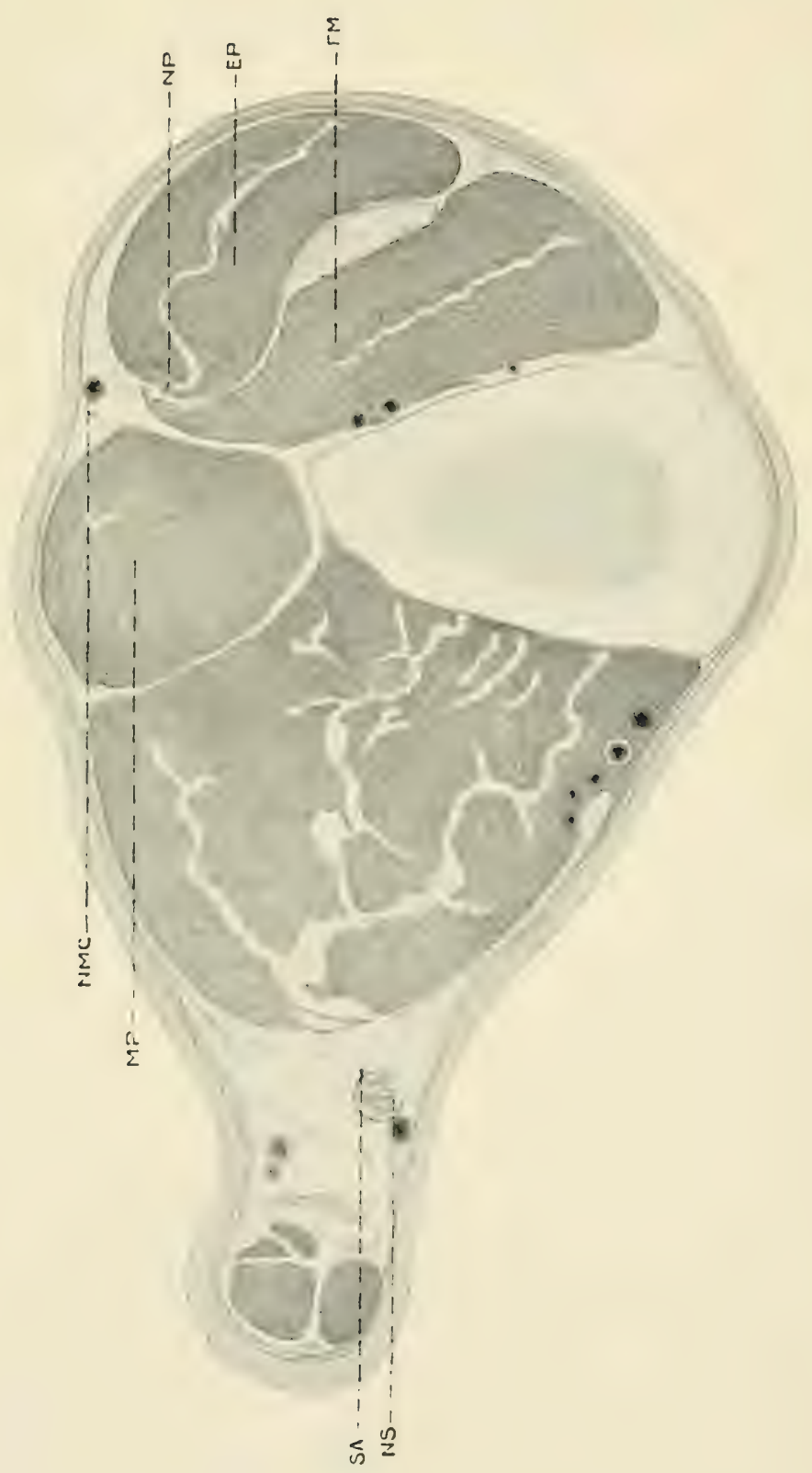




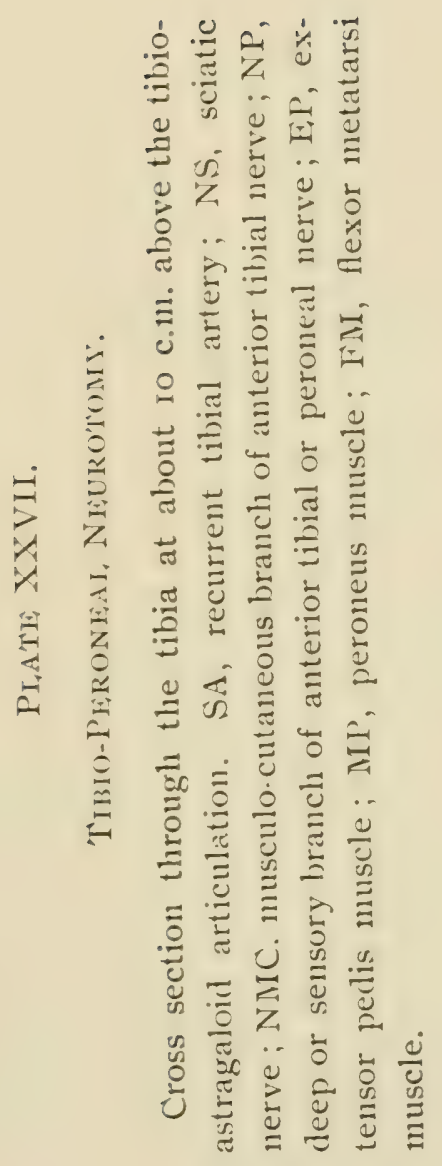




\section{PIATE XXYI.}

ANTERIOR TibIal, NeURotoity.

EP, extensor pedis muscle; P, peroneus muscle ; NP, deep branch of the peront al or anterior tibial nerve; FM, flexor metatarsi muscle. 


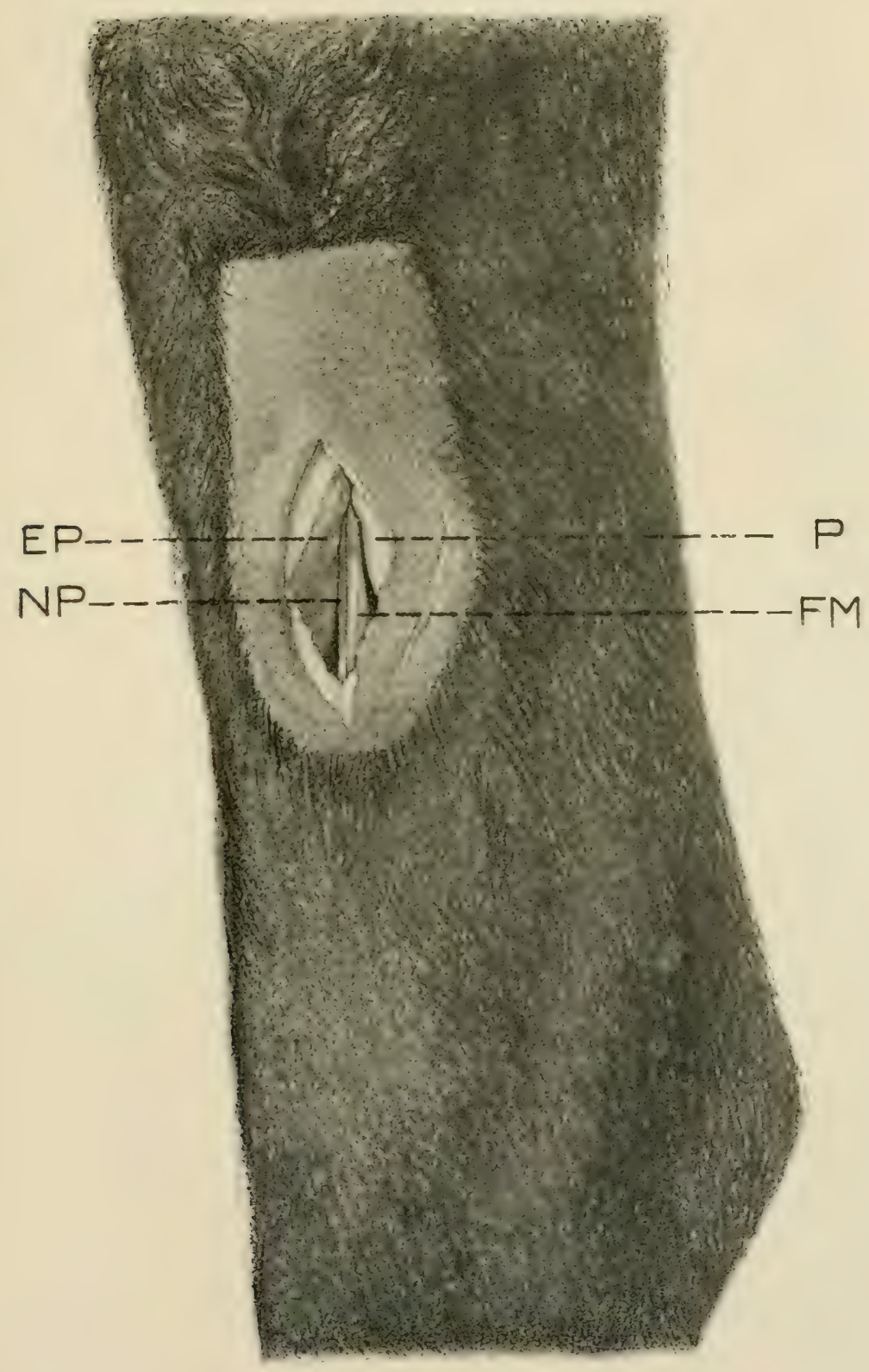



by a large amount of adipose tissue. Cut through this fat and connective tissue and the tibial nerve, $n$, Plate XXV and NS, Plate XXVII, is in sight, immediately before it lies the plantar vein and on the lateral side is situated the recurrent tibial artery SA, Plate XXVII. The cross section in Plate XXVII is located somewhat below the point for operation and the vein has crossed obliquely over the nerve so that it appears behind instead of in front of it, as is the case generally at the point where the operation is performed. Separate the ressels completely from the nerve with the handle of the scalpel, pass two anemism needles from before backward beneath it and drawing these apart separate the nerre trunk from the adjacent tissues and cut it off at the upper and lower angles of the wound remoring a section at least 5 cm. long. Suture the cutaneous wound and apply a bandage allowing it to remain eight days. Healing by first intention.

40. ANTERIOR TIBIAL NEUROTOMY.

Neurotomy of the DeEp Branch of the PERoneal Nerve.

\section{PLATES XXVI AND XXVII.}

Object. An adjunct operation to the preceding as it supplies sensation to the tarsus in common with the sciatic. The two constitute what is known as Bossi's double neurotomy for spavin.

Instruments. Same as in the preceding.

Technic. Confine as in the preceding but with the affected leg uppermost. Locate the furrow dividing the extensor pedis longus muscle, EP, Plates XXVI and XXVII, and the peroneus muscle, P, Plate XXVI, MP, Plate XXVII, and shave and disinfect the skin orer an area $6 \mathrm{~cm}$. long by $3 \mathrm{~cm}$. wide directly over this depression and extending up- 
ward from a point 6 or $7 \mathrm{~cm}$. above the tibio-astragoloid articulation.

At a point 8 to Io $\mathrm{cm}$. above the flexure of the hock make an incision through the skin and subcutis 5 or $6 \mathrm{~cm}$. long over the line of division between the two extensors of the foot. Superficially the operator passes near by the musculocutaneous division of the anterior tibial nerve, NMC, Plate XXVII, which must not be mistaken for the deep branch.

The peroneus muscle, MP, Plate XXVII, and P, Plate $\mathrm{XXVI}$, is separated from the extensor pedis longus, EP, Plates XXVI and XXVII, by a strong aponeurotic sheath continuous with the tibial aponeurosis. Penetrate the latter anterior to the aponeurotic partition directly against the extensor pedis, EP, and passing along its posterior border to a depth of 2 to $4 \mathrm{~cm}$.; there appears the thin margin of the flexor metatarsi magnus F.I, Plates XXVI and XXVII, which lies immediately against the extensor pedis withont a visible connective tissue partition but revealing itself by a markedly lighter shade of color and its ready separation with the scalpel from the extensor. The deep branch of the peroneal nerve, NP, Plates XXVI and XXVII, lies loosely imbedded on the anterior side of the margin of the flexor metatarsus facing the extensor pedis, at times visible at the margin, at others placed more deeply reaching in some cases a distance from the margin of 4 or $5 \mathrm{~mm}$. Within this range is seen the slender nerve trunk almost devoid of surrounding connective tissue and measuring about $2 \mathrm{~mm}$. in diameter. Pass the anenrism needle beneath it and remove a piece 3 to $4 \mathrm{~cm}$. long. Close the cutaneous wound with interrupted sutures and dress antiseptically without a bandage. 
RESECTION OF THE LATERAL CARTILAGE. 165

4I. RESEC'TION OF 'THE LATERAL CARTILAGE.

PLATE XXVIII.

Object. The cure of quittor or necrosis of the cartilage. Instruments. Elastic ligature, drawing knife, scissors, razor, hoof rasp, hoof plane, craniotomy or other heavy forceps for the removal of the horn, artery forceps, elevator or long bone chisel, double-edged sage knife, curette, needle holder, thread, needles, iodoform ether, iodoform gauze, tampons, absorbent cotton, bandages.

Technic. For a few hours before the operation place the affected foot in a bath of creolin solution after having first made a semicircular groove in the horn of the lateral wall and quarter down to the horny lamina, as shown at $s$ in Fig. I, Plate XXVIII.

The operation is performed upon the recumbent anaesthetized animal, in such a position that the diseased cartilage of the affected foot lies upward. The operating table constitutes incomparably the best means of confinement in every respect. After the application of the elastic ligature the groore in the horn is deepened with the drawing knife down to the sensitive laminae without injuring them. 'The groove must be so located that it extends beyond the anterior and posterior borders of the lateral cartilage, remaining a few $\mathrm{cm}$. distant from the bearing surface of the wall and approximately perpendicular to the surface of the horn wall so that it will form a secure support for the dressing to be later applied. The hair on the coronary band is clipped or shaved and the entire foot up to the fetlock joint thoroughly cleansed with brush, soap, creolin or sublimate solution and 50 per cent. alcohol. The levator or long bone chisel is then inserted beneath the lowest part of the semi-circular piece of horn which has been isolated, the horn is elevated from the sensitive structures somewhat. grasped with the heavy forceps and carefully loosened from the sensitive laminae by drawing upward parallel 
to the laminae and then backward from the coronary papilla and keraphyllous tissue. After the coronary band has been smoothed with the scissors, make two perpendicular incisions through the skin of the coronary band and the band itself, one behind the anterior and the other in front of the posterior border of the groove in the horn and connect the two by means of a semi-circular incision in the sensitive laminae. 'This U-shaped incision must be so made that between it and the horny wall there is left an area of sensitive laminae at least $2 \mathrm{~cm}$. wide, in order that there may be suffcient room in the soft tissues for the application of the sutures, as shown in Fig 2. The isolated flap is now dissected closely against the os pedis and its ala and later from the lateral surface of the cartilage, the operator first lifting the flap with forceps, later with the hand. Above the cartilage toward the fetlock the operator must keep the fingers of one hand against the external skin in order to avoid cutting through it or thinning it too much at this point. The flap is held turned upwards by an assistant or by a suture. As a rule there is now seen a prominent, greenish colored necretic piece of cartilage surrounded by brownish red masses of granulations. By means of an incision through the cartilage parallel to the axis of the foot, divide it into anterior and posterior halves and extirpate the latter first, by dissecting it ont on the inner side from the parachondrial tissue with the double-edged sage knife. The point of the knife must be constantly directed against the cartilage. Since the inner surface of the anterior half of the cartilage lies immediately against the capsular ligament of the coronopedal articulation the latter should be sharply extended by which means the capsular ligament is drawn away from the cartilage during its extirpation. The anterior half of the cartilage, $k$, is then removed in the same way, except with the greatest possible care to avoid puncturing the coronopedal articulation. Remnants of cartilage at its juncture 


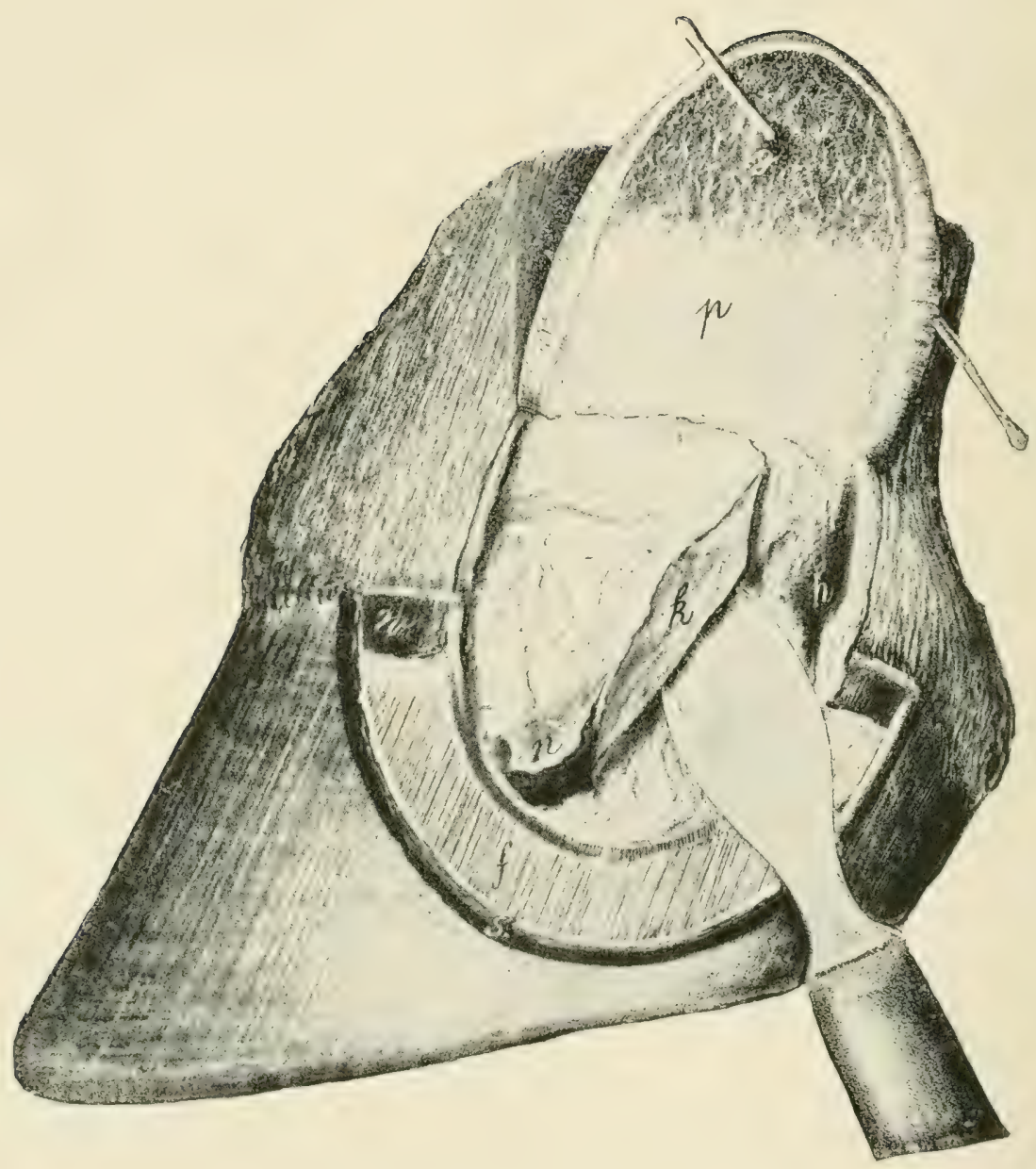

FIG. I.

RESECTION OF THE LATERAI, CARTILAGES OF THE OS PEDIS.

Horny wall removed, sensitive laminæ and cutaneous flap held upwards. Posterior half of the cartilage excised. $f$, sensitive laminæ; $w$, coronary band; $k$, anterior half of cartilage ; $h$, cavity caused by the removal of the posterior half of the cartilage $; n$, necrotic cartilage; $p$, parachondral surface of the skin and sensitive lamina ; $s$, perpendicular, crescent-shaped incision in the horny wall; $g$, fistula. 
XXVIII.

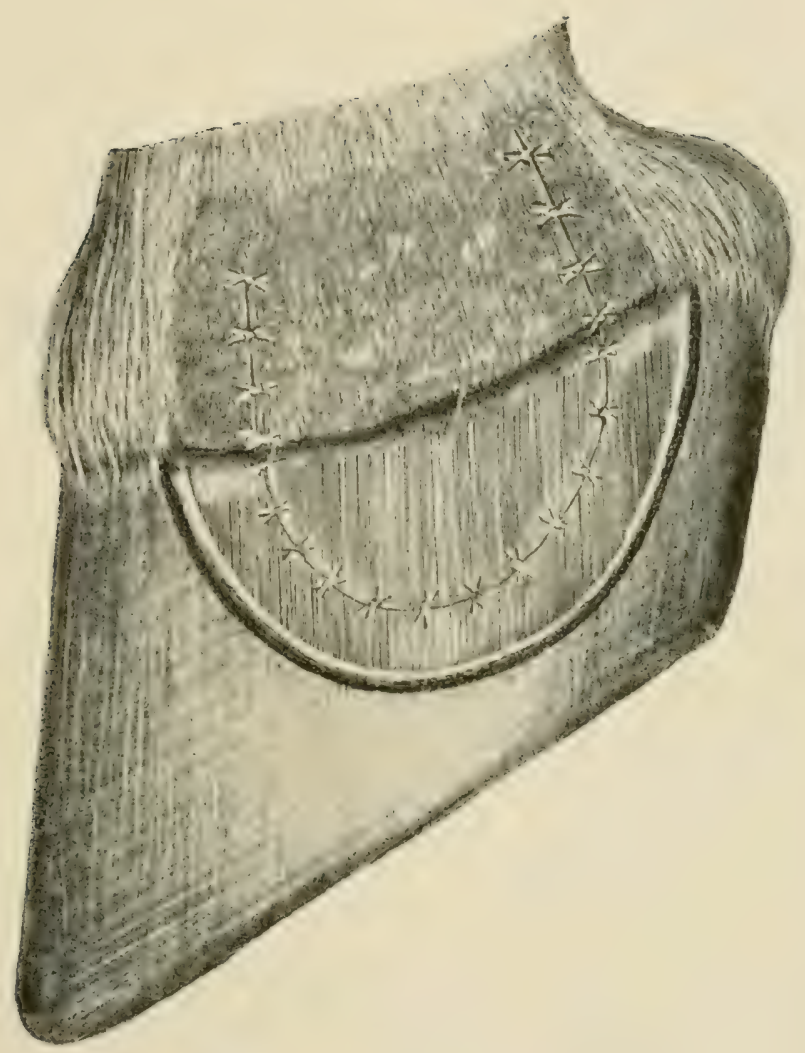

FIG. 2.

RESECTION OF THE LATERAL CARTIIAGES OF THE OS PEDIS.

Completed operation showing the sutures in place and the parts ready for the application of dressings. 

with the retrossal process of the os pedis, and granulations are to be removed with the curette. Cut away with the scissors and knife any remnants of cartilage adherent to the flap, $p$, thin if necessary the entire flap and excise the fistulous openings, $g$. After thorough disinfection of the entire field of operation return the flap to its former position and retain it there by a sufficient number of interrupted sutures, Fig. 2, irrigate the wound surface with iodoform ether and cover the parts over with iodoform gauze and tampons which rest firmly upon the perpendicular wall of horn. Finally inrest the hoof and pastern up to the fetlock joint with oakum and lay a heary tar bandage over it, the turns of which must completely invest it at every point and render the dressing impermeable to moisture. Remore the elastic ligature. If the animal is free from ferer, feels and eats well, the bandage is left in position from I 2 to 14 days. Healing by first intention. 
42. RESECTION OF THE FLEXOK PEDIS TENDON.

FirG. I 2 .

Object. The removal of necrotic tissues and disinfection in cases of infected wounds, chiefly of nail pricks of the navicular bursa.

Instruments. Elastic ligature, drawing knife, doubleedged sage knife, scissors, tenaculum forceps, curette, scalpels, tenaculæ, bandage material.

Technic. Before the operation thin the horn of the sole, frog and bars until the soft parts can be seen through them and apply an antiseptic bandage saturated in creolin solution for 24 hours if time will warrant. Secure the patient on the operating table or by casting in lateral recumbency with the affected foot extended. Anaesthetize. Cleanse and disinfect the entire foot with soap, brush, creolin or sublimate solution and 50\% alcohol and apply the elastic tourniquet in the metacarpal or metatarsal region. Make a transverse incision through the base of the frog 2 to $3 \mathrm{~cm}$. from the balls through the horny and sensitive portions and the fatty cushion down to the flexor pedis tendon. Follow this by two curved incisions extending forward and inward in an oblique direction corresponding to the semi-lunar crest of the os pedis, the line of incision being in the bars about $1 / 2 \mathrm{~cm}$. ontward from the lateral groove of the frog and uniting at its apex. This triangular piece of frog which has been isolated by the incision is now grasped with the tenaculum and dissected away. As a general rule the operator finds that he has not yet reached the flexor pedis tendon but only the fatty cushion which covers the latter. The remnants of the fatty frog should be removed with the double-edged sage knife or scalpel by means of a horizontal incision, and there is then seen the greenish or yellowish colored necrotic flexor pedis tendon, which may at times be covered with 
reddish colored granulations. Should the operation be indicated on account of a suppurative pododermatitis the bars on the affected side must be excised along with the other portions. The position and extent of the navicular bone can be determined by feeling through the flexor tendon. A transverse incision is then made over the middle of the navicular bone through the flexor pedis tendon into the naricular bursa, the distal end of the tendon grasped with

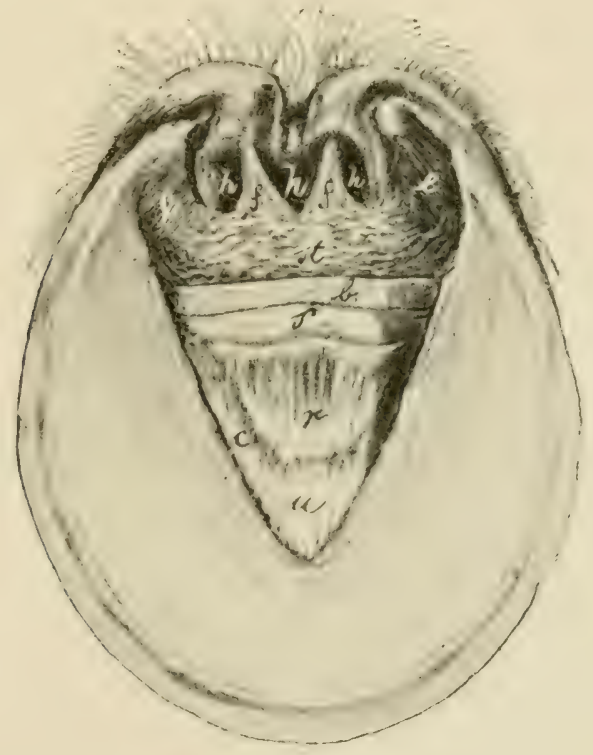

FIG. I 2.

RESECTION OF THE FLEXOR PEDIS TENDON.

Solar surface of the foot. $c$, Semilunar crest of os pedis; $u$, os pedis; $r$, navicular-pedal ligament; $s$, navicular bone; $b$, flexor pedis tendon; $e$, sensitive laminæ of the bars; st, fatty frog $; f$, sensitive frog; $h$, horny frog.

the tenaculum forceps and lifted up from the navicular bone with the aid of two lateral curved incisions. Between the inferior border of the navicular bone and the semi-lunar crest of the os pedis stretches the capsular ligament of the inferior articulation between these two bones reinforced by dense fibrons bands. The flexor pedis tendon is mited to 
this by a few bundles of fibres. Dissect the tendon carefully away from the capsular ligament, avoiding opening the articulation, and beyond from the semi-lunar crest of the os pedis. If necrotic or discolored pieces of the fatty cushion or the tendon still remain, remove these with scissors, scalpel or curette. With the latter, currette the roughened cartilage of the navicular bone and remove any necrotic portions. In extensive necrosis of the suspensory ligaments of the heel and of the ligaments extending from the fetlock joint to the lateral cartilages, the necrotic portions as well as the neighboring fatty cushion with its numerous elastic fibres, must be resected. Disinfect the operation wound, irrigate with iodoform ether and tamponade it with dry iodoform gauze. Over this apply a firm pad of oakum, enclose the entire hoof up to the fetlock in oakum and apply over this a bandage. Over this apply a tar bandage and remove the elastic ligature. In the absence of fever the bandage remains in position for eight days.

\section{AMPUTATION OF THE CLAIVS OF RUMINAN'TS.}

\section{PLATE XXIX.}

Uses. The cure of "foul in the fout" or panaritium when complicated with suppurative arthritis or osteitis.

Instruments. Half round rasp, double-edged sage knife, scissors, convex scalpel, artery forceps, drawing knife, elastic ligature.

Technic. Cast the animal and secure the foot to be operated upon in an extended position, apply the elastic ligature after disinfecting the claws with soap, water, brush and creolin solution, rasp away the horn on the lateral side of the diseased claw, especially at the posterior part of it, until the horny wall becomes so thin that it can readily be pressed in with the fingers. Anaesthetize. The corono- 
pedal articulation can be felt, about $3 \mathrm{~cm}$. below the coronary band, by grasping the claw with the left hand in such a manner that the thumb rests upon the thinly rasped horn while with the other hand the claw is moved from side to side. At the lowest point of the articulation push the doubleedged sage knife into the joint, the concarity of the knife being directed toward the fetlock, and make a curved incision at first forward and upward to the neighborhood of the coronary band, then with stiong flexion of the foot a second curved incision backward and upward which, however, extends only to the navicular bone. By this incision the operator divides the horn, the sensitive lamina, the external corono-pedal ligament and the capsular ligament of the corono-pedal articulation. Pass the knife between the naricular and pedal hones and extend the incision downards perpendicular to the solar surface through it, separating the navicular bone from the os pedis. In this manner the navicular bone is preserved as well as the ball of the heel, the latter of which is of special significance in healing. The inner wall of the claw with the powerfully dereloped coronopedal ligament is dirided from before backward. After the ressels which can be seen are ligated, the articular surfaces of the naricular and coronary bones curetted and the necrotic remnants of tendon remored an antiseptic bandage is applied and a tar bandage placed over it for protection. The bandage remains for 12 or 14 days.

If the structures above this point of amputation are irremediably inrolved the digit should be amputated higher up, at the articulation of the first and second phalanges or through the first phalanx. In these higher amputations a flap operation is generally practicable. 


\section{PLATE XXIX.}

AMPUTATION OF THE CraWS OF RUMINANTS.

FiG. I. $d$, horny wall, rasped thin ; $g$, articular condyle of 2nd phalanx; $a, b, c$, course of incision.

Fig. 2. Median claw preserved. Viewed from the solar surface outward. $a$, external corono-pedal ligament; $i$, internal do ; $k$, tendon of the flexor pedis muscle; $g$, distal articular surface of the 2nd digit; $g^{\prime}$, articular surface of $3^{\text {rd digit } ; ~} g^{\prime \prime}$ navicular bone ; $l$, lateral claw ; $m$, median claw; $b$, bulb of the heel. 


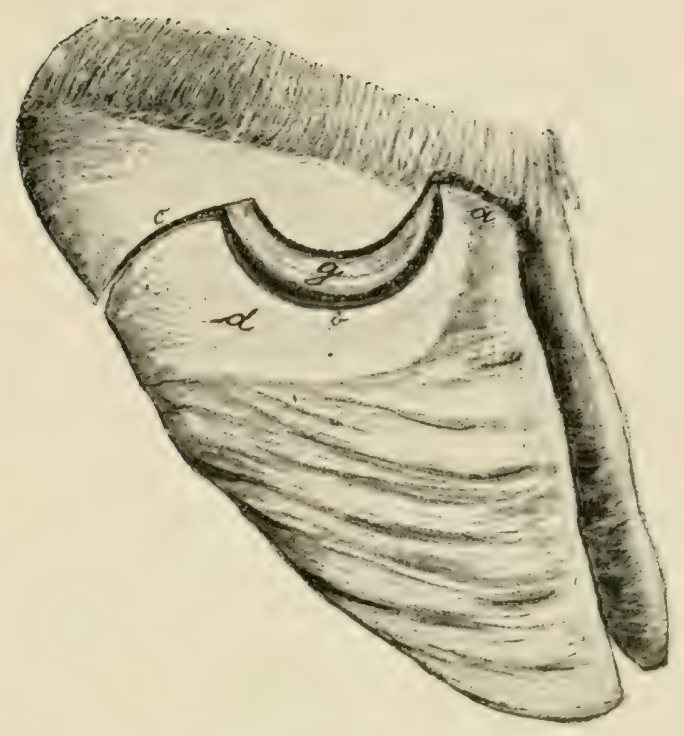

IifC 1 .

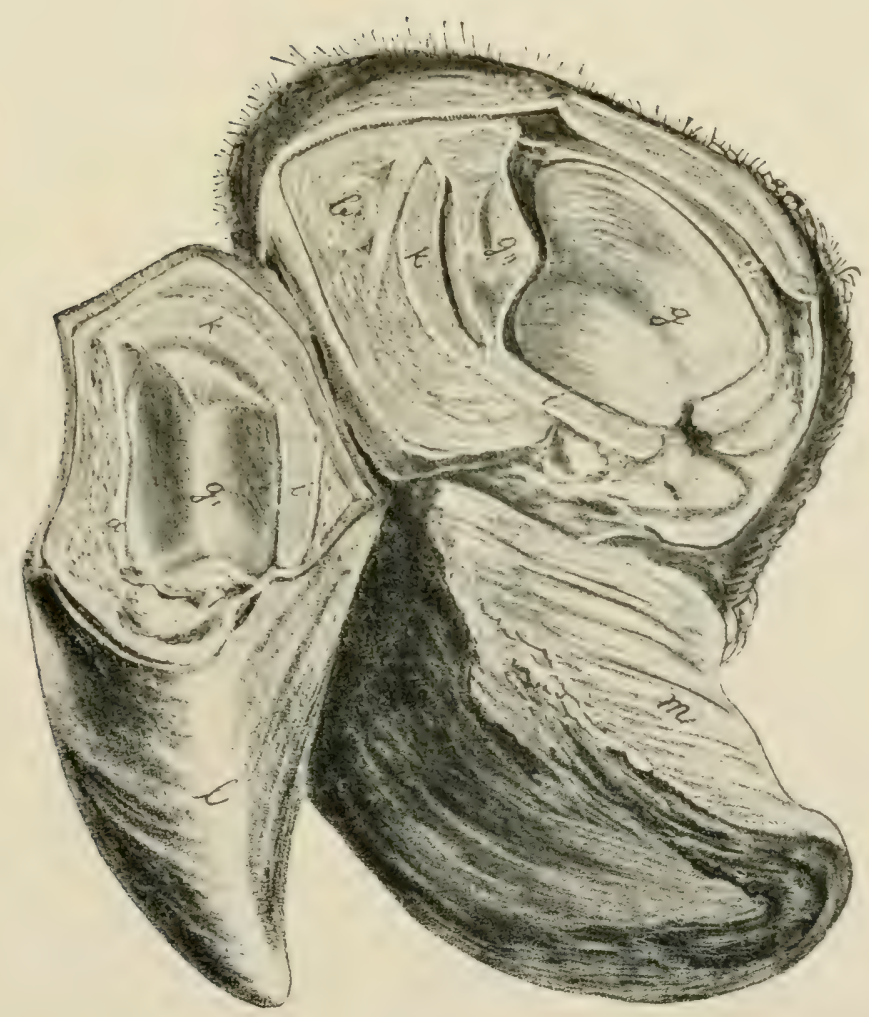

Fig. 2. 

44. THE BAYER SUTURE.

FIG. I 3 and I 4.

Uses. The closure of large or penetrant wounds with convenient and secure means for applying and retaining antiseptic dressings.

Instruments. Large curved suture needle armed with strong silk thread, about $20 \mathrm{~cm}$. long, which is doubled and

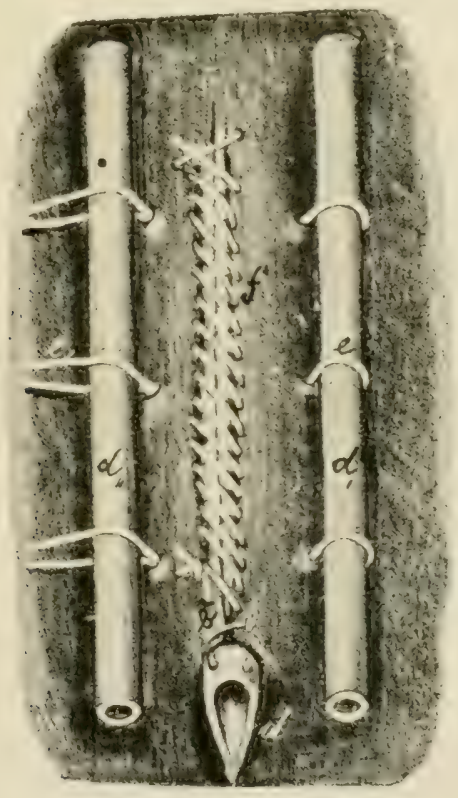

FIG I3.

RETENTION, AND CONTINUOLS APPROXIMATION SUTURES.

$d, d^{\prime}, d^{\prime \prime}$, drainage tuhes ; $e$, retention suture (closed end); $e^{\prime}$, open end; $b$, fixation suture for the lrainage tube $f$, continuous approximation suture.

passed through the eye in such a manner that the closed end extends considerably beyond the cut ends; small needles and thread; needle forceps; drainage tubing preferably two very large and one small with lateral openings; thin wooden! 
splints I $5 \mathrm{~cm}$. long, 2 to $4 \mathrm{~cm}$. wide, with rounded ends; iodoform gauze; iodoform ether I: ro.

Technic. After the skin has been shaved over an area having a radius of 5 to $6 \mathrm{~cm}$. from the wound, the suture needle is inserted 2 to $3 \mathrm{~cm}$. from the lips through the skin and subjacent tissues, a strong drainage tube, $d^{\prime}$, passed

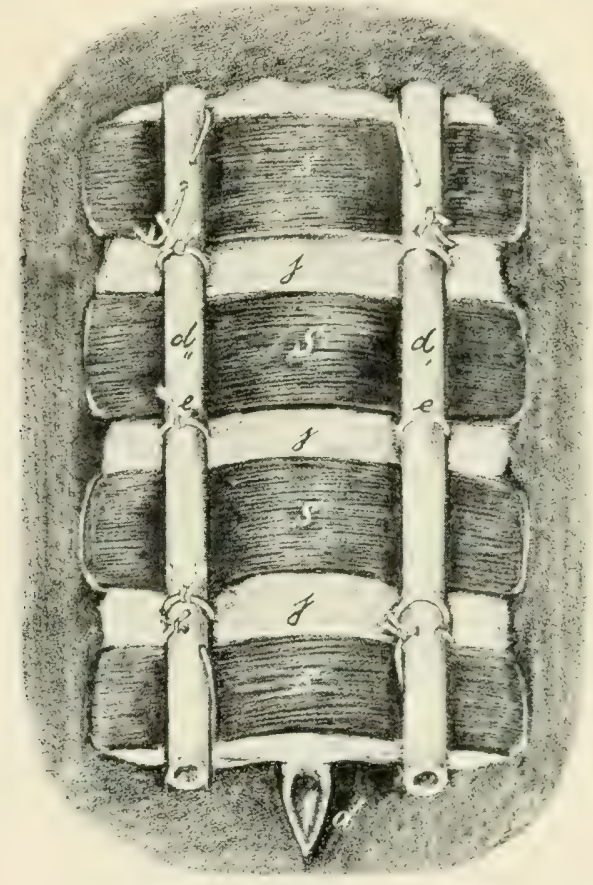

Fig. I 4 .

SPLINT BANDAGE

$d, d^{\prime}, d^{\prime \prime}$, drainage tubes; $e$, retention suture (closed end); $e^{\prime}$, do, open end $; j$, iodoform gauze ; $s$, splints.

through the closed end of the suture and the thread drawn tight. If before threading the needle a clore hitch is made at the middle of the thread, or if threaded as above directed and the thread is thrown about the tube in a double noose, the two threads will be kept in contact as they leave the tube and enter the soft tissues and thus prevent to some degree, the pressure necrosis otherwise taking place, due to the tense 
threads of the suture separating from each other. The needle is then passed through the opposite lip of the wound from within to without at the same distance from the lips, the needle remored, the free ends drawn tant and a single knot tied against the skin to prevent the separation of the two threads for the reasons just stated above, the second large drainage tube, $d^{\prime \prime}$, is laid between the open ends of the double silk thread and these are tied upon it with a triple knot, after they have been drawn sufficiently tight that the approximated wound lips form a crest. If the lips of the wound can be grasped with the hand and held together in such a manner as to form a ridge 3 or $+\mathrm{cm}$. high, the suture needle can be passed through both simultaneously. The first suture should be located about $3 \mathrm{~cm}$. beneath the upper angle of the wound, the other retention sutures follow at distances of about $5 \mathrm{~cm}$. from each other and applied in the same way. The lips of the wound are united by continuous approximation sutures like an orercasted seam. This suture ends at least $2 \mathrm{~cm}$. above the lower angle of the wound. The third drainage tube is introduced into the latter and fixed by a special suture. The entire cutaneous surface lying between the drainage tubes is corered with iodoform gauze, and between each two retention sutures there is laid over this gauze the wooden splints previously cut to the proper size, the ends of which are shoved under the tubing. The upper- and lowermost splints should be secured to the drainage tubing by means of sutures passed through them. 'The entire bandage is finally saturated with iodoform ether. The bandage and retention sutures remain eight days, the approximation sutures fourteen. 



\section{EMBRYOTOMY OPERATIONS.}

General Considerations. 'The following exercises in embryotomy operations are designed to gire to the student a general view of the subject by a simple plan as carried ont through the aid of a skeleton provided with an artificial uterus into which are placed freshly killed, newly born calves in such a position as may be desired and the operations carried out by the student as described. At the same time it is hoped to offer throngh these descriptions to the veterinary obstetrist a simple and effective plan for performing embryotomy which has been fully tested by the anthor in an extensive obstetrical practice. In describing these operations we purposely limit the instruments to be used to the fewest number and simplest kinds, yet using all that are essential in the performance of any of the following obstetrical operations. We designate the same instruments for each operation. They are: a hooked ring knife; a Colin's scalpel like Fig. I i an embryotomy chisel I m. in length, the handle $1.5 \mathrm{~cm}$. in diameter with a ring end, the blade about ro cm. long by $4 \mathrm{~cm}$. wide and 2 to $3 \mathrm{~mm}$. thick, the cutting edge concare from side to side and the corners dull and rounded; mallet; several cotton ropes I cm. in diameter with a small spliced loop at one end.

\section{CEPHALOTOMY.}

Object. The diminution of the size of the head on account of its oversize or of the smallness of the maternal pelvis, so that it will pass through the pelvic canal.

Technic. In these cases the head is usually engaged in the canal sufficiently tight that no further fixation is necessary. After thoronghly cleansing and disinfecting the parts 
inject a copious amount of tepid lysol solution into the vagina, then carry th: chisel carefully guarded by one hand into the passage and place it accurately upon that part of the head of the fœtus where it is desired to begin the operation; generally on the median line of the nose with the blade of the chisel standing parallel to the septum nasi of the fetus. Holding the blade of the chisel firmly against the part with one hand in such a manner as to effectively guard the instrument from slipping aside and wonnding the maternal organs, steady and direct the handle with the other hand and have an assistant drive the chisel by means of blows of proper vigor with the mallet into the bones of the face and head. Do not drive the chisel deeper than the length of the blade withont stopping and forcibly revolving the chisel upon its long axis and breaking the fotal bones apart. The partially detached pieces of bone may be torn away with the fingers or in case the skin is quite adherent to them the bone may be held with the fingers of one hand, the chisel introduced with the other and using it as a spatula separate the skin from the bone. Repeat the use of the chisel as often as may be necessary in order to bring about the required diminution of the head, care being taken at all times to not wound the maternal parts and to conserve as far as practicable the skin of the face and head in order that it may protect the maternal parts from the jagged bones during the passage of the remains of the head. The removal of the partially detached pieces of bone may in many cases be greatly facilitated by looping one of the cords over them and having an assistant apply traction sufficient to pull them away, the operator guarding the maternal organs by holding the piece of bone during its detachment and extraction, in the palm of his hand. 


\section{DECAPITATION.}

Objects. The facilitation of repulsion and correction of deriation of fetal parts. The operaticn is generally carried out when the foetal head is far advanced in the pelvic canal or has passed beyond the vulva.

Technic. Attach a cord to the inferior maxilla or around the neck of the foetus and have one or more assistants draw the head out as far as possible. Make a circular incision throngh the skin encircling the head at a convenient point and separate the skin backward toward the occiput by forcing the hand between it and the bones or by using the chisel as a spatula or dissecting it away with the Colin's scalpel, continuing the separation over the occiput to the atloid region. Make a transverse incision below across the trachea and cesophagus and surrounding muscles and above through the ligamentum nuchae. Grasp the head firmly with both hands and twist it forcibly on its long axis rupturing the articular ligaments and the remaining muscles and other soft tissues, detaching the head at the occipito-atloid articulation. The remoral of the head greatly diminishes the bulk of the foetus and it may now he repelled, or deriated parts brought into the desired position or other operations performed.

\section{SLBCLTANEOCS AMPUTATION OF ANTERIOR LIMIB.}

Objects. Amputation of the anterior limbs is very frequently called for in obstetric practice especially in the mare, chiefly in cases of transverse presentation with all four feet presenting where it may be impossible to safely correct the deriation, in cases of wry neck in the foal in the anterior presentation, dorso-sacral position when it is impossible to correct the deviation of the head or in any case in the mare or corv where deviation of the head cannot 
be corrected or is not so readily overcome as is the amputation of the limb.

Technic. Our larger herbivorous animals being devoid of a clavicle, the anterior limb is attached to the thorax by means of the skin and muscles only and is therefore comparatively easily amputated. Attacin a cord to the pastern of the limb, the shoulder of which lies most exposed or is most readily reached and have one or two assistants exert traction on it and draw the limb ont as far as possible with safety to the mother. Insert one hand armed with the hooked embryotomy knife up to the top of the scapula or as nearly thereto as can be reached, the knife being well guarded in the palm of the hand which rests against the limb of the foetus; press the knife into the skin and subcutaneous tissues and drawing the hand downward slit them freely and deeply from the top of the scapula down to the pastern. Lay aside the knife and force the fingers between the skin and subjacent tissues of the limb and while the assistant maintains gentle traction upon the limb separate the skin upward by forcing the hand or the ball of the thumb throngh the loose connective tissues until the upper region of the scapula is reached. The separation of the skin from the subjacent parts may require at certain points, like the olecranon or carpus, the aid of the chisel or knife to divide firm bands of connective tissue. This separation of the skin from the subjacent parts has removed the chief source of resistance to the tearing of the limb away from the body. The next most important obstacle is the pectoral muscles which should be torn asunder by separating them into small bundles and tearing them through with the fingers between the sternum and limb, or the process may be aided by incision with a knife or with the chisel. When these are well divided the remaining impediments to tearing the shoulder away consists largely of the trapezius and rhomboldeus muscles at the top, the latissimus dorsi behind and the great serratus and the angularis scapula which 
only come into action when the shonlder is nearly severed. It is only necessary then to separate the skin from the limb and divide the pectoral muscles in order to readily draw the limb away by traction. Divide the skin now aronnd the pastern and have two or three assistants exert traction upon the limb while the operator places his hand against the sternum and pushes in the opposite direction. The impact upon the maternal organs due to the traction may be reduced to almost any desired degree by applying a repelling force to the sternum of the fetus so that the impact upon the maternal organs equals the difference between the traction applied npon the cord and the repulsion applied to the fetal sternum. If traction does not bring the limb away prompty the op rator should attempt to extend the dirision of the muscles attaching the limb to the thorax while moderate traction upon the limb is continued. Further diminution of the size of the fetus may now be had by removal of the other limb in the same way which is especially desirable in the transverse presentation of all four limbs in the passages or we may reduce the size of the trunk by evisceration as described under 53 .

This diminution suffices to permit the remnant of the fetus to be withdrawn with the liead deviated to the side, the total resistance being no greater than had the head and neck presented normally. This diminution also makes the foetal body rery flaccid, rendering it easy of repulsion and simplifies the correction of deviations of any parts.

\section{AMIPUTATION AT HLMERO-RADIAL ARTICULATION.}

Object. Amputation at this point is rarely desirable, but may at times be necessary in the mare in order to remove an anterior limb when it is impossible, on account of the position to reach the shoulder.

Technic Attach a cord to the pastern and have an 
assistant render the leg tense by exerting moderate traction, as in the preceding. Introduce the hand armed with the embryotomy knife, carefully concealed in the palm, and girdle the skin around the articulation. Passing above the head of the olecranon on the posterior side, divide the attachment of the anconean group of muscles with the knife by cutting from behind forward. Then divide transversely, as far as possible, the muscles and ligaments passing over the articulation. Rotate the limb forcibly on its long axis while strong traction is maintained, and rupture the principal ligaments until the limb is completely detached and comes away. In cases of limited room it may sometimes be easier to detach the skin of the limb from the pastern up to the articulation, as in the preceding chapter, rather than to girdle the skin at the articulation.

\section{DETRUNCATION.}

PLATE XXX.

Object. In case a fetus in the anterior presentation and dorso-sacral position has one or both posterior limbs deviated forward and the feet engaged in or against the pubis, it is necessary, or at least advisable in the mare, that the trunk of the fetus be divided in order to bring about delivery without serious or fatal injury to the mother.

Technic. Secure the two hind feet by means of cords, if possible, prior to other manipulations. Apply cords to the two anterior limbs and the head, have one or two assistants draw the anterior part of the fetus as far out as is practicable and safe, and then girdle the fotal body immediately against the maternal rulva by making an incision through the skin and skin muscle. If practicable it is best at this point to remove one shoulder subcutaneously, 47, and follow with evisceration, 53, in order to give greater operative room and increased mobility of the fœtus. Insinuate the 
. 


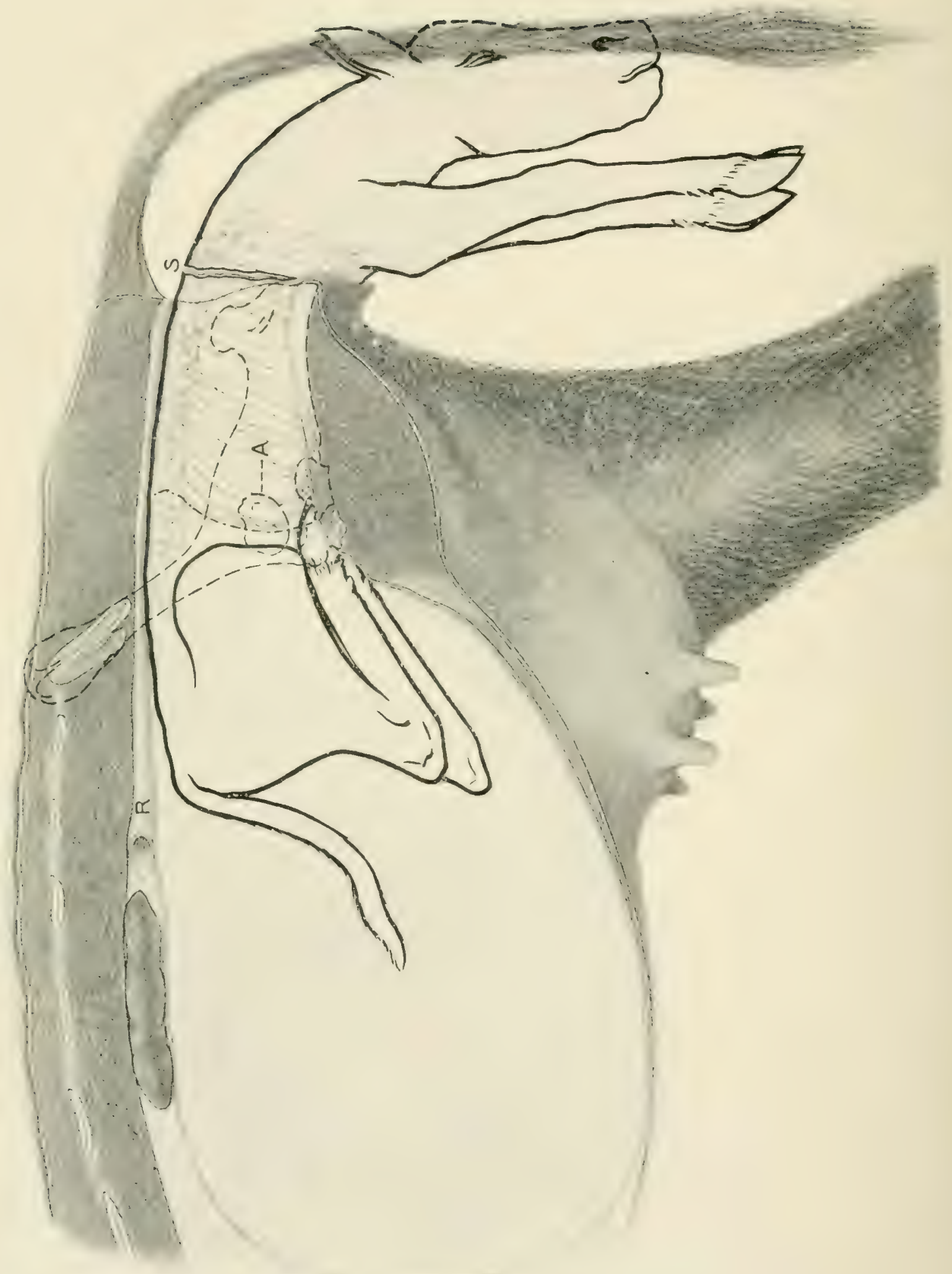




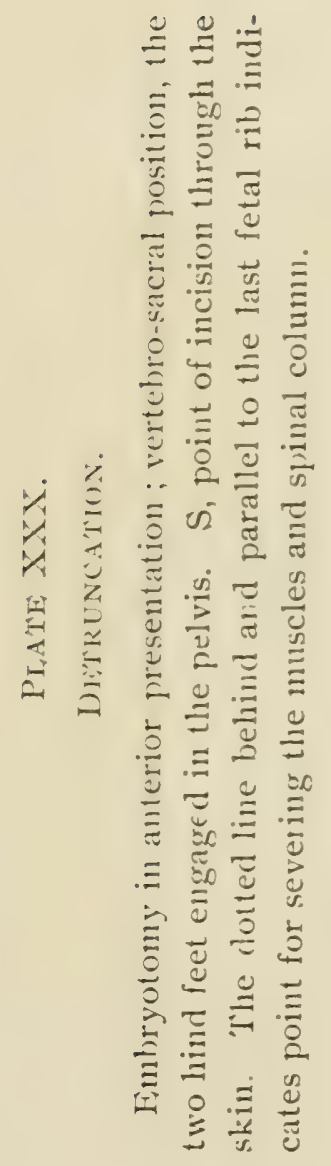


hand between the skin and the deeper structures and forcibly separate it from the fotal body backward until the last rib is passed, as shown at the curved line on the posterior border of the last fotal rib in Plate XXX. Force the finger tips throngh the abdominal wall behind the last rib and passing along the entire border of each posterior rib, separate the abdominal walls from the ribs and sternum. After the abdominal muscles have been detached from the posterior ribs and sternum, and the fœtus has been eviscerated, rotate the thorax upon its long axis which will cause a division of the vertebral column near the dorso-lumbar articulation and the anterior portion of the fotus falls away. Secure the two posterior feet with cords, minless this has already been done, spread the detached skin which has been pushed back from the thorax, carefully orer the amputation stump of the lumbar vertebrae, repel these by means of the hand while an assistant draws upon the cords attached to the feet, push the remnant of the foetal trunk into the uterus and advance the feet along the genital passages, thus converting the remnant into a posterior presentation. Ordinarily this would result in a lumbo-pubic, which should be converted into the lumbo-sacral position when its extraction can be readily brought about.

5O. DESTRUCTION OF THE PELVIC GIRDLE IN THE AN'TERIOR PRESEN'TA'TION.

PLATE XXXI.

Object. In somewhat rare instances perhaps more frequently in the cow the pelves of the mother and fotus become interlocked, the antero-external angle of the fotal ilium I', becoming locked. with the shaft of the maternal ilium I at $\mathrm{C}$ in such a manner that any safe degree of traction fails to dislodge it.

Technic. Remove one anterior limb subcutaneously, 47, and eviscerate, 53 , through an opening made by the removal 


\section{,}




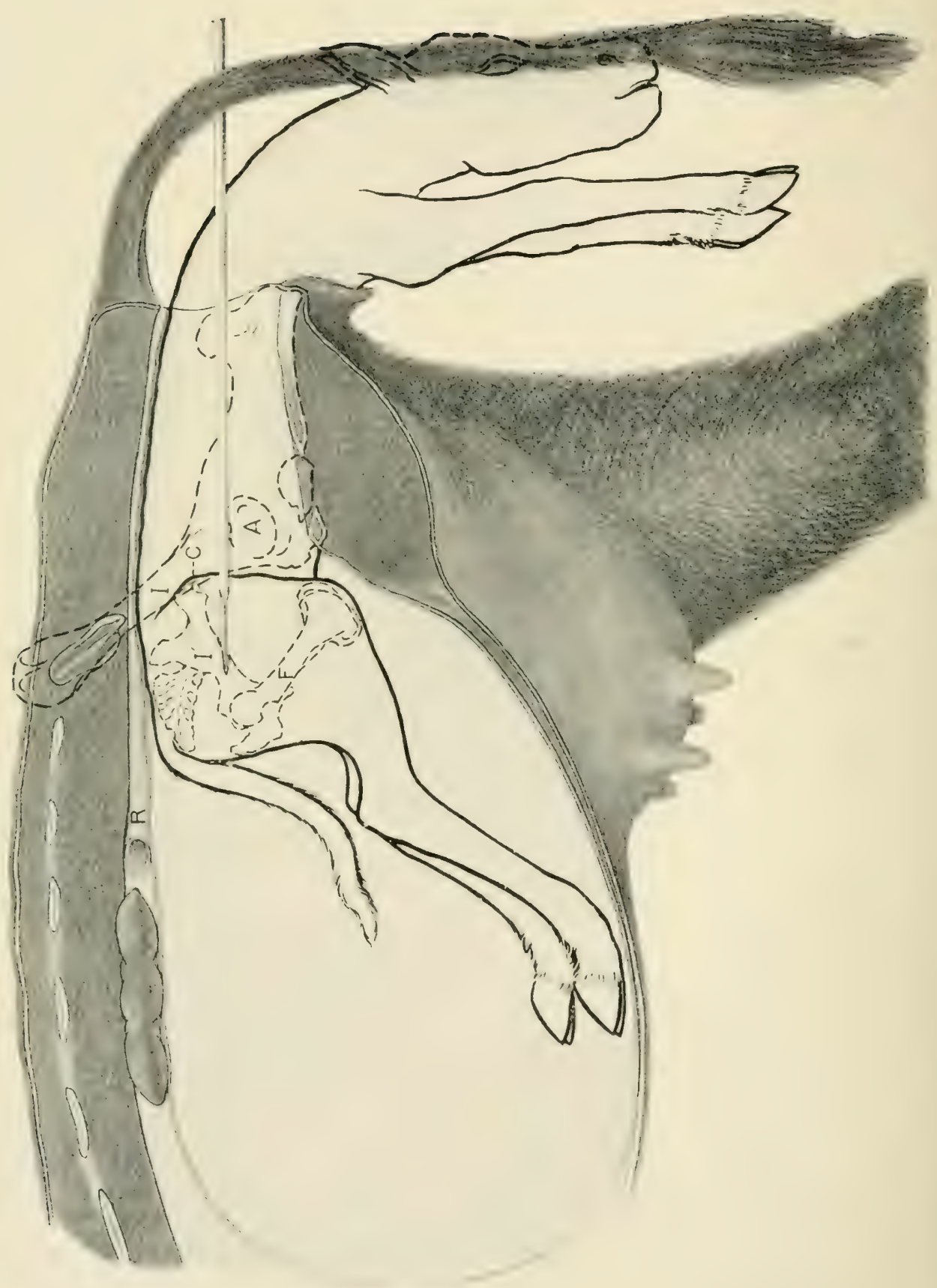




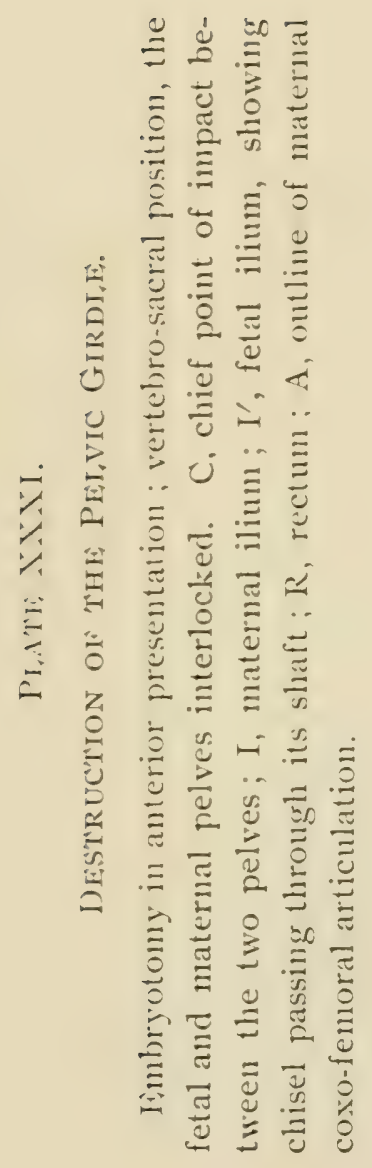


of two or three of the exposed ribs. Introduce the chisel through this opening and carry it back with the hand, placing it against the shaft of the fetal ilium, I', have an assistant drive it through the shaft from before to behind and then withdrawing the chisel replace it against the pubic brim either at the symphysis pubis or opposite the foramen ovale, and drive it through the pubis and ischinm at either of these points. The coxo-femoral articulation is thus detached and isolated so that the entire limb may drop backward beyond its fellow, the remnant of the severed ilium, I', can drop downward or move in any direction and the entire pelvis thus loses its rigidity and undergoes great diminution in size so that it can readily be withdrawn.

\section{I. AMPUTATION OF THE LIMBS AT THE TARSTS.}

Plate XXXII.

Object. It occasionally happens in the mare, far more rarely in the cow in the posterior presentation with the hind limbs retained at the hock that owing to the unusual size of the fetus or its having been dead for some time, dry and empliysematous, that the deviation can not be overcome or its correction would entail an unnecessary amount of labor. In these cases it is frequently easier for the obstetrist and safer for the mother to amputate the limb at the tarsus.

Technic. Pass a cord around the leg above the tarsus as indicated in Plate XXXII and have an assistant hold the leg steady by gentle traction. Introduce the chisel carefully guarded in the palm of the hand, and place it against the lower part of the tarsus as shown between 'T'T. The chisel should be placed as nearly perpendicular as possible to the long axis of the metatarsus. The proper direction of the chisel may at times be greatly favored by placing the cord upon the meta- 


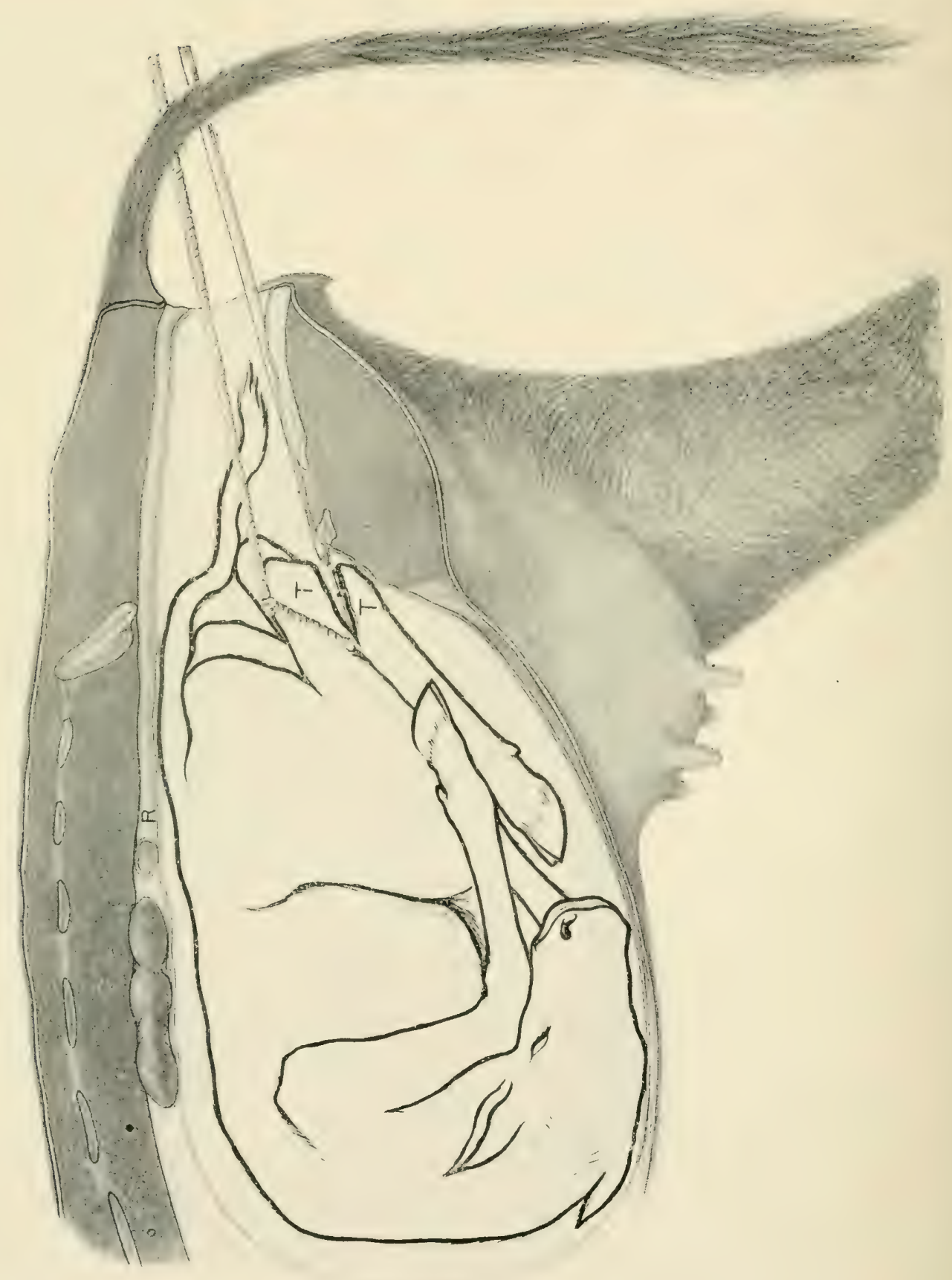




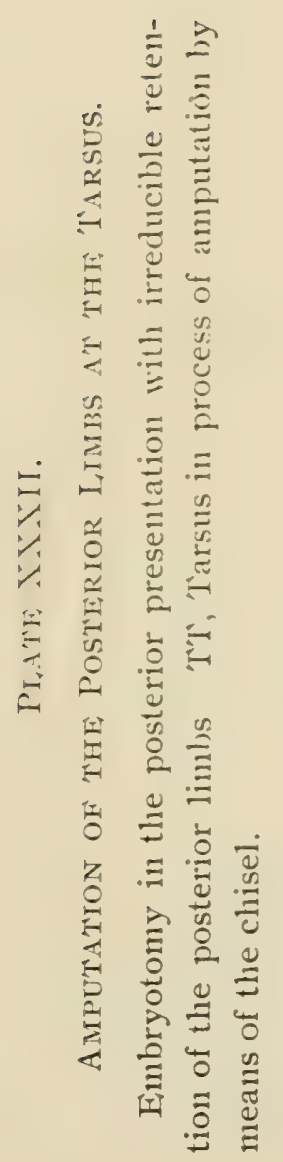


tarsus instead of the leg thus forcing the tarsus torvard the sacrum of the mother and tending to throw the metatarsus straight across the pelvic cavity. When the foetus is in the lumbo-sacral position and it is desired to amputate the left limb the chisel should be held in the palm of the left hand with the back of the hand against the vaginal walls and the chisel carefully guarded and guided during the entire operation. Do not drive the chisel entirely through the hock without removal as it may become caught and clamped between the divided bones, but drive for a few inches along the lateral side being sure that the skin on that side is severed along with the bone, then loosen the chisel by rotation and lateral motion and drive somewhat deeper into the tarsus until it is completely severed. Withdraw the severed metatarsus and remove any dangerous spicules of bone remaining on the stump and see that the latter is safely secured by a cord passing around the leg above the os calcis. Repeat the operation on the other hock in a similar manner using the right hand to guide the chisel. Extend the two limbs into the passages by traction and effect a posterior delivery.

52. INTRA-PELVIC AMPUTATION OF THE POSTERIOR IIIIBS, BREECH PRESENTATION.

PLATES XXXIII AND XXXIV.

Uses. The overcoming of dystocia due to a posterior presentation with the hind limbs completely retained in the uterus, the so-called breech presentation, in cases where the deviation can not be readily corrected.

Technic. Introduce one hand armed with the embryotomy knife through the maternal passages until the perinaeum of the fetus is reached and make a free incision through that region involving the anus in the male fetus and the anus and vulva in the female and enlarge the 


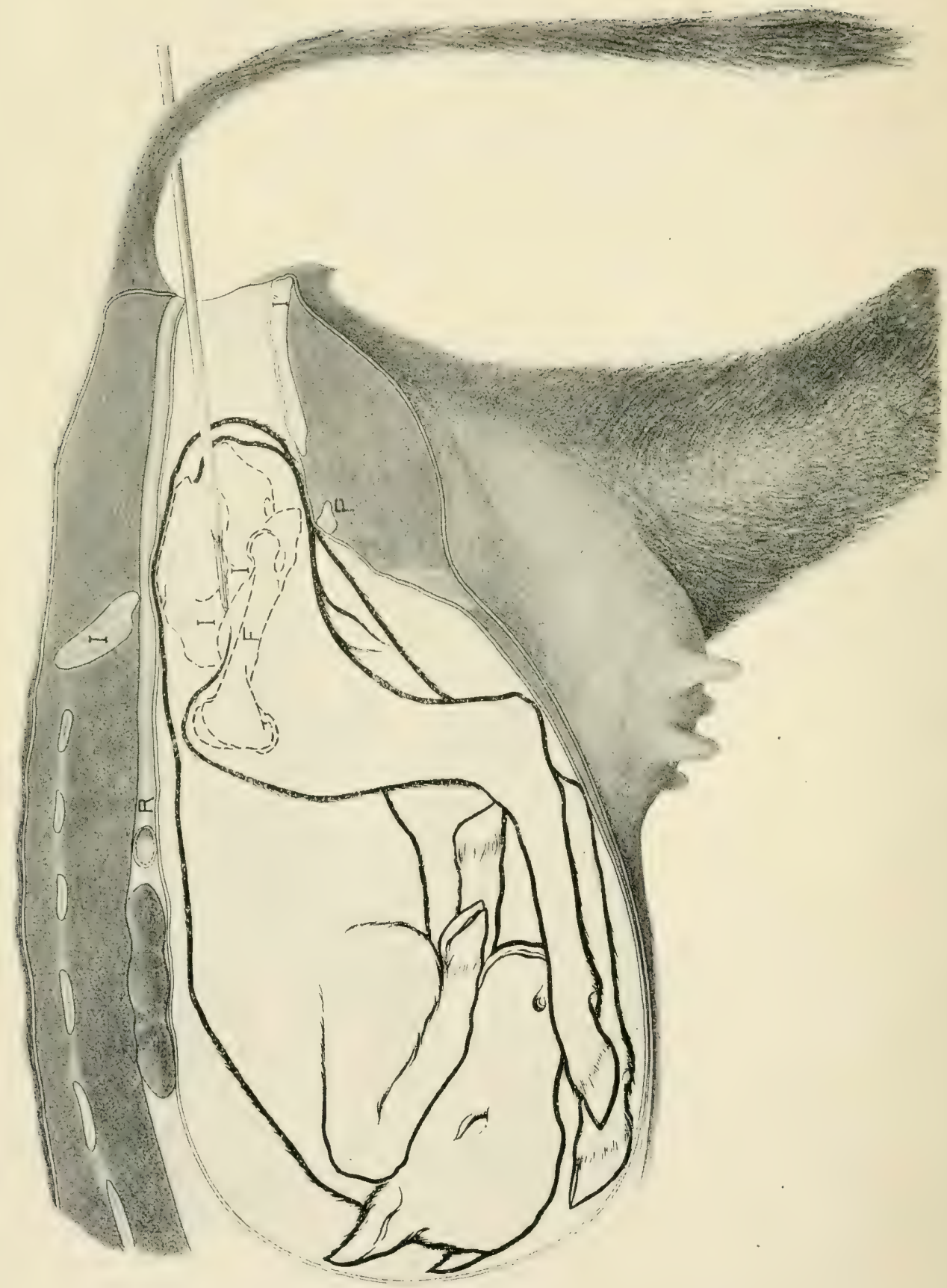




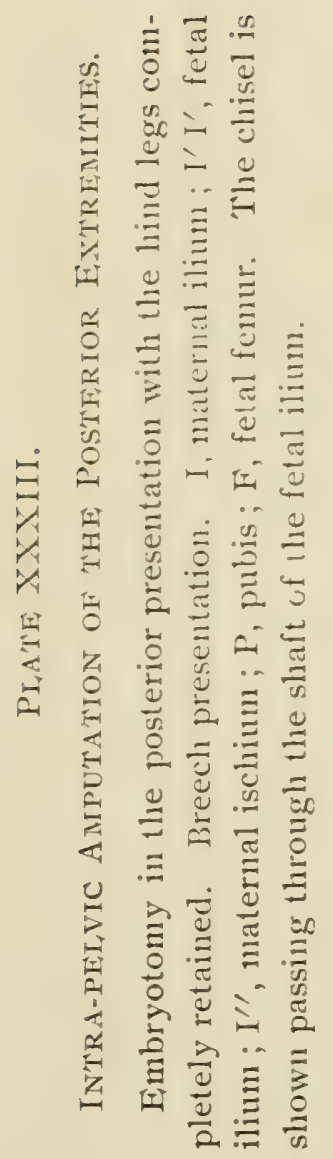


incision sufficiently to admit the operator's hand into the fetal pelvis. Locate the great sciatic ligament and inserting the knife at the shaft of the ilium divide the former backward to the perinaenm allowing the pelvic cavity to dilate freely and giving ample operating room. If the pelvis of the fetus is too small to admit the hand of the operator at all before serering the sciatic ligament this may be accomplished by cautiously cutting from behind forward with Colin's scalpel or with the chisel. When this has been severed and sufficient operating room attained carry the chisel with one hand and place it against the shaft of the ilium as shown between I' I' in Plate XXXIII as nearly perpendicular to the long axis of the shaft as possible and keeping the hand in tonch with the chisel blade have an assistant drive it through the bone until it and its periosteum are completely severed. Disengage the chisel and then place it against the symphysis pubis or against the ischium opposite the foramen ovale and drive it through the ischinm and pubis at this point. Using the chisel as a lever, separate the isolated portion of the pelvis as completely as practicable from the surrounding tissues, and with the fingers separate the muscles from the detached pelvic bone for a short distance on eitler side from the severed ends. Carry a cord in and pass the loop over the ends of the severed section and tightening it secure the isolated portion of the pelvis and have one or more assistants exert traction upon the cord as indicated in Plate XXXIV. The chief obstacle to the withdrawal of the limb is the great gluteus muscle which should be sought for, identified and torn through with the fingers at a distance of 5 or $6 \mathrm{~cm}$. from its attachment to the great trochanter. Other important points of resistance are the attachment posteriorly of the skin, vulva and anus to the ischium through the medium of aponeurosis and anteriorly, chiefly on the median line, the prepubic tendon; these are to be cut, if necessary, with the chisel or knife. Vigor- 


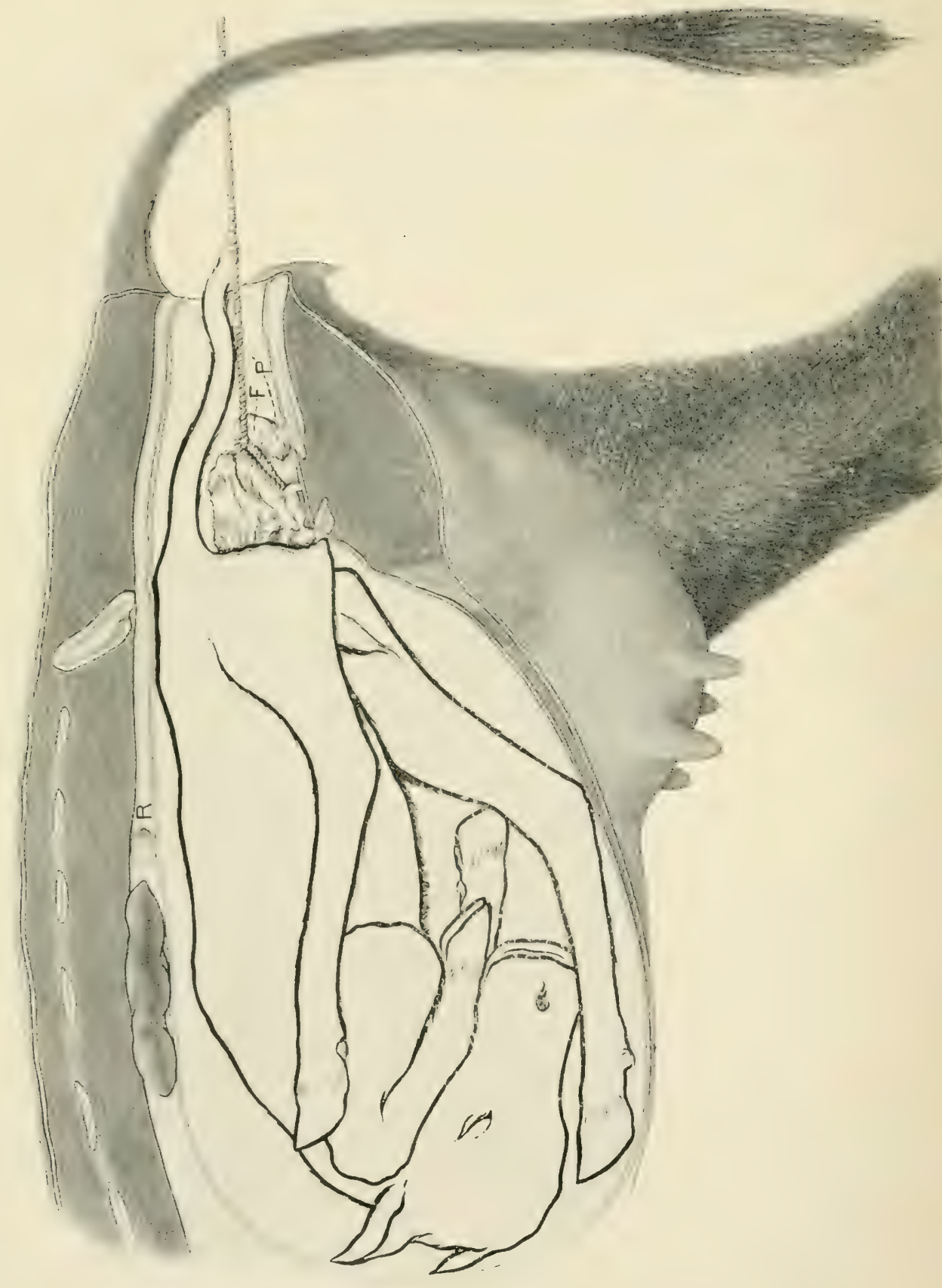




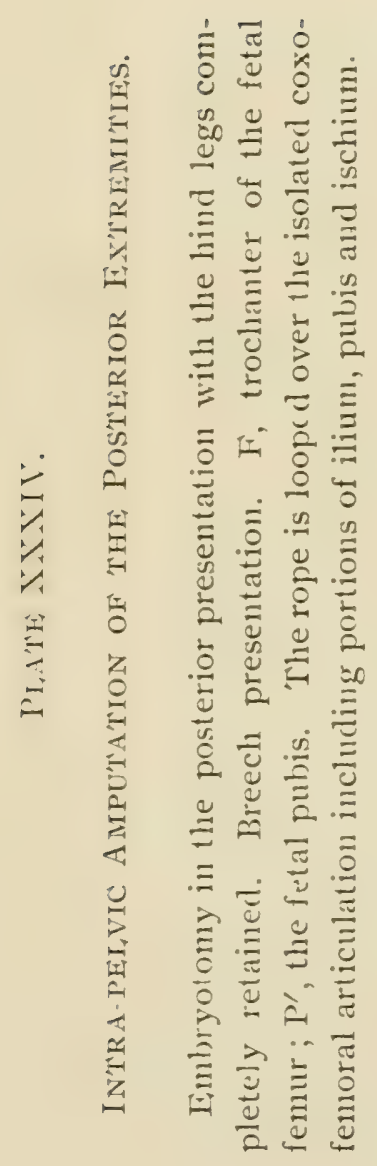


ous traction may now be applied by means of the cord, the operator in the meantime guarding the most advanced end of the detached piece of pelvis with the palm of his hand in order to prevent injury to the maternal organs. Sometimes this detached piece of the pelvis tears away from the femur when traction is applied and comes away alone. In such a case the cord is to be applied orer the head and trochanter of the femur and traction again applied drawing the limb away in a reversed position; the skin being turned back or everted as the limb advances until the region of the hock is reached where the skin does not so readily separate from the limb and only requires to be cut loose and the limb allowed to come away. During the removal of the limb the operator is to constantly note the progress with his hand and sever by tearing or cutting any tendons or muscles which offer special obstruction to the work. Repeat the operation upon the opposite limb in the same manner except that but one incision need be made through the bone, that is, through the shaft of the ilium. During the entire work the operation is carried out subcutaneously or rather intrafoetally and the maternal parts are amply guarded against injury. 'The size of the foetal trunk may be further reduced if desirable, by evisceration, 53, and followed still further by the introduction of the chisel guided by the hand and the ribs, on one or both sides, severed one after another wntil the chest can completely collapse and if need be some of the ribs may be removed and one of the anterior limbs caught by a cord around the scapula and removed intra-foetally. The remnant of the foetus is to be extracted by means of a cord fastened about the lumbar region of the spine. 


\section{EVISCERATION.}

The evisceration of the fœus is frequently desirable in obstetric practice and has a variety of uses. It decreases the size of the foetal trunk considerably and permits its more ready passage through the genital canal, as in the anterior presentation; with lateral deriation of the head it renders the fotal trunk flaccid through the removal of the viscera supporting the body walls and permits the body remmant to be bent or moved more readily for the correction of any deviations present; it permits freedom of intra-fœetal operations directed against other parts, as for detruncation, or for the destruction of the pelvic girdle in the anterior presentation.

Technic. Evisceration may be variously performed, but is generally demanded in either the anterior or posterior presentation and a description of these will suffice.

In the anterior presentation, unless the foutus is far advanced through the rulva, erisceration is best performed by the removal of one or more of the anterior ribs. The ribs are generally best reached by the removal of the shoulder, as already described under subcutaneous amputation of the anterior limbs, 47. When these have been laid bare in the manner described the operator can thrust the finger tips through the intercostal muscles in the first intercostal space and enlarge the opening thus made by tearing through the muscles upwards to the spinal column and downwards to the sternum ; then grasping the posterior border of the rib near its middle, fracture it by means of a sudden and vigorous pull. The fractured ends may then be grasped and pulled, broken or twisted off. The chisel may be brought into use if required in order to divide the rib, the hand of the operator constantly guiding and guarding the chisel blade. The operation is then to be repeated if required, upon the second and third ribs in the same manner until an opening into the 
chest is secured ample in size for the introduction of the operator's hand.

Force one hand through the opening and tear the mediastium above and below from the thoracic walls, and then grasp either the trachea at its bifurcation or the heart and tear them away. 'The heart, which constitutes the greater bulk of the thoracic viscera, is best grasped in the palm of the hand, with the fingers engaging the aorta and pulmonary arteries. When the thoracic riscera have been withdrawn, thrust the fingers through the diaphragm and locating the liver, isolate the area of the diaphragm to which it is attached, and engaging both with the fingers remove the two together. The liver constitutes, in a normal fotus, the chief intra-abdominal mass, occupying more space than all other organs combined. After the liver has been removed the intestinal tube, with its contents, are withdrawn withont difficulty, as its attachments are feeble. The kidneys may also be removed.

Evisceration in the posterior presentation is preferably performed throngh the pelvis, generally in connection with 52. It may be performed without destruction of the pelvic girdle by making an incision through the perineal region and then severing the sacro-sciatic ligament as directed nnder 52. When admission has been gained to the abdominal cavity introduce the hand and withdraw the alimentary tube, then rupture the diaphragm about the liver and tear away the latter organ in the same manner as in the anterior presentation. The liver is so friable that it cannot well be torn away by grasping the organ itself, but comes away entire with the central part of the diaphragm.

Remove the heart and lings as above directed. 

. 
.

$$
\text { . }
$$


, 
SEP 301908 
LIBRARY OF CONGRESS

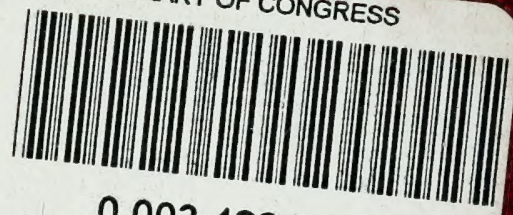

00034223117 